\title{
Parada circulatória total em cães por diferentes períodos de tempo através da técnica de "Inflow Occlusion". Avaliação clínica e hemogasométrica
}

Dissertação apresentada ao Programa de PósGraduação em Clínica Cirúrgica Veterinária da Faculdade de Medicina Veterinária e Zootecnia da Universidade de São Paulo para obtenção do título de Mestre em Medicina Veterinária

\section{Departamento:}

Cirurgia

Área de concentração:

Clínica Cirúrgica Veterinária

Orientador:

Prof. Dr. Angelo João Stopiglia 
Autorizo a reprodução parcial ou total desta obra, para fins acadêmicos, desde que citada a fonte.

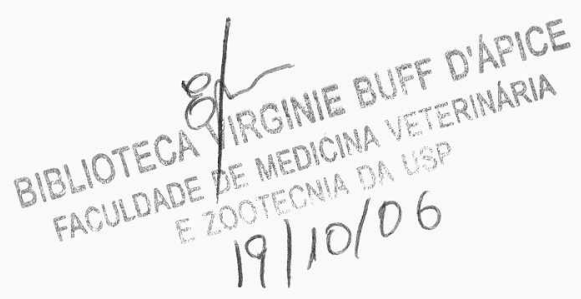

\section{DADOS INTERNACIONAIS DE CATALOGAÇÃO-NA-PUBLICAÇÃO}

(Biblioteca Virginie Buff D'Ápice da Faculdade de Medicina Veterinária e Zootecnia da Universidade de São Paulo)

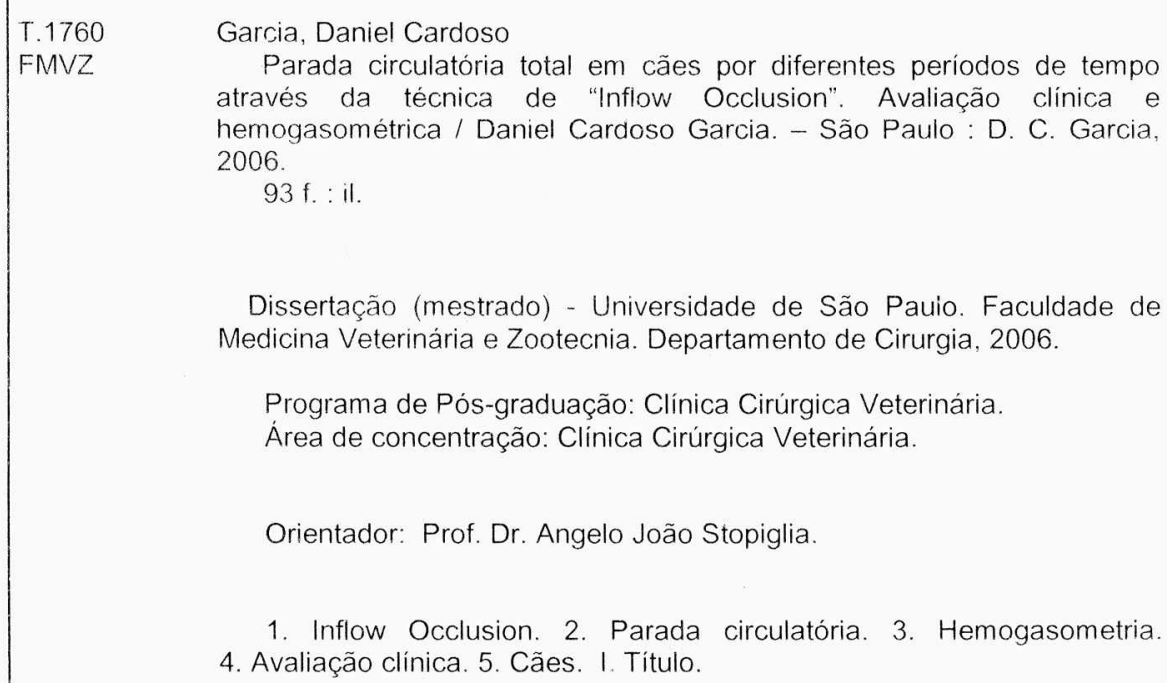

FMVZ Parada circulatória total em cães por diferentes períodos de tempo através da técnica de "Infiow Occlusion". Avaliação clínica e hemogasométrica / Daniel Cardoso Garcia. - São Paulo : D. C. Garcia, 2006.

$93 \mathrm{f}$ : : il.

Dissertação (mestrado) - Universidade de São Pauio. Faculdade de Medicina Veterinária e Zootecnia. Departamento de Cirurgia, 2006.

Programa de Pós-graduação: Clínica Cirúrgica Veterinária. Area de concentração: Clinica Cirúrgica Veterinária.

Orientador: Prof. Dr. Angelo João Stopiglia

1. Inflow Occlusion. 2. Parada circulatória. 3. Hemogasometria. 4. Avaliação clínica. 5. Cães. I. Titulo. 


\section{UNIVERSIDADE DE SÃO PAULO \\ Faculdade de Medicina Veterinária e Zootecnia \\ Cidade Universitária "Armando de Salles Oliveira" \\ Comissão Bioética \\ CERTIFICADO}

Certificamos que o Projeto intitulado "Parada circulatória total em cães segundo a técnica do "inflow occlusion". Avaliação clínica e hemogasométrica", Protocolo n453/2004, utilizando 10 cães, sob a responsabilidade do Prof. Dr. Angelo João Stopiglia, está de acordo com os princípios éticos de experimentação animal da Comissão de Bioética da Faculdade de Medicina Veterinária e Zootecnia da Universidade de São Paulo e foi aprovado "ad referendun".

(We certify that the Research "Total circulatory arrest in dogs using inflow occlusion" technique. Clinical and hemogasometric evaluation", protocol number 453/2004, utilizing 10 dogs, under the responsibility of Prof. Dr. Angelo João Stopiglia, agree with Ethical Principles in Animal Research adopted by Bioethic Commission of the Faculty of Veterinary Medicine and Zootechny of University of São Paulo and was approved "ad referendun", meeting.

São Paulo, 19 de julho de 2004

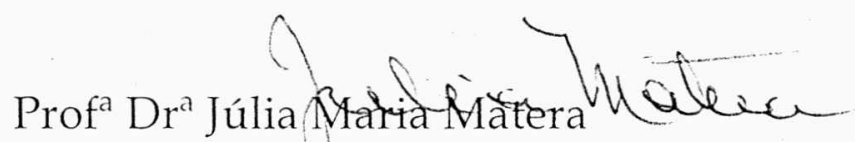

Presidente da Comissão de Bioética

FMVZ/USP 


\section{FOLHA DE AVALIAÇÃO}

\section{Nome: GARCIA, Daniel Cardoso}

Título: Parada circulatória total em cães por diferentes períodos de tempo através da técnica de "Inflow Occlusion". Avaliação clínica e hemogasométrica

Dissertação apresentada ao Programa de Pós-Graduação em Clínica Cirúrgica Veterinária da Faculdade de Medicina Veterinária e Zootecnia da Universidade de São Paulo para obtenção do título de Mestre em Medicina Veterinária

Data:

Banca Examinadora

Prof. Dr. Instituição:

Assinatura: Julgamento:

Prof. Dr. Instituição:

Assinatura: Julgamento:

Prof. Dr. Instituição:

Assinatura: Julgamento: 


\section{DEDICATÓRIAS}

Dedico esta tese a meus pais, Carlos e Bartyra, por tudo aquilo que me ensinaram ao longo destes anos, pelo apoio incondicional, e também por sua dedicação ímpar para com seus filhos. Com vocês aprendi a perseguir meus objetivos e desejos, sendo sempre perseverante na busca de tudo aquilo que julgue trazer maior alegria e felicidade em minha vida.

À minha esposa Larissa, por sua inestimável cooperação neste projeto, pela parceria, pelos conselhos, atenção, amor e compreensão diários, os quais foram necessários para a realização desta pesquisa. 


\section{AGRADECIMENTOS}

Ao meu orientador e Professor Dr. Angelo João Stopiglia, por permitir meu ingresso na PósGraduação dentro desta Universidade, e poder desenvolver a pesquisa na área que tanto aprecio. Agradeço pela minuciosa correção deste trabalho e por seus conselhos ao longo destes anos de convivência.

Ao Dr. Rodrigo Ramos de Freitas, quem primeiro me mostrou a beleza que é cirurgia cardíaca, por seu entusiasmo na área da cirurgia cárdio-torácica e pela cooperação no início deste trabalho.

À Professora e Dra. Denise Tabacchi Fantoni, pela disposição, dedicação, colaboração e paciência em cada cirurgia, e por seu ensinamento imprescindível ao longo desta pesquisa.

Aos anestesistas Reynaldo Carreira e Márcia, pela assistência prestada e colaboração ao longo da pesquisa.

Aos colegas do Laboratório de Cirurgia Cárdio-Torácica (LCCT), Gustavo Nogueira e Eduardo Toshio Irino, pela ajuda nas cirurgias, sempre que necessário.

À estagiária Carina Ramos, agora colega de profissão, pela cooperação e dedicação em todas as cirurgias. 


\section{RESUMO}

GARCIA, D. C. Parada circulatória total em cães por diferentes períodos de tempo através da técnica de "Inflow Occlusion". Avaliação clínica e hemogasométrica. [Total circulatory arrest in dogs for different periods of time using "Inflow Occlusion" technique. Clinical and hemogasometric evaluation]. 2006. 93 f. Dissertação (Mestrado em Medicina Veterinária) - Faculdade de Medicina Veterinária e Zootecnia, Universidade de São Paulo, São Paulo, 2006.

A técnica de "Inflow Occlusion" pode ser utilizada em cirurgias cardíacas quando se pretende manter o coração aberto apenas por alguns minutos, para realização de pequenos reparos. No entanto, a parada circulatória total, evento decorrente da técnica em questão, pode acarretar severas alterações metabólicas e neurológicas, sendo necessária monitorização trans e pósoperatória do paciente. Neste estudo foram utilizados 12 cães sem raça definida, os quais foram divididos em dois grupos, A e B, submetidos a 7 e 8 minutos de parada circulatória total, respectivamente, utilizando-se da técnica de "Inflow Occlusion". Tentou-se estabelecer normotermia dos animais durante os procedimentos cirúrgicos. Foram realizados exames hemogasométricos, e avaliações clínica e neurológica nos momentos preconizados. Alterações neurológicas transitórias foram observadas em ambos os grupos. Ocorreram dois óbitos transoperatórios no grupo B, e um animal do mesmo grupo apresentou cegueira permanente no período pós-operatório. Apesar da acidose metabólica observada durante os procedimentos, o pH, pressão parcial de dióxido de carbono no sangue arterial, e bicarbonato plasmático arterial de ambos os grupos, retornaram aos valores normais após trinta minutos da parada circulatória. Apesar das alterações observadas, é lícito afirmar que o "Inflow Occlusion" é seguro por até 7 minutos. Após este período, no entanto, é contra-indicado, segundo resultados obtidos e óbitos transoperatórios relatados.

Palavras-chave: Inflow Occlusion. Parada circulatória. Hemogasometria. Avaliação clínica. Cães. 


\begin{abstract}
GARCIA, D. C. Total circulatory arrest in dogs for different periods of time using "Inflow Occlusion" technique. Clinical and hemogasometric evaluation. [Parada circulatória total em cães por diferentes períodos de tempo através da técnica de "Inflow Occlusion". Avaliação clínica e hemogasométrica]. 2006. 93 f. Dissertação (Mestrado em Medicina Veterinária) - Faculdade de Medicina Veterinária e Zootecnia, Universidade de São Paulo, São Paulo, 2006.
\end{abstract}

"Inflow Occlusion" technique can be used in heart surgeries when heart is required to be opened just for few minutes, to allow quick repairs. However, circulatory arrest, event occasioned by this technique, can produce serious metabolic and neurologic consequences to the patient, and monitorization on trans, and postoperatory moments is well recommended. In this study, 12 mongrel dogs were used, and were divided into two groups, A and B, submmited to 7 and 8 minutes of total circulatory arrest, respectively, using "Inflow Occlusion" technique. Normothermia was tried during surgical procedures. Hemogasometric analysis, and clinical and neurological exams were made, each of them, on the moments established for the experiment. There were some transitory neurological problems related to both groups. There were two transoperatory deaths in group B and one case of permanent blindness in the same group, on postoperatory period. Despite metabolic acidosis occurred during procedures, $\mathrm{pH}$ values, arterial dioxide carbon parcial pressure, and arterial plasmatic bicarbonate related to both groups, returned to basal levels thirty minutes after surgery. Even occuring some hemogasometric and neurologic alterations, we can say that "Inflow Occlusion" is safe for periods up to 7 minutes. After this period of time, however, it is contraindicated, as seen after these results and because transoperatory deaths.

Key words: Inflow Occlusion. Circulatory arrest. Hemogasometry. Clinical evaluation. Dogs. 


\section{LISTA DE ABREVIATURAS}

AINES - anti-inflamatórios não-esteroidais

bat./min. - batimentos por minuto

C.E.C. - circulação extra-corpórea

$\mathrm{cm}$ - centímetros

$\mathrm{CO}_{2}$ - dióxido de carbono

DP - desvio padrão

$\mathrm{ETCO}_{2}$ - taxa de dióxido de carbono no ar expirado

F.C. - freqüência cardíaca

$\mathrm{FiO}_{2}$ - concentração inspirada de oxigênio

F.E.C. - fluido extra-celular

F.R. - freqüência respiratória

F.S.C. - fluxo sangüíneo cerebral

FMVZ - USP - Faculdade de Medicina Veterinária e Zootecnia da Universidade de São Paulo

$\mathrm{H}^{+}$- íon hidrogênio

$\mathrm{HCO}_{3}^{-}$- íon bicarbonato

IM - intra-muscular

IV - intra-venosa

M0 - momento zero

M1 - momento um

M2 - momento dois

M3 - momento três

M4 - momento quatro

M5 - momento cinco

M6 - momento seis

M7 - momento sete

$\mathrm{mEq} . / \mathrm{L}$ - miliequivalente por litro

$\mathrm{mg} / \mathrm{kg}$ - miligramas por quilograma

$\mu \mathrm{g} / \mathrm{kg}$ - microgramas por quilograma

$\mathrm{ml}$ - mililitros

$\mathrm{ml} / \mathrm{g} / \mathrm{min}$ - mililitros por gramo por minuto 
mmHg - milímetros de mercúrio

mov. resp./min. - movimentos respiratórios por minuto

$\mathrm{O}_{2}$ - oxigênio

P.A.D. - pressão arterial diastólica

P.A.M. - pressão arterial média

P.A.S. - pressão arterial sistólica

$\mathrm{PaCO}_{2}$ - pressão parcial de dióxido de carbono no sangue arterial

$\mathrm{PaO}_{2}$ - pressão parcial de oxigênio no sangue arterial

$\mathrm{PvO}_{2}$ - pressão parcial de oxigênio no sangue venoso

$\mathrm{PO}_{2}$ - pressão de oxigênio

pH - concentração hidrogeniônica

$\mathrm{PvCO}_{2}$ - pressão parcial de dióxido de carbono no sangue venoso

$\mathrm{PvO}_{2}$ - pressão parcial de oxigênio no sangue venoso

$\mathrm{SaO}_{2}$ - saturação arterial de oxigênio

$\mathrm{SC}$ - subcutânea

$\mathrm{SpO}_{2}$ - saturação periférica de oxigênio

$\mathrm{SvO}_{2}$ - saturação venosa de oxigênio

$\mathrm{T}^{\circ} \mathrm{C}$ - temperatura em graus Celcius

II - segundo par de nervos cranianos

III - terceiro par de nervos cranianos

VII - sétimo par de nervos cranianos

VIII- oitavo par de nervos cranianos

$\mathrm{X}$ - décimo par de nervos cranianos 


\section{LISTA DE SÍMBOLOS}

\pm - mais ou menos

${ }^{\circ} \mathrm{C}$ - grau centígrado

$\uparrow$ - óbito

p - grau de significância

** - indicação que valor de p é muito significante 


\section{SUMÁRIO}

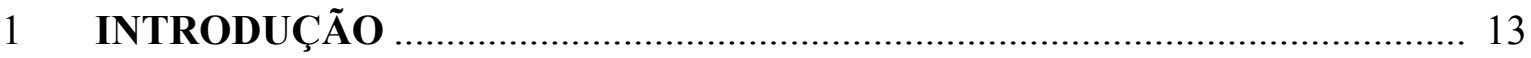

2 OBJETIVO …………………………………………………………. 15

3 REVISÃO DA LITERATURA …………………………………………..... 16

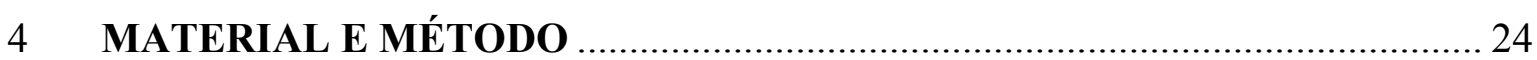

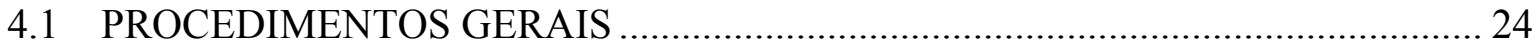

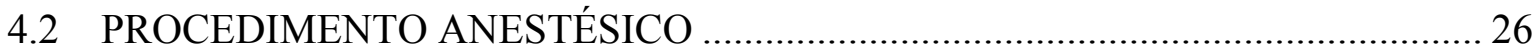

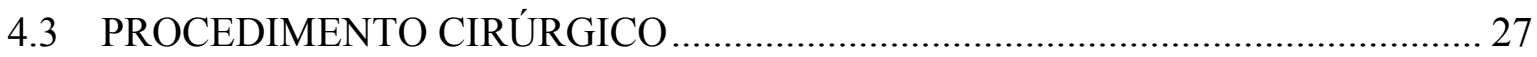

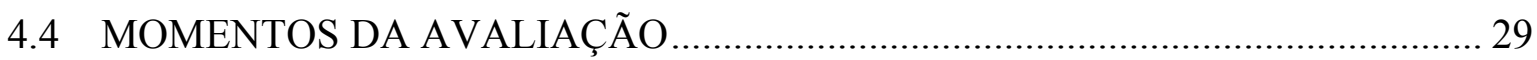

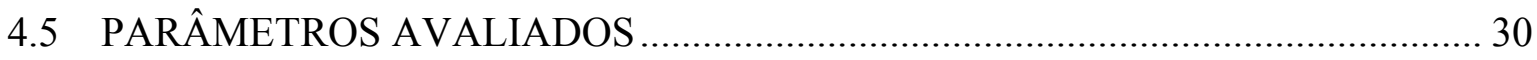

4.5.1 Momentos pré e pós-operatórios (M0, M6 e M7) ……………………………..... 30

4.5.2 Momentos transoperatórios (M1, M2, M3, M4 e M5) ……………………….... 31

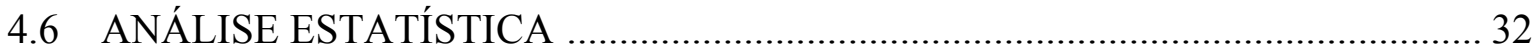

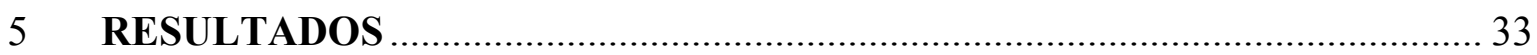

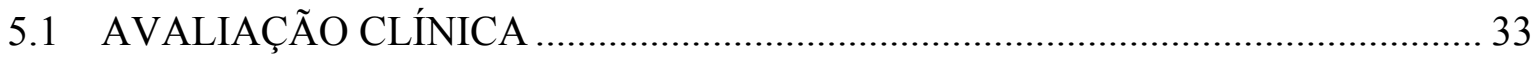

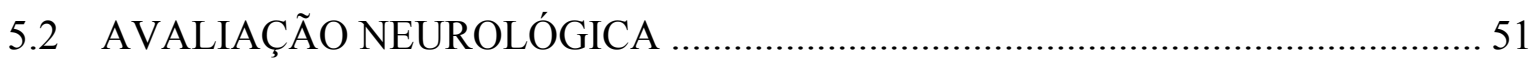



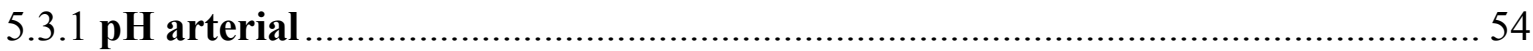

5.3.2 Pressão parcial de dióxido de carbono no sangue arterial $\left(\mathrm{PaCO}_{2}\right)$.................... 57

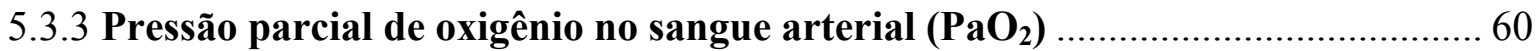



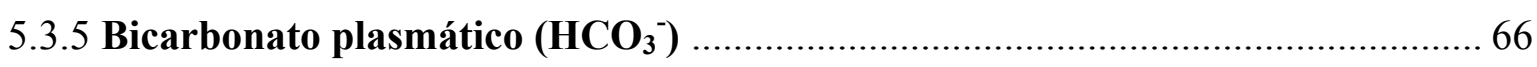

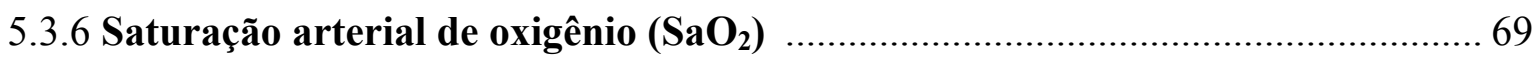

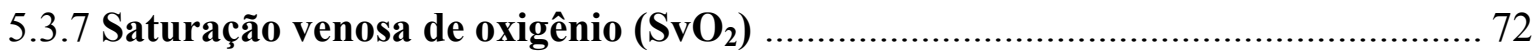

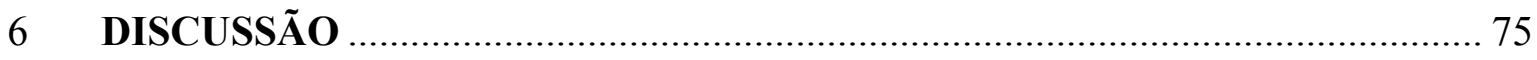

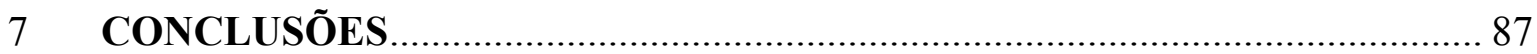

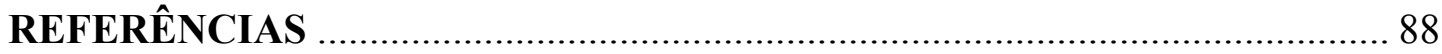




\section{INTRODUÇÃO}

O interesse pela cirurgia cardíaca vem ganhando destaque na medicina veterinária, à medida que o aprimoramento do diagnóstico clínico das afecções cardíacas, bem como o incremento técnico nessa área, tem aumentado cada vez mais, tendo sido praticada nos grandes centros universitários, principalmente durante as duas últimas décadas.

$\mathrm{Na}$ atualidade, um grande número de animais portadores de doenças cardíacas recebe somente tratamento medicamentoso quando necessário, entretanto, em alguns casos, este pode ser ineficaz para a melhora do quadro clínico do paciente. Se a moléstia em questão for passível de correção cirúrgica, tal intervenção poderia contribuir para a melhora do quadro clínico, da qualidade de vida, e em muitos casos, até aumentar a sobrevida dos animais, já que atualmente, algumas intervenções cirúrgicas cardíacas são realizadas com grau de sobrevida altamente favorável.

Nas correções cirúrgicas de doenças cardíacas envolvendo as câmaras cardíacas, é indispensável o uso da circulação extracorpórea (C.E.C.). Porém, esta técnica ainda é pouco utilizada na medicina veterinária, pois apresenta o inconveniente de se dispor de equipe treinada para sua aplicação, e apresentar resultados e prognósticos desfavoráveis para que possa ser instituída de forma segura nas rotinas hospitalares, necessitando de estudos complementares. Além disso, o uso de C.E.C. carece de equipamentos descartáveis e permanentes de alto custo, os quais inviabilizam sua utilização em muitos centros.

No entanto, em cirurgias nas quais pretende-se manter o coração aberto apenas por alguns minutos para realização de pequenos reparos, pode-se lançar mão de outra técnica cirúrgica denominada em inglês de "Inflow Occlusion" ou "Inflow Stasis", a qual é caracterizada pela parada circulatória total, impedindo a entrada de sangue no coração. Esta técnica é mais simples quando comparada a C.E.C., porém pode apresentar resultados satisfatórios com um custo reduzido. Levando-se em conta os atuais altos custos dos procedimentos médico-veterinários de ponta, é extremamente relevante citar-se a importância do binômio custo-benefício, pois neste caso qualquer técnica operatória que economize, apresentando resultados semelhantes e favoráveis a outras mais onerosas, é preferida.

Outro fator importante e indispensável em relação às cirurgias cardíacas é a monitorização trans e pós-operatória dos pacientes. Os parâmetros hemogasométricos devem ser monitorados continuamente a fim de garantir que fenômenos nocivos ao paciente, como alterações ácido-básicas, por exemplo, as quais ocorrem freqüentemente em cirurgias 
cardíacas, possam ser corrigidas imediatamente, a fim de manter a homeostase. Tal conduta visa a uma boa recuperação do paciente, tentando-se evitar quaisquer complicações e alterações clínicas do mesmo, no período pós-operatório.

Em relação à técnica em questão, novos estudos em relação ao tempo de parada foram realizados, em continuidade à linha de pesquisa desenvolvida no Laboratório de Cirurgia Cardiotorácica do Departamento de Cirurgia da FMVZ-USP, visto que estudos anteriores revelaram evolução clínica e neurológica satisfatória de cães submetidos a um período de cinco minutos de parada circulatória total. Porém, quando o período de parada foi de dez minutos, a grande maioria dos animais evoluiu com distúrbios ácido-básicos importantes e seqüelas neurológicas indesejáveis, muitas vezes fatais (KWASNICKA et al., 2000; STOPIGLIA et al., 2001). Em alguns casos, por vez, um período de cinco minutos pode não ser suficiente para a execução das manobras cirúrgicas, como, por exemplo, na síntese de correção de uma comunicação inter-atrial, sendo necessário estender este período por mais alguns minutos, fundamentais para o cirurgião. Porém, ao não se saber quantos minutos a mais, além dos cinco minutos, e inferiores aos dez previamente avaliados, poderiam ser utilizados com segurança, a fim de ampliar o tempo de execução da técnica operatória por parte do cirurgião, é que se resolveu dar seqüência à referida linha investigatória, despertando o interesse pela realização deste projeto. 


\section{OBJETIVO}

O objetivo deste trabalho consistiu em comparar as possíveis alterações clínicas e hemogasométricas que possam ocorrer em cães submetidos à parada circulatória total pela técnica do "Inflow Occlusion", valendo-se de normotermia, por dois diferentes períodos de tempo - sete e oito minutos - a fim de tentar estabelecer um limite máximo de tempo de parada circulatória total para possíveis reparos intra e extra-cardíacos, com mínimo comprometimento clínico do paciente no período pós-operatório. 


\section{REVISÃO DA LITERATURA}

A perquirição bibliográfica atinente ao assunto em estudo mostrou trabalhos relevantes para a elaboração desse capítulo.

A técnica de "Inflow Occlusion", também chamada de "Inflow Stasis", consiste em impedir que o sangue entre no coração, e com isso possibilite intervenções cirúrgicas intra ou extra-cavitárias rápidas, nas quais, quando não utilizada a técnica em questão, permite sangramento muito intenso (JONAS; CASTANEDA; FREED, 1985; ODEGARD et al., 2004).

Desde a década de 50, na Medicina, houve a preocupação, tanto experimental quanto clínica, em se aplicar à técnica de "Inflow Occlusion", introduzida por Varco em 1951 (JONAS; CASTANEDA; FREED, 1985; JONAS et al., 1985; MISTROT et al., 1976), e conforme foi relatado nos trabalhos de Bahnson e Baker (1953), Cookson, Neptune e Bailey (1952), Pinto (1955), e Kameya (1960), tanto valendo-se da normotermia como da hipotermia ou hibernação artificial.

Estudos foram realizados com cães, em hipotermia acentuada, a fim de provocar parada circulatória total com o intuito de se observar resultados que pudessem servir de base à rotina em cirurgias intra-cardíacas em humanos, o que, de fato, ocorreu até a década de 80 (PINTO, 1955). Sobre este aspecto, Raia e Zerbini (1988) enalteceram a importância ímpar da técnica de "Inflow Occlusion" na história da cirurgia cardíaca no homem.

Contudo, com o incremento da utilização da circulação extracorpórea (C.E.C.) e seus excelentes resultados na medicina humana (AWARIEFE; CLARKE; PAPPAS, 1983), e em contraste com possíveis riscos de arritmias e dificuldade de ressuscitação cardíaca, a técnica de "Inflow Occlusion" ficou relegada a segundo plano nas últimas duas décadas, sendo utilizada, principalmente, para intervenções rápidas ou quando o paciente não suportaria o uso da C.E.C. (KIZILTEPE et al., 2003).

Por outro lado, em Medicina Veterinária, em face aos altos custos, equipe numerosa e problemas pós-operatórios observados em cães com o uso da C.E.C., o interesse pela estudada técnica de "Inflow Occlusion" ganhou adeptos (HUNT et al., 1992; KWASNICKA et al., 2000; ORTON, 1990; STOPIGLIA et al., 2001). Além disso, com o emprego da referida técnica há boa exposição cirúrgica de estruturas cardíacas, não há necessidade de hemodiluição, o sangramento é menor, e tampouco utiliza-se heparinização durante parada circulatória, e relata-se baixa mortalidade e morbidade (AGHAJI; GALLEN; LITWIN, 1988; 
MISTROT et. al., 1976). Os custos, o tempo total de cirurgia, e o uso de bolsas de sangue também são menores se comparados à cirurgia com C.E.C. (JONAS; CASTANEDA; FREED, 1985; SADE; CRAWFORD; HOHN, 1982; SINK et al., 1984).

A utilização da técnica em questão apresenta controvérsias na literatura quanto ao tempo máximo ao qual pode ser aplicada sem graves conseqüências ao organismo, e quais as possíveis complicações que o paciente viria a ter quando esse tempo fosse excedido. A prática dessa técnica fez com que os cirurgiões não excedessem em dois minutos o tempo de parada da circulação valendo-se de normotermia e, quando utilizada hipotermia $\left(30^{\circ} \mathrm{C}\right.$ a $\left.32^{\circ} \mathrm{C}\right)$, em cinco minutos e trinta segundos (ORTON; BRUECKER; MCCRACKEN, 1990). Porém, não se estabeleceu quanto mais esse tempo poderia ser estendido em normotermia, e com isso, quais outros tipos de cirurgias poderiam ser executados utilizando-se desta técnica, evitandose assim, as complicações e custos gerados com o emprego da circulação extracorpórea.

O "Inflow Occlusion" primariamente foi utilizado para correção de estenose das valvas semilunares, particularmente da valva pulmonar (AGHAJI; GALLEN; LITWIN, 1988; AWARIEFE; CLARKE; PAPPAS, 1983; JONAS; CASTANEDA; FREED, 1985; HUNT et al., 1992; KIZILTEPE et al., 2003; MISTROT et al., 1976; ORTON, 1995; ORTON; BRUECKER; MCCRACKEN, 1990; SADE; CRAWFORD; HOHN, 1982; SLEIGH et al., 1986), a qual se mostrou uma técnica muito simples de ser aplicada e segura, se estendendo, hoje em dia, para outros tipos de correções, como estenose de valva aorta, septectomia atrial, colocação de enxerto na via de saída do ventrículo direito na atresia de artéria pulmonar (AGHAJI; GALLEN; LITWIN, 1988; BERNHARD et al., 1973; JONAS; CASTANEDA; FREED, 1985; JONAS et al., 1985; SINK et al., 1984), e para outras condições, nas quais o período de exposição intra-cardíaca não ultrapasse dois a três minutos, como na retirada de marcapassos transvenosos (BRODMAN et al., 1990; JONAS et al.,1985; ODEGARD et al., 2004), coleta de fragmento de miocárdio para biópsia (JONAS et al., 1985; ODEGARD et al., 2004) e no tratamento cirúrgico de doenças cardíacas congênitas, como no caso relatado por Mitten, Edwards e Rishniw (2001) de dois cães apresentando Cor Triatriatum Dexter, os quais foram operados com sucesso com a técnica em questão. Ademais que os pacientes apresentem sinais de insuficiência cardíaca congestiva, ainda assim é possível submetê-los a este tipo de procedimento (MISTROT et al., 1976).

Tokmakoglu et al. (2002) relataram a retirada de trombo em átrio direito utilizando a técnica de "Inflow Occlusion", porém em duas etapas, com paradas circulatórias de um minuto e meio, e um minuto, respectivamente. Freitas et al. (2005), relataram um caso de correção de defeito de septo atrial também utilizando dois períodos de parada circulatória total 
em normotermia, sendo de três e cinco minutos, respectivamente, a fim de confeccionar duas suturas na parede atrial. Um grupo de pesquisadores também utilizou esta técnica em cirurgias de implantação de próteses de arco aórtico com grande sucesso (BRODMAN et al., 1990).

Estudos envolvendo cães sadios concluíram que o "Inflow Occlusion" pode ser realizado com segurança por até cinco minutos. (KWASNICKA et al., 2000; STOPIGLIA et al., 2001). Fantoni (2002) relata que a parada circulatória não pode exceder o tempo de quatro minutos em pacientes normotérmicos. Orton (1995) utilizaram a mesma técnica em hipotermia leve $\left(30^{\circ}-32^{\circ}\right)$ por cinco minutos e meio. Entretanto, Hunt et al. (1992) realizaram a aludida técnica por até oito minutos sem comprometimento orgânico pós-operatório em três animais. Nos períodos acima de oito minutos é recomendada a utilização de hipotermia moderada, para proteção cerebral (HUNT et al., 1992; MANOHAR; TYAGI, 1972; SLEIGH et al., 1986). Isto pode ser verificado em trabalho realizado por Stopiglia et al. (2001), no qual com dez minutos de parada circulatória total, todos os cães apresentaram sinais de comprometimento neurológico, sendo observado óbito em alguns dos casos. Odegard et al. (2004) realizaram estudo com 11 pacientes, tendo observado um óbito (9\%), porém aqueles que sobreviveram não apresentaram nenhum tipo de comprometimento neurológico no pósoperatório. Em estudo realizado por Jonas et al. (1985) em 140 pacientes humanos utilizandose do "Inflow Occlusion" para diferentes procedimentos cirúrgicos e valendo-se de normotermia, somente sete deles morreram no pós-operatório imediato, sendo as mortes não relacionadas à técnica em questão, mas à debilidade do paciente. Em outro trabalho realizado por Mistrot et al. (1976), relatou-se uma taxa de mortalidade de 3,6\% em 110 casos operados. Keane et al. (1975), empregando o "inflow Occlusion" em 24 neonatos para correção de estenose da aorta, apresentaram sucesso em 14 casos, sendo constatadas oito mortes no pósoperatório imediato e duas no pós-operatório tardio. Em trabalho realizado por Fyler ${ }^{1}$ (1980 apud JONAS et al., 1985, p. 42), no qual se faz a comparação entre o uso da C.E.C. e "Inflow Occlusion" para valvotomia em neonatos, observou-se mortalidade de 40\% vs. 14\%, respectivamente. Nugent ${ }^{2}$ et al. (1977 apud JONAS et al., 1985, p. 42), para cirurgias de estonose de valva pulmonar, relataram que de 242 pacientes tratados tanto com C.E.C. ou "Inflow Occlusion", somente quatro morreram $(1,7 \%)$, sendo apenas um caso em decorrência da segunda técnica.

\footnotetext{
${ }^{1}$ FYLER, D. C. Report of the New England Regional Infant Cardiac Program. Pediatrics, 65:suppl., p. 447-449, 1980.

2 NUGENT, E. W.; FREEDOM, R. M. NORA, J. J. et al. Natural Hystory Study: Clinical course in pulmonary stenosis. Circulation suppl., v. 1, n. 56, p. 138-147, 1977.
} 
Em Medicina Veterinária encontram-se poucos trabalhos na literatura sobre cirurgia cardíaca, principalmente no Brasil, sendo que a maioria delas é de caráter experimental. Além de objetivar sua prática e obter métodos seguros para realizá-las, pouco se sabe sobre as principais complicações relacionadas a este tipo de cirurgia, principalmente ao que se refere ao aspecto neurológico e comportamental no pós-operatório. Complicações neurológicas estão intimamente relacionadas à cirurgia cardíaca e são muito estudadas na Medicina Humana, na tentativa de minimizar intercorrências durante e após os procedimentos (FORTUNA, 2002).

Embora o cérebro corresponda a aproximadamente 2\% da massa corporal, ele recebe $15 \%$ a $20 \%$ do débito cardíaco. E apesar do fluxo sanguíneo cerebral ser de aproximadamente sete vezes maior que o da circulação sistêmica global, o seu consumo de oxigênio é onze vezes maior. Com essas características de alto consumo de oxigênio e extração aumentada já em condições basais, o cérebro facilmente sofre eventos isquêmicos se houver queda do seu fluxo sanguíneo (NETO, 2000). As estruturas vegetativas e o tronco cerebral são mais resistentes à hipóxia, enquanto que o córtex cerebral é a área mais sensível. Assim, após isquemia global, em decorrência de uma parada cardíaca, por exemplo, poderia ocorrer a perda apenas do córtex cerebral, acarretando estado de inconsciência permanente (coma), mas com manutenção de funções vegetativas, conhecidas como estado vegetativo permanente (NETO, 2000).

Dragosavac (1995) relata taxa de 1\% a 2\% de complicações neurológicas em pacientes humanos após cirurgias cardíacas. Já Atik (2004) relata taxa de 1\% a 6\%, dependendo do tipo de cirurgia relacionada ao coração. $\mathrm{O}$ acidente vascular encefálico é a complicação mais temida e grave na espécie anteriormente citada, porém problemas mais comuns são encefalopatia metabólica e distúrbios neuro-psicológicos (FORTUNA, 2002). Porém, a maioria delas se deve ao uso da C.E.C., idade dos pacientes, e doença vascular prévia. Outros fatores que levam ao comprometimento cerebral durante a cirurgia cardíaca são a hipotensão ou hipertensão (P.A.M. inferior a 4 ou superior a $110 \mathrm{mmHg}$, os quais resultam em lesões graves), tromboembolismo por fragmentos de fibrina, cálcio, ou partículas de ar, hipoxemia e hiperglicemia (FORTUNA, 2002). A tendência de maior longevidade da população expõe esse grupo a um maior risco de problemas neuro-cognitivos (ATIK, 2004; FORTUNA, 2002).

Já na Medicina Veterinária, alguns dados foram obtidos avaliando-se cães no período pós-operatório, incluindo dados neurológicos e comportamentais. Stopiglia et al. (2001) comparando dois grupos (cinco e dez minutos de parada circulatória total) observaram evolução clínica satisfatória no grupo de cinco minutos, sendo que os cães deste grupo não 
apresentaram qualquer alteração neurológica, inclusive comportamental pelo período de seis semanas de observação. Já no grupo de dez minutos de parada circulatória total, houve um óbito transoperatório por fibrilação ventricular, e apenas um animal evoluiu satisfatoriamente no pós-operatório, com função visual e olfatória presentes, permanecendo em estação e se alimentando. Os outros animais apresentaram déficit nos itens citados anteriormente, também apresentando reflexo pupilar-fotomotor diminuído ou ausente, diminuição de reflexo palbebral, midríase e reflexo pupilar diminuído, indicando perda da capacidade visual e possível lesão no núcleo pretectal, corpo geniculado lateral, ou mesmo em córtex occipital. Outro quadro relatado foi o de medo durante o manejo dos animais, o que não se mostrava presente no período pré-operatório. Relatou-se também nestes animais sinais de hiperestimulação e tetania, o que sugere lesão difusa em medula espinhal ou mesencéfalo. Tremores e reflexos espinhais hiperativos em alguns dos animais também foram relatados, apresentando os cães, marcha com membros torácicos rígidos e com ligeira abdução (“tateando" o chão), podendo indicar lesão espinhal (neurônio motor superior).

Pacientes que sofrerão cirurgia cardíaca devem ser monitorados adequadamente, incluindo análises dos gases sanguíneos, $\mathrm{pH}$, bicarbonato, já que sofrerão alterações na ventilação e sistema circulatório. Estes fatores, associados ao tempo de parada circulatória são muito importantes para minimizar os problemas no pós-operatório, como as alterações neurológicas e óbitos citados em trabalhos anteriormente (KWASNICKA et al., 2000). A $\mathrm{PaCO}_{2}$ atua de modo importante no controle do fluxo cerebral por meio de vasodilatação/vasoconstrição cerebral. O fluxo sanguíneo cerebral (F.S.C.) varia quase que diretamente com a $\mathrm{PaCO}_{2}$, para valores de $\mathrm{PaCO}_{2}$ entre 25 e $80 \mathrm{mmHg}$. O aumento da $\mathrm{PaCO}_{2}$ é um potente vasodilatador cerebral, e para cada elevação de $1 \mathrm{mmHg}$ dela, o F.S.C. aumenta em $2 \%$ a $3 \%$ (ou 1 a $2 \mathrm{ml} / 100 \mathrm{~g} / \mathrm{min}$ ). O F.S.C. dobra quando a $\mathrm{PaCO}_{2}$ atinge 80 a $100 \mathrm{mmHg}$. Já a queda da $\mathrm{PaCO}_{2}$, provoca vasoconstrição cerebral, levando o F.S.C. a diminuir em $40 \%$ quando se encontra em $25 \mathrm{mmHg}$. Quando cai para $20 \mathrm{mmHg}$, a queda do F.S.C. é máxima, diminuindo em torno de 50\% ou atingindo 20-25 ml/100g/min. Em condições normais, esses valores de F.S.C. se correlacionam com isquemia cerebral leve, tanto do ponto de vista clínico como eletroencefalográfico, mas não com morte neuronal (NETO, 2000).

A avaliação dos gases sangüíneos pode refletir distúrbios circulatórios e insuficiência na ventilação, os quais predizem a sobrevivência no decorrer de uma cirurgia cardíaca (KITAGAWA; YASUDA; SASAKI, 1994). A má perfusão tissular, os estados de baixa excreção e insuficiente reposição de sangue, juntamente com o colapso pulmonar, pode levar 
a alterações ácido-básicas, as quais podem requerer a administração de bicarbonato de sódio (HALL; CLARKE, 1987; LUNA, 2002; TIMERMAN, 1995).

Distúrbios ácido-básicos durante as cirurgias cardíacas são comuns e constituem grande risco ao paciente, principalmente quando se tem a interrupção da oferta de oxigênio a regiões do organismo determinando hipóxia tecidual. (AULER JR., 2004; HASKINS, 1988; RAIA; ZERBINI, 1988). O fato de que desvios no balanço ácido-básico facilmente se tornam fatais evocou grande interesse por estudos experimentais e desenvolvimento de novos métodos para o monitoramento preciso dos parâmetros ácido-básicos do sangue. Assim, a monitorização e o exame hemogasométrico são de enorme importância no acompanhamento peri-operatório do paciente submetido à cirurgia cardíaca e anestesia geral (AULER JR.; ANDRADE, 2004; FANTONI, 2002; FORTUNA, 2002; KWASNICKA et al., 2000; MASSONE, 1994).

Brooks e Feldman (1962) relataram o processo de acidose metabólica observado inúmeras vezes no período pós-operatório imediato, que quando não diagnosticado através do exame hemogasométrico, tende a agravar-se rapidamente até a irreversibilidade e morte do doente. Auler Jr. e Andrade (2004) e DiBartola (2000) descreveram o processo de acidose metabólica como causador de sérios problemas para a função do sistema cardiovascular, incluindo diminuição do débito cardíaco, diminuição da pressão arterial e diminuição de fluxo sanguíneo para rins e fígado. A contratilidade do miocárdio também diminui quando o $\mathrm{pH}$ cai abaixo de 7.20, visto que com o pH intracelular diminuído, há deslocamento de íons de cálcio dos sítios de ligação nas proteínas de contração. A acidose metabólica também predispõe a arritmias ventriculares, principalmente fibrilação ventricular, diminui a contratilidade intrínseca e o débito cardíaco, reduz os efeitos inotrópicos positivos das catecolaminas, pode causar dilatação arterial periférica e venoconstrição central (aumentando pressões de enchimento e diminuindo pressões sistêmicas), além de causar aumento da resistência vascular pulmonar (AULER JR.; ANDRADE, 2004; FANTONI, 2002).

É fato que a restauração de eficiente circulação sangüínea e, conseqüentemente, da preservação da vida do paciente só são possíveis se houver reconhecimento preciso da acidose, principalmente metabólica, e de seu tratamento adequado (HAMM; JACOBSON, 1986; RAIA; ZERBINI, 1988), pelo menos nas primeiras 24 horas após o ato operatório (HALL, 1987). Portanto, nas cirurgias nas quais se utiliza a técnica de "Inflow Occlusion", levando à queda de pressão arterial e diminuição da freqüência cardíaca (AWARIEFE; CLARKE; PAPPAS, 1983), privando os tecidos de adequada perfusão sangüínea, observa-se como conseqüência situação de hipóxia, e a análise hemogasométrica pode tornar-se essencial 
para o sucesso da intervenção cirúrgica, logo, para a manutenção da vida do paciente (KWASNICKA et al., 2000; WARE; MERKLEY; RIEDESEL, 1994).

O quadro de anaerobiose metabólica durante a parada circulatória, decorrente da redução da perfusão tissular e da diminuição da oferta de $\mathrm{O}_{2}$, provoca glicólise anaeróbica, culminando com a acidose lática. A concentração de lactato em cães já foi descrita em diversos trabalhos, sendo considerada normal concentrações plasmáticas abaixo de $2 \mathrm{mEq} / \mathrm{L}$. (DIBARTOLA, 2000; OLIVA, 2002; TIMERMAN, 1995). Na eventualidade de não haver melhora de perfusão periférica e persistir ou se agravar o estado de hipóxia tecidual, a glicose produzida no fígado pela gliconeogênese volta aos tecidos e sofre novamente o processo de glicólise fermentativa, aumentando os níveis de ácido lático. Nesta eventualidade, os níveis elevados de ácido lático circulantes não conseguem ser neutralizados pelo bicarbonato plasmático, resultando em acidose lática. Esta acidose aliada à insuficiente produção de energia leva à asfixia e morte celular (TERZI, 1995). Em condições de isquemia miocárdica prolongada em que há dano irreversível às células cardíacas, ocorre infarto ou necrose do coração (GIRALDEZ; RAMIRES, 2000).

Um fator importante de se avaliar após parada circulatória é a lesão de reperfusão. Sabe-se que a reperfusão está associada a alguns efeitos adversos como: lesão miocárdica, destruição das células miocárdicas ainda viáveis ao final da isquemia induzida pela reperfusão, lesão vascular, dano à microvasculatura com redução da reserva coronariana, "miocárdio atordoado", disfunção contrátil do coração a despeito da restauração do fluxo sanguíneo, e arritmias de reperfusão. A disfunção mecânica após a reperfusão do miocárdio pode trazer significativas complicações para a hemodinâmica dos pacientes, já que podem ocorrer distúrbios nas funções sistólica e diastólica. A depressão miocárdica é maior após a isquemia prolongada, uma vez que o grau de "atordoamento" do miocárdio é proporcional ao tempo de duração da isquemia. Ele pode ocorrer de forma leve após isquemias transitórias de demanda, ou severa com sinais de falência cardíaca após reperfusão do infarto agudo do miocárdio, ou cirurgia com parada cardíaca (GIRALDEZ; RAMIRES, 2000). Após eventos de isquemia e reperfusão, há prejuízo também nas respostas dos vasos cerebrais a vários estímulos, especialmente da resposta vasodilatadora. Estudos em animais demonstraram que, após isquemia cerebral global, a resposta da circulação cerebral à hipocapnia está atenuada ou abolida, e a resposta à hipercapnia, muito aumentada (NETO, 2000).

Alguns trabalhos foram realizados na tentativa de avaliar a ventilação e possíveis comprometimentos do sistema circulatório utilizando o "Inflow Occlusion”. Kwasnicka et al. (2000) verificaram quadros amenos de hipoxemia e acidose metabólica em animais 
submetidos a cinco minutos de parada circulatória total, moderados no grupo de dez minutos, e severos no grupo de quinze minutos de parada circulatória total. Apesar de não haver diferenças significativas entre os três grupos no que se refere ao $\mathrm{pH}$, apenas no grupo de 15 minutos não houve restabelecimento dos valores basais após 48 horas. Nos outros grupos, após 24 e 48 horas de pós-operatório os valores já se encontravam normais. No que diz respeito ao bicarbonato, os menores valores estão relacionados aos grupos de dez e quinze minutos de parada circulatória total, indicando comprometimento metabólico resultante do quadro de isquemia imposto aos animais. Já em relação a $\mathrm{PaCO}_{2}$, seu aumento era esperado durante a parada circulatória, uma vez que a oferta de oxigênio está diminuída tanto pela interrupção da circulação, quanto pela ausência de ventilação. Em relação à $\mathrm{PO}_{2}$, seus valores diminuíram durante a parada circulatória, mas em seguida voltaram ao normal nos sobreviventes após a parada circulatória, indicando que não houve comprometimento da capacidade de oxigenação dos animais. A saturação de oxigênio diminuiu nos três grupos, mas para aqueles que sobreviveram, a mesma retornou aos valores basais após restabelecimento da circulação. Stopiglia et al. (1998), avaliando a hemodinâmica no uso do "Inflow occlusion" com cinco e dez minutos de parada circulatória, verificaram somente alterações significativas de pressão capilar pulmonar e pressão de artéria pulmonar maiores no grupo de dez minutos e aumento de freqüência cardíaca no grupo de cinco minutos, mas que voltaram ao nível basal ao final do procedimento. A pressão arterial média diminuiu significantemente em relação aos valores controle no grupo de dez minutos após restabelecimento do fluxo sanguíneo. Já o índice cardíaco, pressão venosa central, índice de resistência vascular sistêmico, oferta de oxigênio e consumo de oxigênio, não mostraram alterações significativas entre os dois grupos. Em trabalho realizado por Sleigh et al. (1986) utilizando o "Inflow Occlusion" em hipotermia para realização de valvotomia pulmonar em um garoto, lançaram mão do uso de bicarbonato de sódio e isoprenaline antes da parada circulatória de oito minutos, na tentativa de manter boa condução cardíaca durante o período isquêmico e aumentar um pouco a frequência cardíaca.

Durante a análise dos valores dos gases sanguíneos é importante lembrar que alterações da temperatura corpórea produzem alterações significativas do $\mathrm{pH}$ sanguíneo, já que a cada grau centígrado, o pH sofre alteração de 0,15 unidades (BAILEY, 1998). Ficou evidente pela literatura consultada que a relação entre o nível da temperatura do paciente no transoperatório e o tempo da parada circulatória total estão intimamente relacionadas quando da aplicação da técnica do "Inflow Occlusion" (BIGELOW; LINDSAY; GREENWOOD, 1990; ORTON, 1995). 


\section{MATERIAL E MÉTODO}

Em relação à metodologia empregada, tendo como base a literatura pertinente ao assunto, a separamos em seis partes, para facilitar seu entendimento. Desta maneira, este capítulo foi dividido em procedimentos gerais, procedimentos anestésicos, procedimentos cirúrgicos, momentos da avaliação, parâmetros avaliados, e análise estatística.

\subsection{PROCEDIMENTOS GERAIS}

Foram utilizados nesta pesquisa doze cães mestiços (Canis familiaris), adultos, machos e fêmeas, com pesos variando entre 11 e 27 quilos, e em condições julgadas satisfatórias para a experimentação. Os animais foram submetidos a um período de adaptação ao canil, que variou de 15 a 40 dias antes do experimento. Dentro deste período foi realizado tratamento preventivo (baseado em doses recomendadas para a espécie canina) para ectoparasitas, através de banhos com amitraz ${ }^{3}$, para hemoparasitas, através da aplicação intramuscular de imidocarb ${ }^{4}$ e subcutânea de ivermectina ${ }^{5}$, para verminoses entéricas, através da administração oral de pamoato de pirantel, praziquantel e febantel ${ }^{6}$, e para doenças infectocontagiosas, através de vacinação com vacina octopla ${ }^{7}$. Além disso, visando a melhora e a manutenção de um estado geral satisfatório, estes animais receberam doses adequadas de complexo $\mathrm{B}^{8}$ e vitamina $\mathrm{C}^{9}$. A avaliação pré-cirúrgica destes animais foi constituída de exame eletrocardiográfico, radiografia torácica, hemogasometria, avaliação clínica e neurológica, e avaliação hematológica (hemograma, contagem de plaquetas e dosagens séricas de uréia, creatinina, aspartato alanil transferase e fosfatase alcalina). Durante os procedimentos cirúrgicos, foi estabelecida temperatura do colchão térmico em $40^{\circ} \mathrm{C}$, na tentativa de manter os animais em normotermia, esperando que as mesmas não diminuíssem os $36^{\circ} \mathrm{C}$ no paciente. Após o procedimento cirúrgico, os animais permaneceram em gaiolas individualizadas onde

\footnotetext{
3 Triatox ${ }^{\circledR}$ - Coopers Brasil Ltda.

${ }^{4}$ Imizol ${ }^{\circledR}$ - Coopers Brasil Ltda.

5 Supramec ${ }^{\circledR}$ - Schering-Plough Veterinária - Indústria Química e Farmacêutica Schering-Plough S. A.

${ }^{6}$ Endal Plus ${ }^{\circledR}$ - Schering-Plough Veterinária - Indústria Química e Farmacêutica Schering-Plough S. A.

7 Duramune DA2PP + CVK/LCl ${ }^{\circledR}$ - Fort Dodge Saúde Animal Ltda.

8 Complexo B - Ariston Indústrias Químicas e Farmacêuticas Ltda.

${ }^{9}$ Vitamina C - Ariston Indústrias Químicas e Farmacêuticas Ltda.
} 
foram avaliados durante todo o período pós-operatório. Durante as primeiras 48 horas estes animais receberam cuidados intensivos e foram submetidos a um protocolo analgésico através do uso de opióides (sulfato de morfina ${ }^{10}$ ou cloridrato de tramadol ${ }^{11}$, dependendo do grau de dor apresentado pelo animal) e anti-inflamatórios não-esteroidais (AINES) (flunixim meglumine $^{12}$ e dipirona sódica $\left.{ }^{13}\right)$. Tanto os procedimentos cirúrgicos como o acompanhamento pós-operatório, foram realizados no Laboratório de Cirurgia Cardiotorácica do Departamento de Cirurgia da Faculdade de Medicina Veterinária e Zootecnia da Universidade de São Paulo.

Ao término do experimento, os animais ausentes de qualquer tipo ou grau de seqüelas foram castrados e encaminhados à doação. Os demais animais foram eutanasiados com o uso de thiopental sódico ${ }^{14}$ e cloreto de potássio ${ }^{15}$ e os cadáveres doados para a confecção de peças anatômicas e uso didático dentro desta Universidade.

Para inclusão dos animais nos grupos, os cães eram divididos aleatoriamente em dois grupos, contendo seis animais cada. Esses grupos foram assim estabelecidos:

Grupo A - animais submetidos a período de sete minutos de Parada Circulatória Total.

Grupo B - animais submetidos a período de oito minutos de Parada Circulatória Total.

A indicação do grupo ao qual o animal pertenceria era realizada no momento antes de ser aplicada a técnica do "Inflow Occlusion".

Todos os procedimentos realizados encontram-se de acordo com as normas e princípios éticos de experimentação animal, estabelecidos pela Comissão de Bioética da Faculdade de Medicina Veterinária e Zootecnia da Universidade de São Paulo, sendo o experimento aprovado pela mesma (protocolo $n^{\circ} 453 / 2004$ ).

\footnotetext{
10 Dimorf® - Cristália Produtos Químicos e Farmacêuticos Ltda.

11 Tramal ${ }^{\circledR}$ - Pharmacia Brasil Ltda.

12 Banamine ${ }^{\circledR}$ - Schering-Plough Veterinária - Indústria Química e Farmacêutica Schering-Plough S. A.

13 Dorpiron ${ }^{\circledR}-$ Ariston Indústrias Químicas e Farmacêuticas Ltda.

14 Thionembutal ${ }^{\circledR}$ - Abbott Laboratórios de Brasil Ltda

15 Cloreto de potássio 10\% - Geyer Medicamentos Ltda
} 


\subsection{PROCEDIMENTO ANESTÉSICO}

Para medicação pré-anestésica realizou-se a administração de $0,05 \mathrm{mg} / \mathrm{kg}$ de maleato de acepromazina ${ }^{16}$ pela via intramuscular (IM) e $0,5 \mathrm{mg} / \mathrm{kg}$ de sulfato de morfina via subcutânea (SC). Decorridos quinze minutos da aplicação destes agentes, utilizou-se propofol ${ }^{17}$ na dose de $5 \mathrm{mg} / \mathrm{kg}$ pela via intravenosa (IV). Foi então realizada a intubação orotraqueal sendo a anestesia mantida com isoflurano ${ }^{18}$ em oxigênio a $100 \%$ em circuito fechado. Durante a manutenção da anestesia com agentes inalatórios, foram realizados os procedimentos habituais de monitorização (reflexos protetores, avaliação eletrocardiográfica, avaliação gasométrica sanguínea, avaliação da pressão arterial sistêmica, avaliação da concentração de anestésico inspirada e expirada e avaliação da saturação de oxigênio). Os animais permaneceram em ventilação controlada mecânica ${ }^{19}$ (ventilador ciclado a tempo e limitado a pressão), com volume corrente e freqüência respiratória necessários para manter a pressão parcial de dióxido de carbono no ar expirado $\left(\mathrm{ETCO}_{2}\right)$ entre 29 e $42 \mathrm{mmHg}$, a qual foi mensurada por intermédio de capnógrafo ${ }^{20}$. O bloqueio muscular para realização da ventilação controlada foi realizado pela administração de pancurônio ${ }^{21}$ na dose de $0,06 \mathrm{mg} / \mathrm{kg}$ (IV).

A reversão do bloqueio neuromuscular, quando necessária, foi feita com o emprego de neostigmine ${ }^{22}$ associado a sulfato de atropina ${ }^{23}$ (IV) na dose de $0,08 \mathrm{mg} / \mathrm{Kg}$ e $0,04 \mathrm{mg} / \mathrm{Kg}$, respectivamente.

Ao final do procedimento cirúrgico, os animais foram retirados gradativamente da ventilação mecânica tendo como base os valores da $\mathrm{SpO}_{2}$ (saturação periférica de oxigênio) e da concentração expirada de $\mathrm{CO}_{2}$.

No decorrer de todos os procedimentos cirúrgicos, optou-se pela infusão de solução de ringer com lactato ${ }^{24}$ (IV).

\footnotetext{
16 Acepran 0,2\% ${ }^{\circledR}$ - Ciba Geigy Química S. A.

17 Diprivan ${ }^{\circledR}$ - Astrazeneca do Brasil Ltda.

18 Forane ${ }^{\circledR}$ - Abbott laboratórios do Brasil Ltda.

19 Aparelho de anestesia Takaoka - Shogun ${ }^{\circledR}$ - (processo Fapesp n 00/00192-7)

20 Capnógrafo e analisador de gases anestésicos - Multinex 4000®- Datascope Inc. - (processo Fapesp n 1996/10508-4)

21 Pavulon 0,2\%® - Akzo Nobel Ltda. Divisão Organon do Brasil.

22 Prostigmine ${ }^{\circledR}$ - ICN Farmacêutica Ltda.

23 Sulfato de Atropina $0.025 \%$ ® - Ariston Indústrias Químicas e Farmacêuticas Ltda.

24 Ringer Lactato® - Astra Química
} 


\subsection{PROCEDIMENTO CIRÚRGICO}

A veia femoral esquerda era dissecada, e individualizada com o auxílio de tesoura delicada; uma pequena incisão era realizada na mesma para permitir a passagem do cateter de artéria pulmonar do tipo Swan-Ganz ${ }^{25}$. Em seguida, a artéria femoral esquerda era cateterizada para obtenção dos valores de pressão arterial. A coleta de sangue arterial para análises hemogasométricas intra-operatórias era realizada pelo próprio cateter ora descrito. Já o sangue venoso misto utilizado para as análises transoperatórias, foi obtido por meio do cateter de artéria pulmonar (Swan-Ganz). Nos momentos pré e pós-cirúrgicos, a coleta de sangue arterial e venoso para realização das gasometrias era procedida por punção da artéria femoral e veia cefálica, respectivamente.

$\mathrm{O}$ volume de sangue coletado em cada amostra foi de $1 \mathrm{ml}$, em seringa plástica heparinizada ${ }^{26}$, sendo a agulha vedada com tampa de borracha, para evitar o contato do sangue com o ar ambiente. $\mathrm{O}$ exame de cada amostra era realizado imediatamente após a coleta em analisador de $\mathrm{pH}$ e gases sanguíneos ${ }^{27}$.

Neste experimento, utilizou-se a toracotomia lateral direita no quarto espaço intercostal como acesso à cavidade torácica. Uma vez dentro do tórax, as veias cavas cranial e caudal, bem como a veia ázigos, eram dissecadas em segmento de $2 \mathrm{~cm}$ e individualizadas com o auxílio de fitas cardíacas, as quais, em seguida, eram inseridas dentro de segmento de plástico de equipo de soro utilizando-se fio de aço (Torniquete de Rumel) (Figura1).

Antes de se fechar os torniquetes, hiperventilação durante 30 segundos era realizada. Os pulmões expandidos por uma última vez, com o objetivo de se esvaziar as câmaras cardíacas, e em seguida os torniquetes eram fechados (Figura 2). A ventilação cessava e a parada circulatória total era estabelecida e marcada com cronômetro, sendo as referidas veias liberadas aos sete ou oito minutos, de acordo com o grupo estudado.

\footnotetext{
25 Swan Ganz® Cateter de Termodiluição - Baxter International Inc.

26 Parinex ${ }^{\circledR}$ - Hipolabor

27 ABL 5® - Radiometer - (processo Fapesp n 1996/10508-4)
} 


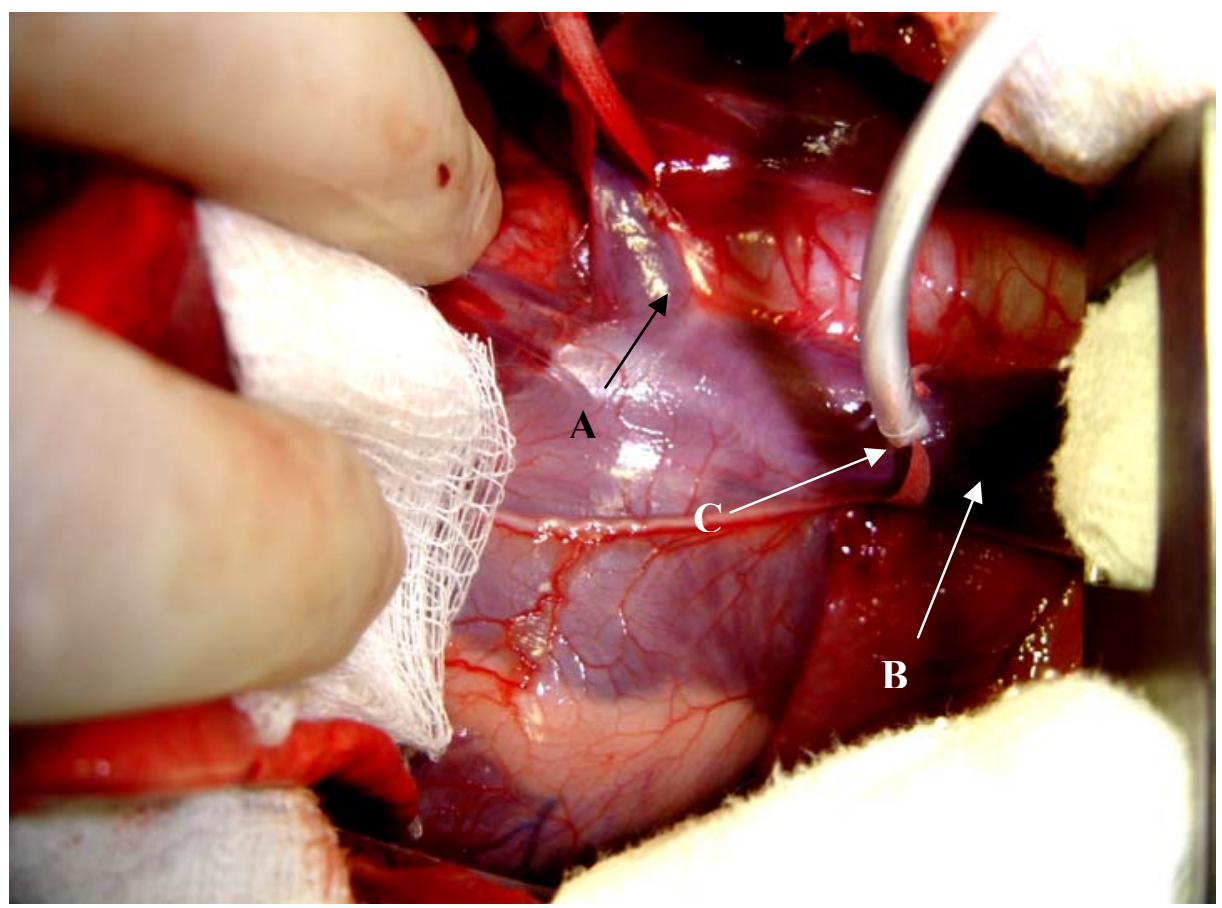

Fonte: Garcia, D. C., 2005

Figura 1 - Imagem fotográfica mostrando as veias ázigos (A) e cava cranial (B). Notar que os torniquetes de Rumel ainda estão abertos (C)

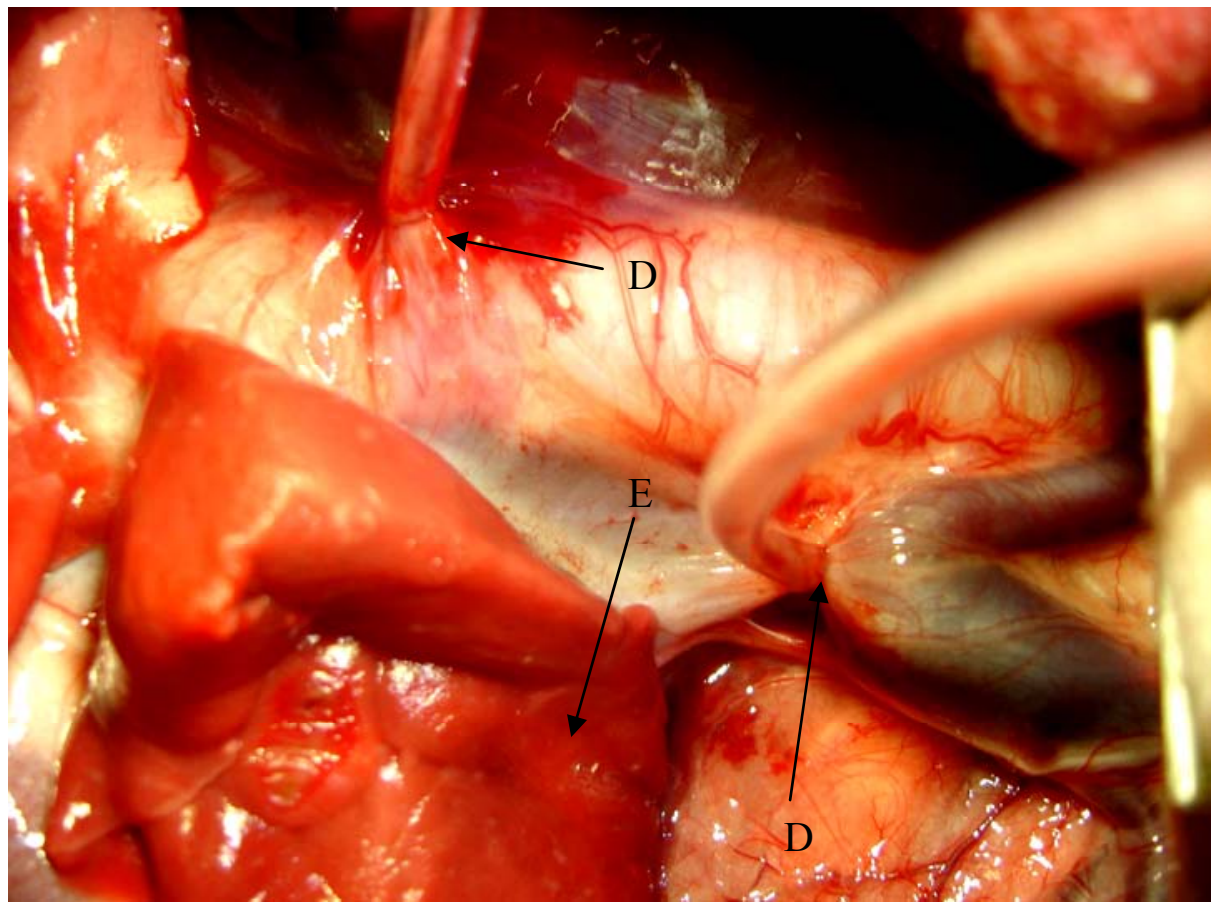

Fonte: Garcia, D. C., 2005

Figura 2 - Imagem fotográfica mostrando as mesmas veias citadas na figura 1, porém neste momento, com os torniquetes de Rumel ocluídos (D), e parada circulatória total instituída. Notar os pulmões atelectásicos (E) 
Os animais foram mantidos aquecidos com colchão térmico ${ }^{28}$, a fim de mantê-los em normotermia. Antes do fechamento do tórax, sempre era realizada aplicação intercostal de bupivacaína, objetivando-se maior grau de analgesia. As toracorrafias, ao término dos experimentos, foram realizadas pelos processos habituais bem como a sutura dos planos anatômicos. Um curativo seco e esterilizado era colocado recobrindo a ferida cirúrgica.

Antes de serem executados os procedimentos cirúrgicos, os animais eram avaliados quanto aos valores basais para a freqüência cardíaca, freqüência respiratória, pressão arterial média, diastólica e sistólica, temperatura corpórea, exame hemogasométrico e eletrocardiográfico. Os animais de cada grupo foram avaliados durante os períodos transoperatório, e pós-operatórios com 24 e 48 horas após a intervenção cirúrgica. Além disso, os cães ficaram em observação por período total de vinte dias no canil para acompanhamento clínico e comportamental.

\subsection{MOMENTOS DA AVALIAÇÃO}

Os momentos de avaliação dos parâmetros para cada grupo foram os seguintes: M0 (momento zero) - trinta minutos antes da medicação pré-anestésica; M1 (momento um) decorridos trinta minutos da estabilização da anestesia; M2 (momento dois) - imediatamente antes da realização de "Inflow Occlusion"; M3 (momento três) - decorridos cinco minutos da parada circulatória; M4 (momento quatro) - cinco minutos após o término da técnica de "Inflow Occlusion"; M5 (momento cinco) - trinta minutos após o término da técnica de "Inflow Occlusion"; M6 (momento seis) - 24 horas após o término da cirurgia; M7 (momento sete) - 48 horas após o término da cirurgia.

28 Thortex ${ }^{\circledR}$ - Medicinal D’água 


\subsection{PARÂMETROS AVALIADOS}

Os parâmetros avaliados para cada grupo são citados a seguir:

\subsubsection{Momentos pré e pós-operatórios (M0, M6, M7)}

- Freqüência cardíaca (F.C.) (bat./min.) - obtida através de auscultação torácica com estetoscópio.

- Freqüência respiratória (F.R.) (mov. resp./min.) - obtida através de auscultação torácica com estetoscópio.

- Pressão arterial sistólica (P.A.S.) (mmHg) - mensurada através de esfingnomanômetro em pata dianteira, região rádio-ulnar, próxima ao cotovelo.

- Pressão arterial diastólica (P.A.D.) (mmHg) - mensurada através de esfingnomanômetro em pata dianteira, região rádio-ulnar, próxima ao cotovelo.

- Pressão arterial média (P.A.M.) (mmHg) - mensurada através de esfingnomanômetro em pata dianteira, região rádio-ulnar, próxima ao cotovelo.

- Saturação venosa de oxigênio $\left(\mathrm{SvO}_{2}\right)(\%)$ - obtida através de análise hemogasométrica de sangue venoso, coletado a partir de punção em veia cefálica.

- Saturação arterial de oxigênio $\left(\mathrm{SaO}_{2}\right)(\%)$ - obtida através de análise hemogasométrica de sangue arterial, coletado a partir de punção em artéria femoral direita.

- Pressão parcial de oxigênio no sangue arterial $\left(\mathrm{PaO}_{2}\right)(\mathrm{mmHg})$ - obtida através de análise hemogasométrica de sangue arterial, coletado a partir de punção em artéria femoral direita.

- Pressão parcial de oxigênio no sangue venoso $\left(\mathrm{PvO}_{2}\right)(\mathrm{mmHg})$ - obtida através de análise hemogasométrica de sangue venoso, coletado a partir de punção em veia cefálica.

- Pressão parcial de dióxido de carbono no sangue arterial $\left(\mathrm{PaCO}_{2}\right)(\mathrm{mmHg})$ - obtida através de análise hemogasométrica de sangue arterial, coletado a partir de punção em artéria femoral direita.

- $\mathrm{pH}$ arterial - adquirido através de análise hemogasométrica de sangue arterial, coletado a partir de punção em artéria femoral direita. 
- Concentração de $\mathrm{HCO}_{3}^{-}$no sangue arterial $(\mathrm{mEq} / \mathrm{L})$ - obtida através de análise hemogasométrica de sangue arterial, coletado a partir de punção em artéria femoral direita.

- Temperatura corpórea $\left(\mathrm{T}^{\circ} \mathrm{C}\right)$ - obtida por termômetro introduzido via retal.

- Alterações clínicas: Os parâmetros observados e utilizados para comparação entre os animais no período pós-operatório (M6 e M7) foram: presença ou ausência de incoordenação motora, deambulação, desvio de objetos, claudicação, enfisema subcutâneo, dor, medo, estado alerta, alimentação/hidratação, micção, defecação, visão, olfato, convulsão, reflexo pupilar, tremores e estado comatoso. Além dos parâmetros citados anteriormente, foram realizados exames neurológicos, incluindo testes de reações posturais, testes de nervos cranianos, reações espinhais, e pontuação dos sintomas relacionados à Escala de Glasgow adaptada a pequenos animais para avaliação de prognóstico neurológico, a qual é utilizada para vítimas de trauma craniano.

\subsubsection{Momentos transoperatórios (M1, M2, M3, M4, M5)}

- Freqüência cardíaca (F.C.) (bat./min.) - obtida através de eletrodos de eletrocardiograma, conectados à superfície corpórea do animal e ao monitor multiparamétrico.

- Freqüência respiratória (F.R.) (mov. resp./min.) - obtida pelo monitor do próprio aparelho de anestesia.

- Pressão arterial sistólica (P.A.S.) (mmHg) - obtida através de cateter introduzido em artéria femoral esquerda, conectado em monitor multiparamétrico.

- Pressão arterial diastólica (P.A.D.) (mmHg) - obtida através de cateter introduzido em artéria femoral esquerda, conectado em monitor multiparamétrico.

- Pressão arterial média (P.A.M.) (mmHg) - obtida através de cateter introduzido em artéria femoral esquerda, conectado em monitor multiparamétrico.

- Saturação venosa de oxigênio $\left(\mathrm{SvO}_{2}\right)(\%)$ - obtida através de análise hemogasométrica de sangue venoso misto, coletado a partir do cateter de Swan-Ganz locado na artéria pulmonar.

- Saturação arterial de oxigênio $\left(\mathrm{SaO}_{2}\right)(\%)$ - obtida através de análise hemogasométrica de sangue arterial, coletado a partir de cateter introduzido em artéria femoral esquerda. 
- Pressão parcial de oxigênio no sangue arterial $\left(\mathrm{PaO}_{2}\right)(\mathrm{mmHg})$ - obtida através de análise hemogasométrica de sangue arterial, coletado a partir de cateter introduzido em artéria femoral esquerda.

- Pressão parcial de oxigênio no sangue venoso $\left(\mathrm{PvO}_{2}\right)(\mathrm{mmHg})$ - obtida através de análise hemogasométrica de sangue venoso misto, coletado pelo cateter de Swan-Ganz locado na artéria pulmonar.

- Pressão parcial de dióxido de carbono no sangue arterial $\left(\mathrm{PaCO}_{2}\right)(\mathrm{mmHg})$ - obtida através análise hemogasométrica do sangue arterial, coletado a partir de cateter introduzido em artéria femoral esquerda.

- $\mathrm{pH}$ arterial - obtido através de análise hemogasomérica do sangue arterial, coletado a partir de cateter introduzido em artéria femoral esquerda.

- Concentração de $\mathrm{HCO}_{3}^{-}$no sangue arterial $(\mathrm{mEq} / \mathrm{L})$ - obtida através de análise hemosométrica de sangue arterial, coletado a partir do cateter introduzido em artéria femoral esquerda.

- Temperatura corpórea $\left(\mathrm{T}^{\circ} \mathrm{C}\right)$ - obtida pelo cateter de Swan-Ganz, conectado ao monitor multiparamétrico.

\subsection{ANÁLISE ESTATÍSTICA}

Para realização da análise estatística, foram comparadas as médias de cada grupo, A (sete minutos de parada circulatória total) e B (oito minutos de parada circulatória total) relativas a cada momento de avaliação. Tanto na comparação pré-operatória e pós-operatória (momentos M0, M6 e M7), bem como na comparação intra-operatória (M1, M2, M3, M4 e M5) foi utilizada a análise de variância (ANOVA) de duplo fator, seguida do pós-teste $t$ de Bonferroni $^{29}$. O grau de significância para os dois testes estatísticos foi de $5 \%(\mathrm{p}<0,05)$.

\footnotetext{
${ }^{29}$ Graphpad Prism ${ }^{\circledR}$ - Graphpad Software, Inc.
} 


\section{RESULTADOS}

Segundo a metodologia empregada, foram observados os resultados que seguem descritos:

\subsection{AVALIAÇÃO CLÍNICA}

Dos doze animais submetidos ao protocolo do experimento e que foram avaliados no período pré-operatório, dois vieram a óbito no período transoperatório, porém, as mortes não estão relacionados à falhas na referida avaliação, mas sim inerente à técnica de "Inflow Occlusion".

Da mesma forma, o protocolo anestésico proposto mostrou-se plenamente satisfatório à execução de todas as manobras exigidas, quer na passagem de cateteres, como também àquelas cirúrgicas, não podendo ser imputada à anestesia as mortes ocorridas.

A avaliação clínica geral, os exames laboratoriais e hemogasométricos, as radiografias torácicas, eletrocardiogramas, e a avaliação neurológica baseada na análise dos testes de reações posturais, dos nervos cranianos, e dos reflexos espinhais, encontravam-se normais para todos os animais do experimento no período pré-operatório, e conseqüentemente no momento M0, minutos antes de serem submetidos ao procedimento cirúrgico.

Todos os animais do grupo A sobreviveram à parada circulatória total por período de sete minutos. Os retornos anestésico e cirúrgico não apresentaram quaisquer alterações dignas de nota. Já, no grupo B, no qual os cães foram submetidos a oito minutos de parada circulatória total, ocorreram dois óbitos (animais 11 e 12), ambos no período transoperatório, especificamente no momento M3 (durante a parada circulatória total). Os dois animais apresentaram o mesmo quadro, sendo este de fibrilação ventricular. Estes episódios ocorreram, em ambos os casos, sete minutos após o estabelecimento do "Inflow Occlusion" e parada circulatória total. Apesar de não ser este o objetivo do experimento, tentou-se empregar medidas de reanimação cardiorrespiratória, porém todas sem sucesso de reversão do quadro de fibrilação ventricular, culminando com os dois óbitos.

Os seis animais do grupo A apresentaram evolução clínica geral satisfatória até 48 horas após o ato operatório, sendo que, todos os cães ainda ficaram em observação no canil 
por mais 20 dias após o experimento, apresentando condições de normalidade. Com 24 horas de pós-operatório, três animais deste grupo já estavam se alimentando (animais 2, 8 e 10), e com 48 horas de seguimento operatório, todos se alimentaram normalmente (animais 2, 4, 6, 7, 8 e 10). Os seis cães do grupo A apresentaram micção adequada, e três deles defecaram inclusive dentro das primeiras 24 horas de pós-operatório. Os animais 6 e 8 apresentaram pequeno enfisema subcutâneo no lado direito do tórax, na região da ferida cirúrgica logo após 24 horas de pós-operatório, continuando após 48 horas do mesmo, e os animais 6 e 7 apresentaram dor quando palpados na mesma região descrita no período M6, porém com melhora progressiva do quadro de algesia observada em M7. Os cães 7 e 10 quando avaliados, pareciam ter medo, ficando mais apreensivos e às vezes se protegendo no canto da sala de observação. Dois dos animais (números 2 e 8) apresentavam-se alertas já em M6, enquanto os demais mostraram-se mais alertas entre os períodos M6 e M7. Quatro cães deste grupo A foram doados (números 2, 4, 8 e 10) e dois foram eutanasiados (números 6 e 7) após vinte dias de seguimento do período pós-operatório, estando todos os seis animais em condições clínicas normais ao final do experimento.

Já no grupo B, apenas três, dos quatro animais que sobreviveram (números 3, 5 e 9), evoluíram satisfatoriamente bem do ponto de vista clínico, mostrando-se sem alterações dignas de nota após 48 horas de evolução pós-operatória, e permanecendo da mesma maneira até 20 dias após o experimento. Neste grupo, aqueles cães que sobreviveram, apresentaram micção adequada logo em M6, apresentando boa evolução do mesmo parâmetro também em M7. Apenas dois animais se alimentaram já em M6 com 24 horas de pós-operatório (números 5 e 9). O cão $n^{\circ} 3$ só veio a alimentar-se em M7, e o animal $n^{\circ} 1$ ainda não havia ingerido alimento até as primeiras 48 horas de pós-operatório, recebendo então, nutrição parenteral. Nenhum dos animais deste grupo apresentou quadro de dor; e somente o cão $n^{\circ} 1$ apresentou em M7, leve enfisema subcutâneo, também em região torácica direita adjacente à incisão cirúrgica. Os animais 5 e 9 também apresentaram quadro semelhante àqueles do grupo $\mathrm{A}$ no que se refere ao quadro de medo. Somente o cão número 1 não apresentou-se alerta em M6, ao contrário dos outros três animais do grupo B, os quais apresentaram-se alertas tanto em M6, quanto em M7.

Dos quatro animais avaliados do grupo $B$, visto que os cães $\mathrm{n}^{\circ} 11$ e 12 vieram a óbito no período transoperatório, um animal foi eutanasiado (cão $n^{\circ} 1$ ) após 48 horas do ato operatório, outro foi eutanasiado após 20 dias de evolução (animal 5) e os outros dois (animais 3 e 9) foram doados. 
$\mathrm{Na}$ avaliação pré, trans e pós-operatória, relatou-se vários dados inerentes aos parâmetros fisiológicos, os quais podem ser observados nas tabelas e gráficos em seqüência (Tabelas 1 a 12 e Gráficos 1 a 12):

- $\quad$ Freqüência Respiratória

Dois animais do grupo A (animais 2 e 8 ) e quatro do grupo B (animais $1,3,5$ e 11) apresentaram movimentos respiratórios acima do normal para o padrão da espécie no momento de coleta dos dados referente a M0. Dois animais do grupo A (animais 8 e 10), o primeiro nos momentos M6 e M7, e o segundo no momento M7; e dois animais do grupo B (animais 3 e 9), ambos nos momentos M6, e o animal 9 também em M7, apresentaram igualmente movimentos respiratórios acima dos valores considerados normais para a espécie canina. Esses dados e todos os valores individuais, médias e desvios-padrão de cada animal de ambos os grupos estão relacionados nas tabelas 1 e 2, para os grupos A e B, respectivamente. Em relação aos momentos transoperatórios, como a ventilação era controlada, todos os valores, de ambos os grupos, estavam dentro dos limites fisiológicos (Tabelas 1 e 2). A análise estatística revelou que não houve diferença significativa na comparação das médias entre os dois grupos, tanto para os momentos pré e pós-operatórios, como para os momentos transoperatórios (Gráficos 1 e 2). O momento M3 não foi considerado para análise de resultados, em relação a este parâmetro.

Tabela 1 - Valores individuais de freqüência respiratória (F.R.) em movimentos respiratórios por minuto, médias e respectivos desvios-padrão dos animais do grupo A, submetidos a sete minutos de parada circulatória total - São Paulo - 2005

\begin{tabular}{l|c|c|c|c|c|c|c|c}
\hline & M0 & M1 & M2 & M3 & M4 & M5 & M6 & M7 \\
\hline Animal 02 & 32 & 20 & 20 & ---- & 20 & 30 & 24 & 24 \\
Animal 04 & 28 & 24 & 20 & ---- & 20 & 20 & 16 & 20 \\
Animal 06 & 16 & 24 & 25 & ---- & 23 & 23 & 25 & 24 \\
Animal 07 & 24 & 18 & 18 & ---- & 18 & 18 & 25 & 24 \\
Animal 08 & 36 & 20 & 20 & ---- & 20 & 20 & 40 & 40 \\
Animal 10 & 30 & 18 & 16 & ----- & 18 & 16 & 30 & 35 \\
\hline Média & 27,70 & 20,70 & 19,80 & ----- & 19,80 & 21,17 & 26,70 & 27,80 \\
\hline DP & 8,55 & 2,70 & 3,00 & ----- & 1,80 & 4,48 & 7,95 & 7,80 \\
\hline
\end{tabular}

M0 (30 minutos antes da medicação pré-anestésica); M1 (30 minutos após estabilização anestésica); M2 (imediatamente antes do "Inflow Occlusion"); M3 (decorridos 5 minutos do "Inflow Occlusion"); M4 (5 minutos após o término do "Inflow Occlusion”); M5 (30 minutos após o término do "Inflow Occlusion"); M6 (24 horas após o término da cirurgia); M7 (48 horas após o término da cirurgia)

DP - desvio padrão

M3 - momento não considerado para a análise do parâmetro 
Tabela 2 - Valores individuais de freqüência respiratória (F.R.) em movimentos respiratórios por minuto, médias e respectivos desvios-padrão dos animais do grupo $\mathrm{B}$, submetidos a oito minutos de parada circulatória total - São Paulo - 2005

\begin{tabular}{l|c|c|c|c|c|c|c|c}
\hline & M0 & M1 & M2 & M3 & M4 & M5 & M6 & M7 \\
\hline Animal 01 & 40 & 20 & 30 & ---- & 30 & 30 & 16 & 16 \\
Animal 03 & 60 & 20 & 20 & ---- & 26 & 21 & 60 & 20 \\
Animal 05 & 35 & 18 & 16 & ---- & 16 & 16 & 16 & 30 \\
Animal 09 & 20 & 20 & 20 & ----- & 20 & 20 & 36 & 34 \\
Animal 11 & 65 & 16 & 16 & ---- & $\dagger$ & $\dagger$ & $\dagger$ & $\dagger$ \\
Animal 12 & 24 & 14 & 14 & ----- & $\dagger$ & $\dagger$ & $\dagger$ & $\dagger$ \\
\hline Média & 40,67 & 18,00 & 19,30 & ----- & 23,00 & 21,75 & 32,00 & 25,00 \\
\hline DP & 20,35 & 2,53 & 5,750 & ---- & 6,22 & 5,90 & 20,91 & 8,41 \\
\hline MP
\end{tabular}

M0 (30 minutos antes da medicação pré-anestésica); M1 (30 minutos após estabilização anestésica); M2 (imediatamente antes do "Inflow Occlusion"); M3 (decorridos 5 minutos do "Inflow Occlusion"); M4 (5 minutos após o término do "Inflow Occlusion"); M5 (30 minutos após o término do "Inflow Occlusion"); M6 (24 horas após o término da cirurgia); M7 (48 horas após o término da cirurgia)

DP - desvio padrão

M3 - momento não considerado para a análise do parâmetro

$\uparrow$ - óbito

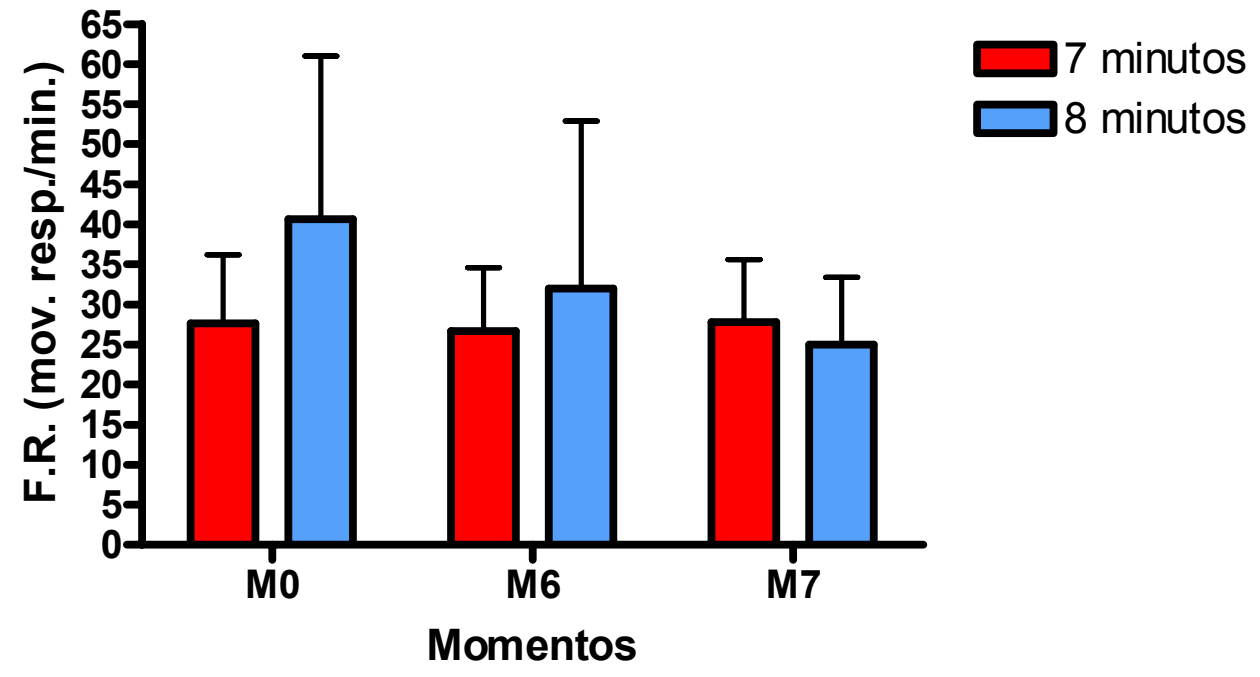

M0 (30 minutos antes da medicação pré-anestésica); M6 (24 horas após término da cirurgia); M7 (48 horas após término da cirurgia)

Gráfico 1 - Comparação entre as médias dos grupos A e B relativas à freqüência respiratória (F.R.), de cães submetidos a sete e oito minutos de parada circulatória total, respectivamente, durante os momentos correspondentes aos períodos pré-operatório M0, e pós-operatórios M6 e M7 - São Paulo - 2005 


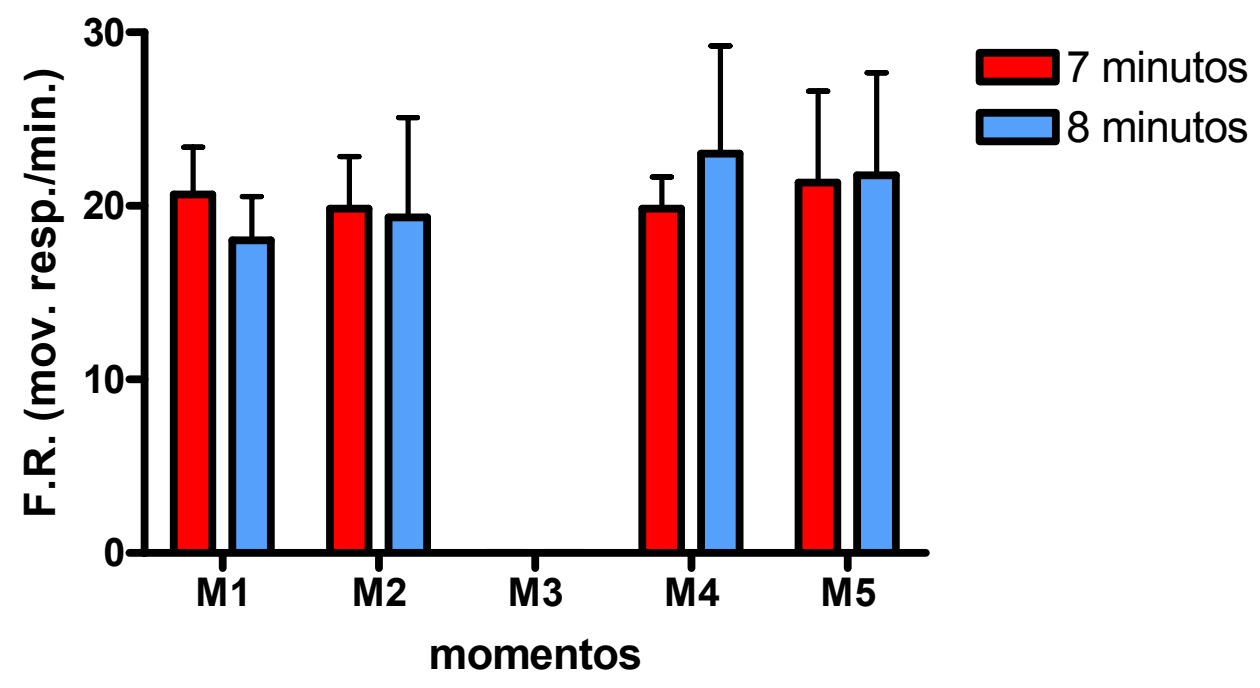

M1 (30 minutos após estabilização anestésica); M2 (imediatamente antes do "Inflow Occlusion"); M3 (decorridos 5 minutos do "Inflow Occlusion"); M4 (5 minutos após o término do "Inflow Occlusion"); M5 (30 minutos após o término do "Inflow Occlusion")

M3 - momento não considerado para a análise do parâmetro

Gráfico 2 - Comparação entre as médias dos grupos A e B relativas à freqüência respiratória (F.R.), de cães submetidos a sete e oito minutos de parada circulatória total, respectivamente, durante os momentos correspondentes ao período transoperatório M1 a M5 - São Paulo - 2005

- $\quad$ Freqüência cardíaca

Em relação à freqüência cardíaca, todos os cães dos dois grupos experimentais, com exceção de dois indivíduos do grupo B (números 1 e 11), os quais apresentaram taquicardia no momento de coleta dos dados, tiveram no momento M0 (trinta minutos antes da medicação pré-anestésica), batimentos cardíacos dentro dos limites físiológicos considerados normais para a espécie canina. Em relação aos momentos pós-operatórios, apenas dois animais do grupo A (animais 6 e 7) apresentaram padrão acima do normal, ambos no momento M7; e somente um animal do grupo B (animal 9) o apresentou aumentado nos momentos M6 e M7. Durante o período transoperatório, relativo aos momentos antes da parada circulatória, todos os animais de ambos os grupos, com exceção do animal 7 do grupo A, e do cão número 1 do grupo B (ambos com padrão aumentado em M2), apresentaram batimentos cardíacos dentro dos limites normais para a espécie em questão. Após a parada circulatória total, apenas os animais 1 e 5 do grupo B mostraram valor aumentado em M4. Já os cães 7 e 8 do grupo A, e os cães 1, 3 e 5 do grupo B, apresentaram valores acima do normal em M5. A análise estatística não revelou diferenças significativas na comparação das médias dos dois grupos. 
Os valores de freqüência cardíaca individuais, médias e desvios-padrão dos animais, estão discriminados nas tabelas 3 e 4, respectivamente para os grupos A e B. As comparações entre as médias dos grupos estão demonstradas nos gráficos 3 e 4.

Tabela 3 - Valores individuais de freqüência cardíaca (F.C.) em batimentos por minuto, médias e respectivos desvios-padrão dos animais do grupo A, submetidos a sete minutos de parada circulatória total - São Paulo - 2005

\begin{tabular}{l|c|c|c|c|c|c|c|c}
\hline & M0 & M1 & M2 & M3 & M4 & M5 & M6 & M7 \\
\hline Animal 02 & 120 & 85 & 101 & ---- & 86 & 109 & 116 & 112 \\
Animal 04 & 120 & 77 & 70 & ---- & 119 & 96 & 116 & 84 \\
Animal 06 & 80 & 91 & 120 & ---- & 100 & 121 & 84 & 124 \\
Animal 07 & 116 & 85 & 144 & ---- & 87 & 154 & 84 & 124 \\
Animal 08 & 109 & 88 & 101 & ---- & 98 & 148 & 104 & 119 \\
Animal 10 & 90 & 80 & 82 & ---- & 77 & 110 & 92 & 89 \\
\hline Média & 105,83 & 84,33 & 103,00 & ----- & 94,50 & 123,00 & 99,33 & 108,66 \\
\hline DP & 16,64 & 5,13 & 26,49 & ----- & 14,68 & 23,17 & 14,84 & 17,80 \\
\hline
\end{tabular}

M0 (30 minutos antes da medicação pré-anestésica); M1 (30 minutos após estabilização anestésica); M2 (imediatamente antes do "Inflow Occlusion"); M3 (decorridos 5 minutos do "Inflow Occlusion"); M4 (5 minutos após o término do "Inflow Occlusion"); M5 (30 minutos após o término do "Inflow Occlusion"); M6 (24 horas após o término da cirurgia); M7 (48 horas após o término da cirurgia)

DP - desvio padrão

M3 - momento não considerado para análise deste parâmetro

Tabela 4 - Valores individuais de freqüência cardíaca (F.C.) em batimentos por minuto, médias e respectivos desvios-padrão dos animais do grupo $\mathrm{B}$, submetidos a oito minutos de parada circulatória total - São Paulo - 2005

\begin{tabular}{l|c|c|c|c|c|c|c|c}
\hline & M0 & M1 & M2 & M3 & M4 & M5 & M6 & M7 \\
\hline Animal 01 & 160 & 105 & 127 & ---- & 137 & 158 & 100 & 120 \\
Animal 03 & 76 & 104 & 105 & ---- & 76 & 152 & 80 & 80 \\
Animal 05 & 108 & 120 & 111 & ---- & 124 & 142 & 88 & 110 \\
Animal 09 & 98 & 97 & 108 & ----- & 109 & 110 & 123 & 122 \\
Animal 11 & 147 & 100 & 96 & ----- & $\dagger$ & $\dagger$ & $\dagger$ & $\dagger$ \\
Animal 12 & 72 & 64 & 102 & ----- & $\dagger$ & $\dagger$ & $\dagger$ & $\dagger$ \\
\hline Média & 110,17 & 98,33 & 108,16 & ----- & 111,50 & 140,50 & 97,75 & 108,00 \\
\hline DP & 31,12 & 18,60 & 10,57 & ---- & 26,28 & 21,37 & 18,73 & 19,39 \\
\hline
\end{tabular}

M0 (30 minutos antes da medicação pré-anestésica); M1 (30 minutos após estabilização anestésica); M2 (imediatamente antes do "Inflow Occlusion"); M3 (decorridos 5 minutos do "Inflow Occlusion"); M4 (5 minutos após o término do "Inflow Occlusion"); M5 (30 minutos após o término do "Inflow Occlusion"); M6 (24 horas após o término da cirurgia); M7 (48 horas após o término da cirurgia)

$\mathrm{DP}$ - desvio padrão

M3 - momento não considerado para análise deste parâmetro

$\dagger$ - óbito 


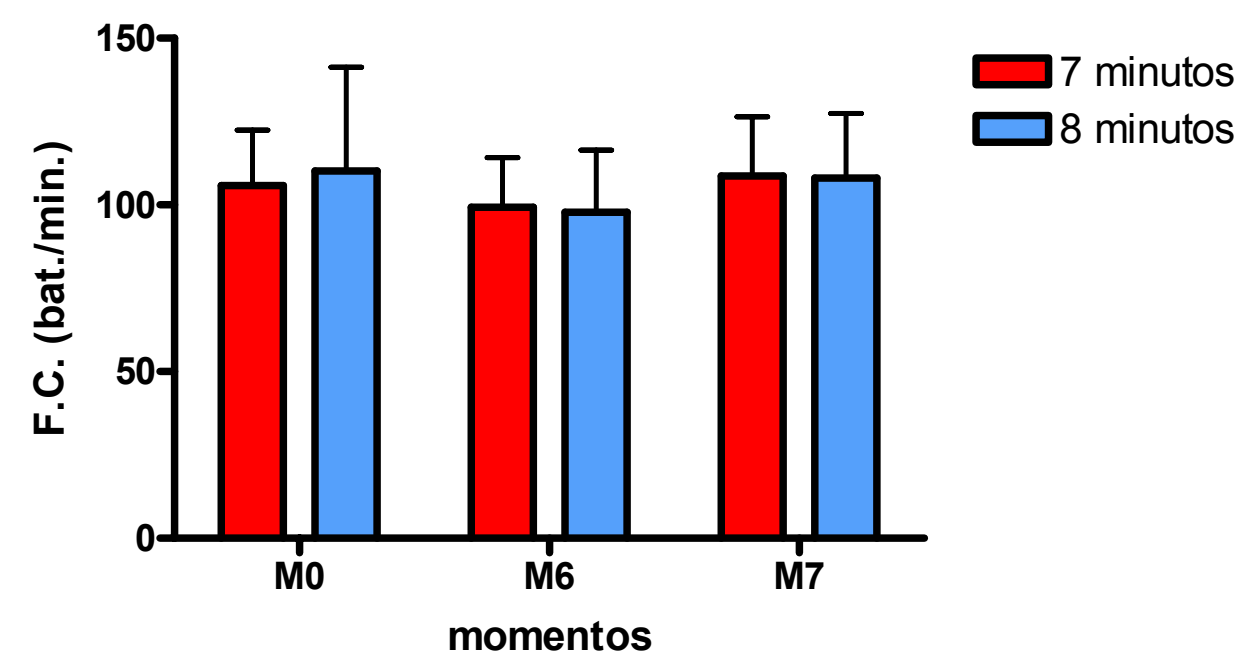

M0 (30 minutos antes da medicação pré-anestésica); M6 (24 horas após o término da cirurgia); M7 (48 horas após o término da cirurgia)

Gráfico 3 - Comparação entre as médias dos grupos A e B relativas à freqüência cardíaca (F.C.), de cães submetidos a sete e oito minutos de parada circulatória total, respectivamente, durante os momentos correspondentes aos períodos pré-operatório M0, e pós-operatórios M6 e M7 - São Paulo - 2005

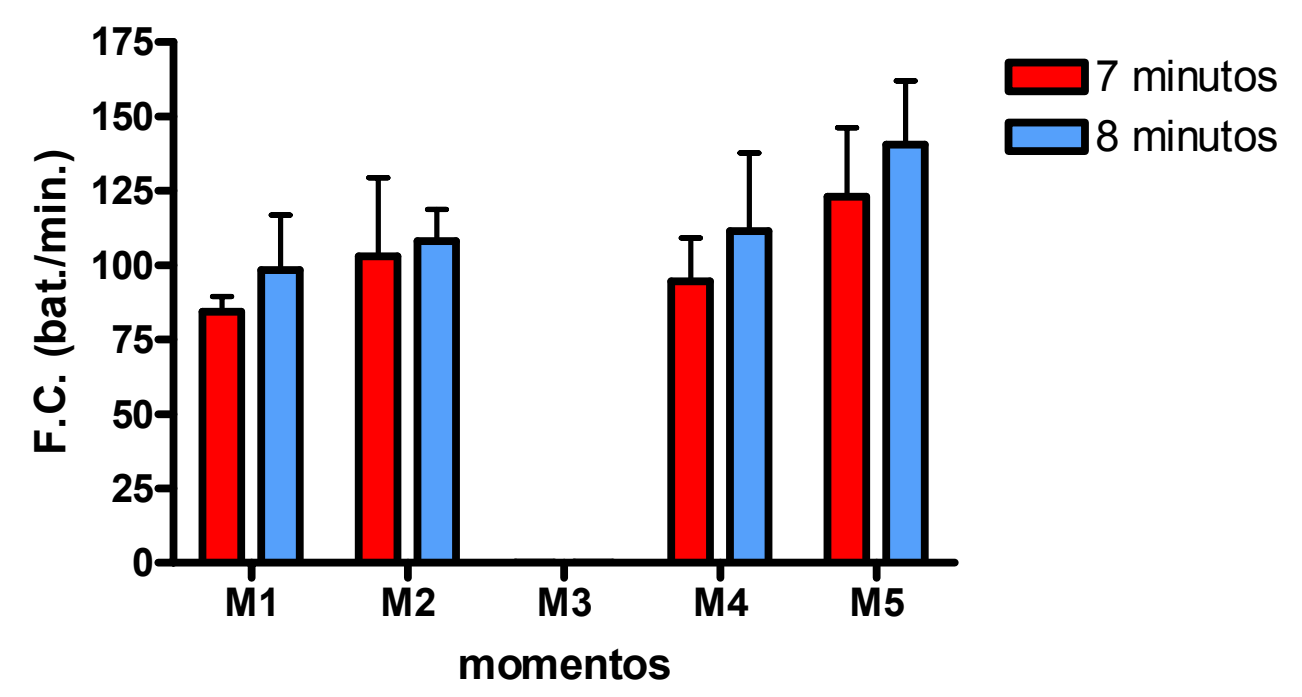

M1 (30 minutos após estabilização anestésica); M2 (imediatamente antes do "Inflow Occlusion"); M3 (decorridos 5 minutos do "Inflow Occlusion"); M4 (5 minutos após o término do "Inflow Occlusion"); M5 (30 minutos após o término do "Inflow Occlusion")

M3 - momento não considerado para análise deste parâmetro

Gráfico 4 - Comparação entre as médias dos grupos A e B relativas à freqüência cardíaca (F.C.), de cães submetidos a sete e oito minutos de parada circulatória total, respectivamente, durante os momentos correspondentes ao período transoperatório M1 a M5 - São Paulo - 2005

- Temperatura corpórea 
No tocante à temperatura corpórea retal, o que se observou foi normalidade da mesma nos animais dos dois grupos no momento M0, porém levemente aumentada em dois do grupo B (animais 1 e 5). No período pós-operatório, apenas um animal do grupo B (animal 9) apresentou valor de temperatura corpórea retal acima do fisiológico, sendo este constatado no momento M7. O que se observou durante o período transoperatório foi queda de temperatura, inclusive nos momentos antecedentes à parada circulatória total. Estes valores ainda permaneceram baixos até a coleta dos dados em M5. Mesmo com o uso do colchão térmico, com temperatura estabelecida em $40^{\circ} \mathrm{C}$, não foi possível manter a temperatura dos cães dentro dos limites fisiológicos no período transoperatório. Os valores individuais, médias e desviospadrão relativos a cada grupo estão demonstrados nas tabelas 5 e 6 , respectivamente para o grupo A e B. Os valores para comparação entre os períodos pré e pós-operatórios, e transoperatórios são visualizados nos gráficos 5 e 6 , respectivamente. A análise estatística não revelou diferenças significativas entre os dois grupos.

Tabela 5 - Valores individuais de temperatura corpórea $\left(\mathrm{T}^{\circ} \mathrm{C}\right)$ em graus Celsius, médias e respectivos desviospadrão dos animais do grupo A, submetidos a sete minutos de parada circulatória total - São Paulo 2005

\begin{tabular}{l|c|c|c|c|c|c|c|c}
\hline & M0 & M1 & M2 & M3 & M4 & M5 & M6 & M7 \\
\hline Animal 02 & 39,0 & 34,4 & 34,9 & 35,1 & 35,0 & 34,8 & 38,8 & 38,8 \\
Animal 04 & 39,0 & 35,3 & 35,8 & 36,0 & 36,0 & 36,1 & 39,0 & 38,9 \\
Animal 06 & 39,5 & 36,0 & 36,0 & 36,4 & 36,1 & 36,2 & 38,7 & 38,9 \\
Animal 07 & 38,7 & 37,0 & 36,7 & 36,9 & 36,4 & 36,2 & 38,7 & 38,9 \\
Animal 08 & 38,0 & 33,9 & 34,2 & 34,3 & 34,3 & 34,2 & 39,2 & 39,0 \\
Animal 10 & 38,0 & 35,9 & 35,1 & 35,9 & 35,1 & 35,6 & 38,3 & 38,5 \\
\hline Média & 38,70 & 35,42 & 35,45 & 35,77 & 35,48 & 35,52 & 38,78 & 38,83 \\
\hline DP & 0,71 & 1,134 & 0,89 & 0,93 & 0,81 & 0,84 & 0,31 & 0,18 \\
\hline
\end{tabular}

M0 (30 minutos antes da medicação pré-anestésica); M1 (30 minutos após estabilização anestésica); M2 (imediatamente antes do "Inflow Occlusion"); M3 (decorridos 5 minutos do "Inflow Occlusion"); M4 (5 minutos após o término do "Inflow Occlusion"); M5 (30 minutos após o término do "Inflow Occlusion"); M6 (24 horas após o término da cirurgia); M7 (48 horas após o término da cirurgia)

DP - desvio padrão 
Tabela 6 - Valores individuais de temperatura corpórea $\left(\mathrm{T}^{\circ} \mathrm{C}\right)$ em graus Celsius, médias e respectivos desviospadrão dos animais do grupo $\mathrm{B}$, submetidos a oito minutos de parada circulatória total - São Paulo 2005

\begin{tabular}{l|c|c|c|c|c|c|c|cc}
\hline & M0 & M1 & M2 & M3 & M4 & M5 & M6 & M7 \\
\hline Animal 01 & 39,9 & 37,8 & 37,6 & 37,5 & 37,4 & 37,1 & 38,3 & 39,3 \\
Animal 03 & 39,0 & 37,2 & 37,0 & 36,9 & 37,0 & 37,0 & 38,4 & 39,3 \\
Animal 05 & 39,7 & 36,2 & 36,3 & 36,6 & 36,3 & 36,2 & 38,7 & 39,0 \\
Animal 09 & 38,1 & 35,9 & 34,6 & 34,6 & 34,6 & 34,0 & 38,8 & 40,6 \\
Animal 11 & 39,5 & 36,7 & 36,7 & 35,4 & $\dagger$ & $\dagger$ & $\dagger$ & $\dagger$ \\
Animal 12 & 37,0 & 35,0 & 35,0 & 35,0 & $\dagger$ & $\dagger$ & $\dagger$ & $\dagger$ \\
\hline Média & 38,87 & 36,47 & 36,20 & 36,00 & 36,32 & 36,07 & 38,55 & 39,55 \\
\hline DP & 1,27 & 0,99 & 1,17 & 1,16 & 1,24 & 1,44 & 0,24 & 0,71 \\
\hline
\end{tabular}

M0 (30 minutos antes da medicação pré-anestésica); M1 (30 minutos após estabilização anestésica); M2 (imediatamente antes do "Inflow Occlusion"); M3 (decorridos 5 minutos do "Inflow Occlusion"); M4 (5 minutos após o término do "Inflow Occlusion"); M5 (30 minutos após o término do "Inflow Occlusion"); M6 (24 horas após o término da cirurgia); M7 (48 horas após o término da cirurgia)

DP - desvio padrão

$\uparrow-$ óbito

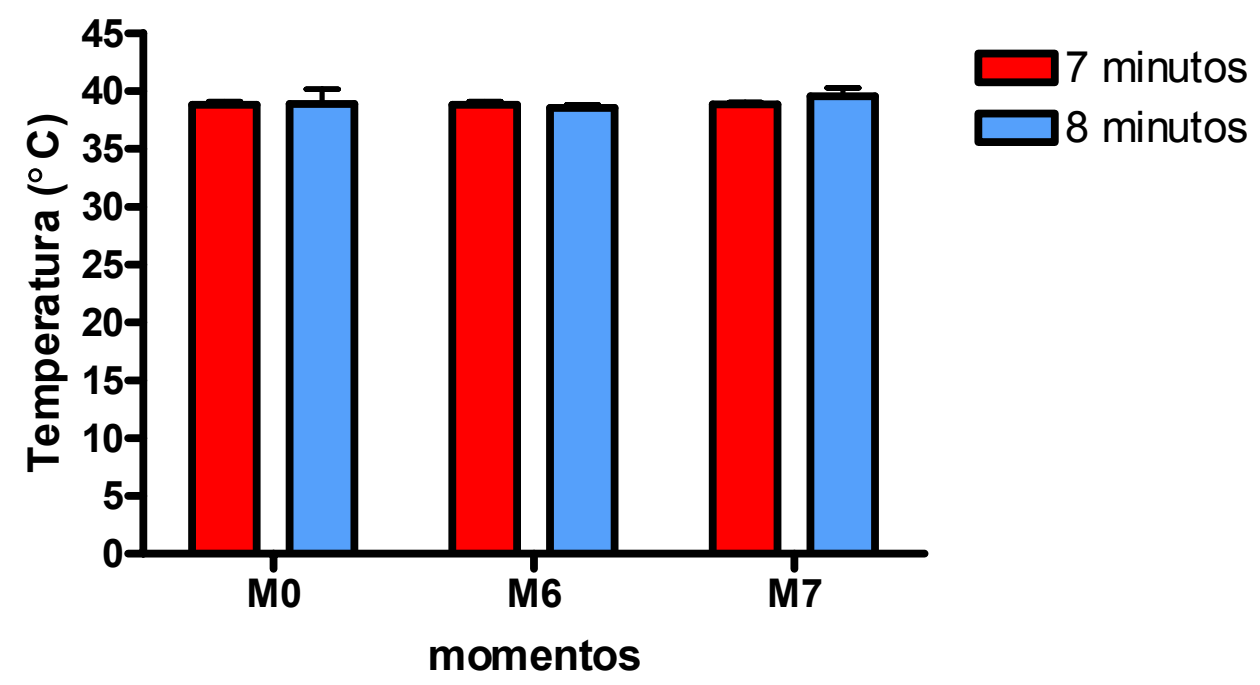

M0 (30 minutos antes da medicação pré-anestésica); M6 (24 horas após o término da cirurgia); M7 (48 horas após o término da cirurgia)

Gráfico 5 - Comparação entre as médias dos grupos A e B relativas à temperatura corpórea $\left(\mathrm{T}^{\circ} \mathrm{C}\right)$, de cães submetidos a sete e oito minutos de parada circulatória total, respectivamente, durante os momentos correspondentes aos períodos pré-operatório M0, e pós-operatórios M6 e M7 - São Paulo - 2005 


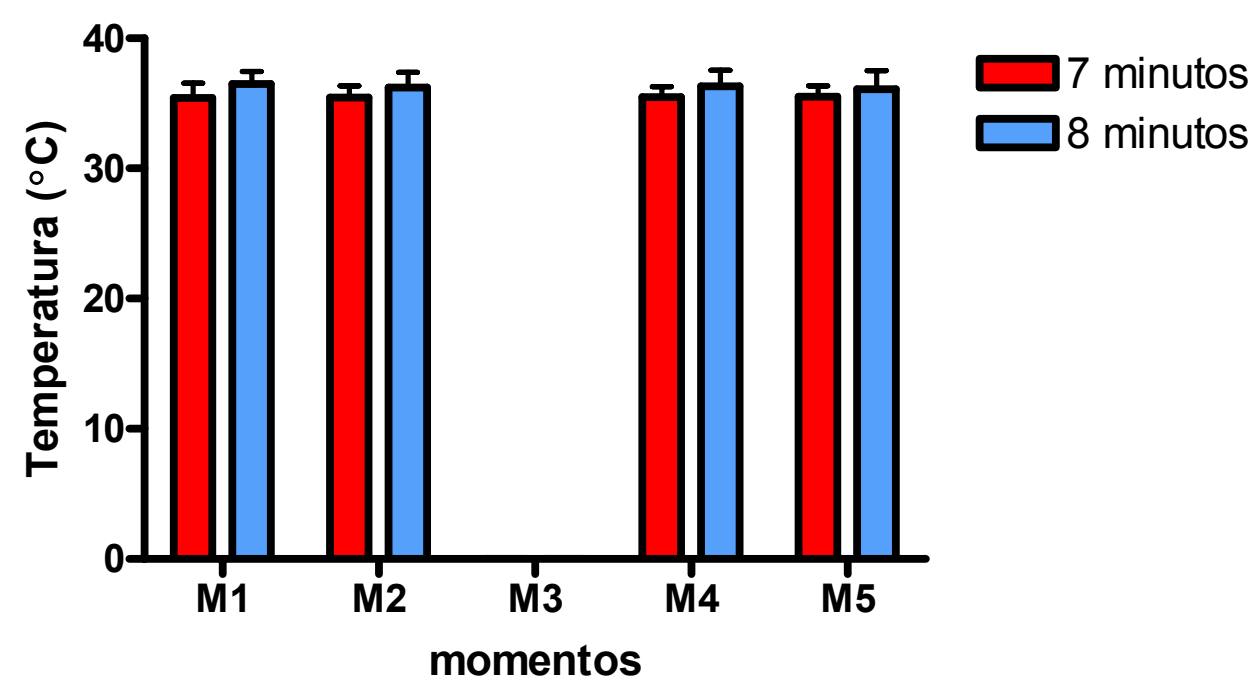

M1 (30 minutos após estabilização anestésica); M2 (imediatamente antes do "Inflow Occlusion"); M3 (decorridos 5 minutos do "Inflow Occlusion"); M4 (5 minutos após o término do "Inflow Occlusion"); M5 (30 minutos após o término do "Inflow Occlusion")

M3 - momento não considerado para análise deste parâmetro

Gráfico 6 - Comparação entre as médias dos grupos A e B relativas à temperatura corpórea $\left(\mathrm{T}^{\circ} \mathrm{C}\right)$, de cães submetidos a sete e oito minutos de parada circulatória total, respectivamente, durante os momentos correspondentes ao período transoperatório M1 a M5 - São Paulo - 2005

- $\quad$ Pressão arterial média

Em relação aos valores de pressão arterial média (P.A.M.) individuais, médias e desvios-padrão relativos aos momentos analisados, os mesmos estão discriminados nas tabelas 7 e 8, para os grupos A e B, respectivamente. A comparação entre as médias dos grupos A e B é visualizada nos gráficos 7 e 8.

$\mathrm{Na}$ análise dos momentos pré e pós-operatórios dos seis cães do grupo A, ou seja, momentos M0, M6 e M7, três animais (números 6, 7 e 10) obtiveram valores de P.A.M. em M6 mais altos que M0, e os outros três (números 2, 4 e 8) os valores correspondentes ao mesmo período foram mais baixos. Os animais 6 e 7, os quais em M6 apresentaram valores maiores que M0, aumentaram a P.A.M. em M7. O cão $\mathrm{n}^{\circ} 10$ apresentou leve queda da mesma em M7, enquanto o $\mathrm{n}^{\circ} 2$ no momento M7, apresentou valor igual a M6; o animal 4 teve diminuição da P.A.M. em M7, e no cão $n^{\circ} 8$, no momento $M 7$, foi constatada elevação dos valores em comparação com M6 e M0. Na análise do período transoperatório, o que ocorreu foi queda brusca da P.A.M. em M3, momento da parada circulatória total, porém com 
retomada dos valores em M4, os quais eram próximos a M2, antes da parada circulatória. Em M5 não houve alterações de monta quando comparado a M4, sendo que a P.A.M. só melhorou e estabilizou-se no pós-operatório em M6. Já na análise dos momentos pré e pós-operatórios do grupo B, o cão número 1 apresentou valor maior em M6 quando comparado a M0; o animal 5 obteve valores iguais da P.A.M. em M6 e M0, enquanto que os animais $n^{\circ} 3$ e $n^{\circ} 9$ apresentaram diminuição da mesma na comparação destes momentos. Já em $\mathrm{M} 7$, todos os animais deste grupo apresentaram valores menores que M0, com exceção do cão 5, o qual manteve M7 igual a M6 e M0. O animal 3 apresentou a P.A.M. em M7 maior que em M6, e o $\mathrm{n}^{\circ} 9$ mostrou valor menor no mesmo período comparado a M6. No período transoperatório, ocorreu fato idêntico ao grupo A, ou seja, queda brusca em M3, seguida de aumento dos valores em M4 e M5 com valores mais próximos a M2. A análise estatística nos períodos pré e pós-operatório mostrou diferença significativa entre os grupos no momento $M 0(p<0,05)$, e também revelou diferença muito significativa entre eles no período transoperatório, sendo a mesma em M4 $(\mathrm{p}<0,01)$.

Tabela 7 - Valores individuais de pressão arterial média (P.A.M.) em mmHg, médias e respectivos desviospadrão dos animais do grupo A, submetidos a sete minutos de parada circulatória total - São Paulo 2005

\begin{tabular}{l|c|c|c|c|c|c|c|c}
\hline & M0 & M1 & M2 & M3 & M4 & M5 & M6 & M7 \\
\hline Animal 02 & 106 & 81 & 80 & 14 & 87 & 71 & 103 & 103 \\
Animal 04 & 97 & 77 & 65 & 23 & 60 & 69 & 90 & 80 \\
Animal 06 & 83 & 67 & 71 & 13 & 93 & 66 & 106 & 126 \\
Animal 07 & 96 & 90 & 80 & 9 & 84 & 80 & 106 & 126 \\
Animal 08 & 103 & 63 & 77 & 25 & 65 & 65 & 100 & 116 \\
Animal 10 & 99 & 64 & 76 & 15 & 83 & 84 & 119 & 115 \\
\hline Média & 97,33 & 73,67 & 74,83 & 16,50 & 78,67 & 72,50 & 104,00 & 111,00 \\
\hline DP & 8,65 & 10,80 & 5,85 & 6,19 & 13,09 & 7,77 & 9,44 & 17,41 \\
\hline
\end{tabular}

M0 (30 minutos antes da medicação pré-anestésica); M1 (30 minutos após estabilização anestésica); M2 (imediatamente antes do "Inflow Occlusion"); M3 (decorridos 5 minutos do "Inflow Occlusion"); M4 (5 minutos após o término do "Inflow Occlusion"); M5 (30 minutos após o término do "Inflow Occlusion"); M6 (24 horas após o término da cirurgia); M7 (48 horas após o término da cirurgia)

DP - desvio padrão 
Tabela 8 - Valores individuais de pressão arterial média (P.A.M.) em mmHg, médias e respectivos desviospadrão dos animais do grupo B, submetidos a oito minutos de parada circulatória total - São Paulo 2005

\begin{tabular}{l|c|c|c|c|c|c|c|c}
\hline & M0 & M1 & M2 & M3 & M4 & M5 & M6 & M7 \\
\hline Animal 01 & 93 & 91 & 103 & 17 & 135 & 83 & 96 & 90 \\
Animal 03 & 126 & 103 & 80 & 10 & 133 & 102 & 86 & 100 \\
Animal 05 & 103 & 87 & 71 & 12 & 85 & 79 & 103 & 103 \\
Animal 09 & 120 & 72 & 90 & 17 & 83 & 89 & 109 & 93 \\
Animal 11 & 125 & 83 & 78 & 6 & $\dagger$ & $\dagger$ & $\dagger$ & $\dagger$ \\
Animal 12 & 117 & 64 & 73 & 17 & $\dagger$ & $\dagger$ & $\dagger$ & $\dagger$ \\
\hline Média & 114,00 & 83,33 & 85,33 & 13,17 & 109,00 & 88,25 & 98,50 & 96,50 \\
\hline DP & 9,43 & 13,87 & 11,34 & 4,62 & 28,89 & 10,05 & 9,88 & 6,03 \\
\hline
\end{tabular}

M0 (30 minutos antes da medicação pré-anestésica); M1 (30 minutos após estabilização anestésica); M2 (imediatamente antes do "Inflow Occlusion"); M3 (decorridos 5 minutos do "Inflow Occlusion"); M4 (5 minutos após o término do "Inflow Occlusion"); M5 (30 minutos após o término do "Inflow Occlusion"); M6 (24 horas após o término da cirurgia); M7 (48 horas após o término da cirurgia)

DP - desvio padrão

$\dagger$ - óbito

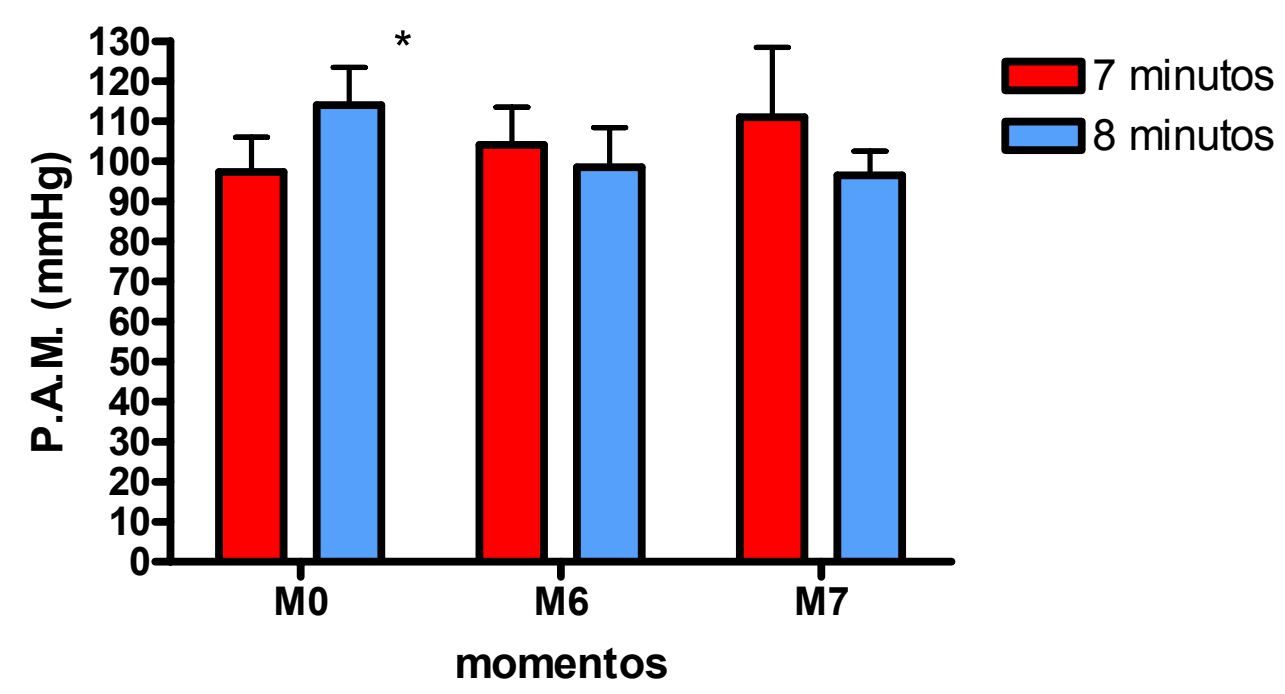

* Segundo a análise estatística, a comparação entre as médias e desvios-padrão dos grupos A e B é considerada significativa $(\mathrm{p}<0,05)$.

M0 (30 minutos antes da medicação pré-anestésica); M6 (24 horas após o término da cirurgia); M7 (48 horas após o término da cirurgia)

Gráfico 7 - Comparação entre as médias dos grupos A e B relativas à pressão arterial média (P.A.M.), de cães submetidos a sete e oito minutos de parada circulatória total, respectivamente, durante os momentos correspondentes aos períodos pré-operatório M0, e pós-operatórios M6 e M7 - São Paulo - 2005 


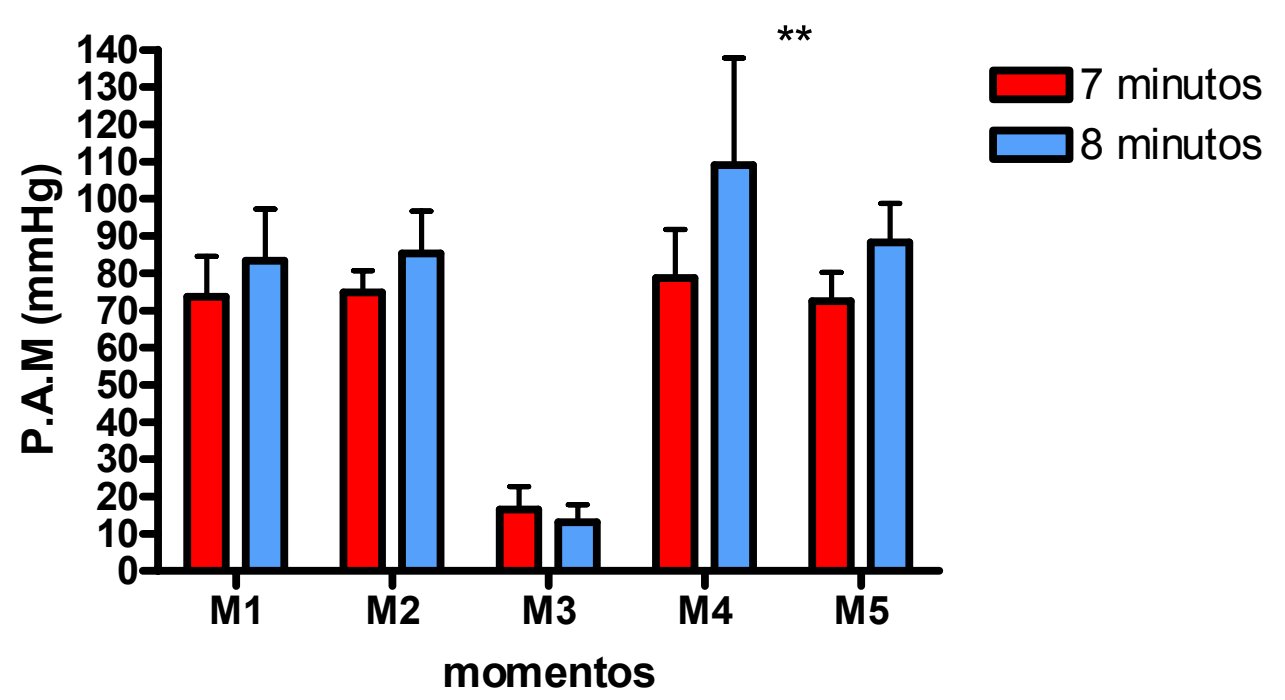

\footnotetext{
** Segundo a análise estatística, a comparação entre as médias e desvios-padrão dos grupos A e B é considerada muito significativa $(\mathrm{p}<0,01)$.

M1 (30 minutos após estabilização anestésica); M2 (imediatamente antes do "Inflow Occlusion"); M3 (decorridos 5 minutos do "Inflow Occlusion"); M4 (5 minutos após o término do "Inflow Occlusion"); M5 (30 minutos após o término do "Inflow Occlusion”)

Gráfico 8 - Comparação entre as médias dos grupos A e B relativas à pressão arterial média (P.A.M.), de cães submetidos a sete e oito minutos de parada circulatória total, respectivamente, durante os momentos correspondentes ao período transoperatório M1 a M5 - São Paulo - 2005
}

- $\quad$ Pressão arterial sistólica

Os valores de pressão arterial sistólica (P.A.S.) individuais, médias e desvios-padrão em relação aos momentos analisados, estão discriminados nas tabelas 9 e 10, para os grupos A e $\mathrm{B}$, respectivamente. $\mathrm{O}$ momento M3 não foi considerado para análise de resultados para este parâmetro. A comparação entre as médias dos grupos A e B pode ser visualizada nos gráficos 9 e 10.

$\mathrm{Na}$ análise da P.A.S. referente aos períodos pré e pós-operatórios dos animais do grupo A, observou-se que quatro animais (números 6, 7, 8 e 10) apresentaram valores maiores em M6 e M7, quando comparados a M0; e outros dois (números 2 e 4) apresentaram valores em M6 iguais a M7, porém nos dois momentos citados os valores foram inferiores em relação a M0. No grupo B, todos os valores de M6 mostraram-se iguais ou próximos aos encontrados em M7, havendo pouca variação individual em relação a M0. O animal $n^{\circ} 5$ apresentou em M6 e M7 valores iguais a M0. Em relação aos períodos transoperatórios, houve coincidências de comportamento entre os grupos A e B. Houve queda da P.A.S. tão brusca que o aparelho, o 
qual fornece os dados, não registrou os valores, impossibilitando de se fazer a análise dos dados no momento M3 tanto da P.A.S., como da P.A.D., permitindo aferência dos dados neste momento, somente da P.A.M. Já em M4, quando do retorno circulatório, a pressão sistólica elevou-se novamente e pôde ser mensurada, mantendo-se estável também em M5. Somente observou-se diferença significativa entre os grupos na comparação das médias no momento M4 ( $<<0,01)$, a mesma não ocorrendo demais.

Tabela 9 - Valores individuais de pressão arterial sistólica (P.A.S.) em mmHg, médias e respectivos desviospadrão dos animais do grupo A, submetidos a sete minutos de parada circulatória total - São Paulo 2005

\begin{tabular}{l|c|c|c|c|c|c|c|c}
\hline & M0 & M1 & M2 & M3 & M4 & M5 & M6 & M7 \\
\hline Animal 02 & 140 & 100 & 103 & ----- & 119 & 96 & 130 & 130 \\
Animal 04 & 130 & 105 & 92 & ----- & 96 & 96 & 110 & 110 \\
Animal 06 & 110 & 81 & 96 & ----- & 125 & 90 & 140 & 160 \\
Animal 07 & 130 & 119 & 109 & ----- & 121 & 106 & 140 & 160 \\
Animal 08 & 130 & 75 & 86 & ----- & 78 & 77 & 160 & 150 \\
Animal 10 & 130 & 81 & 97 & ----- & 98 & 98 & 156 & 151 \\
\hline média & 128,33 & 93,50 & 97,17 & ----- & 106,17 & 98,83 & 139,33 & 143,55 \\
\hline DP & 10,00 & 17,20 & 8,08 & ----- & 18,45 & 9,72 & 18,18 & 19,74 \\
\hline
\end{tabular}

M0 (30 minutos antes da medicação pré-anestésica); M1 (30 minutos após estabilização anestésica); M2 (imediatamente antes do "Inflow Occlusion"); M3 (decorridos 5 minutos do "Inflow Occlusion”); M4 (5 minutos após o término do "Inflow Occlusion"); M5 (30 minutos após o término do "Inflow Occlusion"); M6 (24 horas após o término da cirurgia); M7 (48 horas após o término da cirurgia)

DP - desvio padrão

M3 - momento não considerado para análise deste parâmetro

Tabela 10 - Valores individuais de pressão arterial sistólica (P.A.S.) em mmHg, médias e respectivos desviospadrão dos animais do grupo $\mathrm{B}$, submetidos a oito minutos de parada circulatória total - São Paulo 2005

\begin{tabular}{l|c|c|c|c|c|c|c|cc}
\hline & M0 & M1 & M2 & M3 & M4 & M5 & M6 & M7 \\
\hline Animal 01 & 120 & 121 & 142 & ---- & 184 & 115 & 130 & 110 \\
Animal 03 & 160 & 141 & 90 & ---- & 204 & 136 & 120 & 120 \\
Animal 05 & 130 & 111 & 97 & ---- & 121 & 104 & 130 & 130 \\
Animal 09 & 160 & 102 & 120 & ---- & 126 & 121 & 133 & 134 \\
Animal 11 & 157 & 100 & 96 & ---- & $\dagger$ & $\dagger$ & $\dagger$ & $\dagger$ \\
Animal 12 & 150 & 89 & 120 & ---- & $\dagger$ & $\dagger$ & $\dagger$ & $\dagger$ \\
\hline média & 146,17 & 108,17 & 107,50 & ----- & 158,75 & 119,00 & 136,50 & 131,75 \\
\hline DP & 13,50 & 22,46 & 19,76 & ----- & 41,56 & 13,34 & 20,22 & 24,88 \\
\hline
\end{tabular}

M0 (30 minutos antes da medicação pré-anestésica); M1 (30 minutos após estabilização anestésica); M2 (imediatamente antes do "Inflow Occlusion"); M3 (decorridos 5 minutos do "Inflow Occlusion"); M4 (5 minutos após o término do "Inflow Occlusion"); M5 (30 minutos após o término do "Inflow Occlusion"); M6 (24 horas após o término da cirurgia); M7 (48 horas após o término da cirurgia)

DP - desvio padrão

M3 - momento não considerado para análise deste parâmetro

$\uparrow$ - óbito 


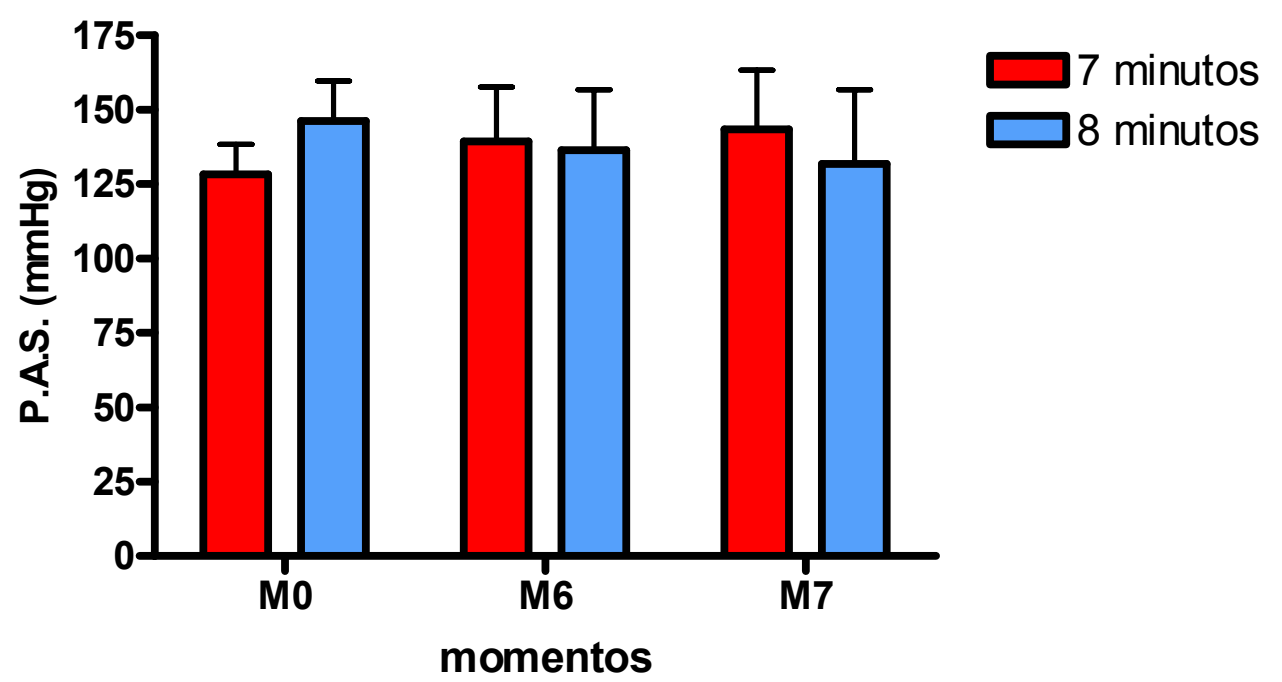

M0 (30 minutos antes da medicação pré-anestésica); M6 (24 horas após o término da cirurgia); M7 (48 horas após o término da cirurgia)

Gráfico 9 - Comparação entre as médias dos grupos A e B relativas à pressão arterial sistólica (P.A.S.), de cães submetidos a sete e oito minutos de parada circulatória total, respectivamente, durante os momentos correspondentes aos períodos pré-operatório M0, e pós-operatórios M6 e M7 - São Paulo - 2005

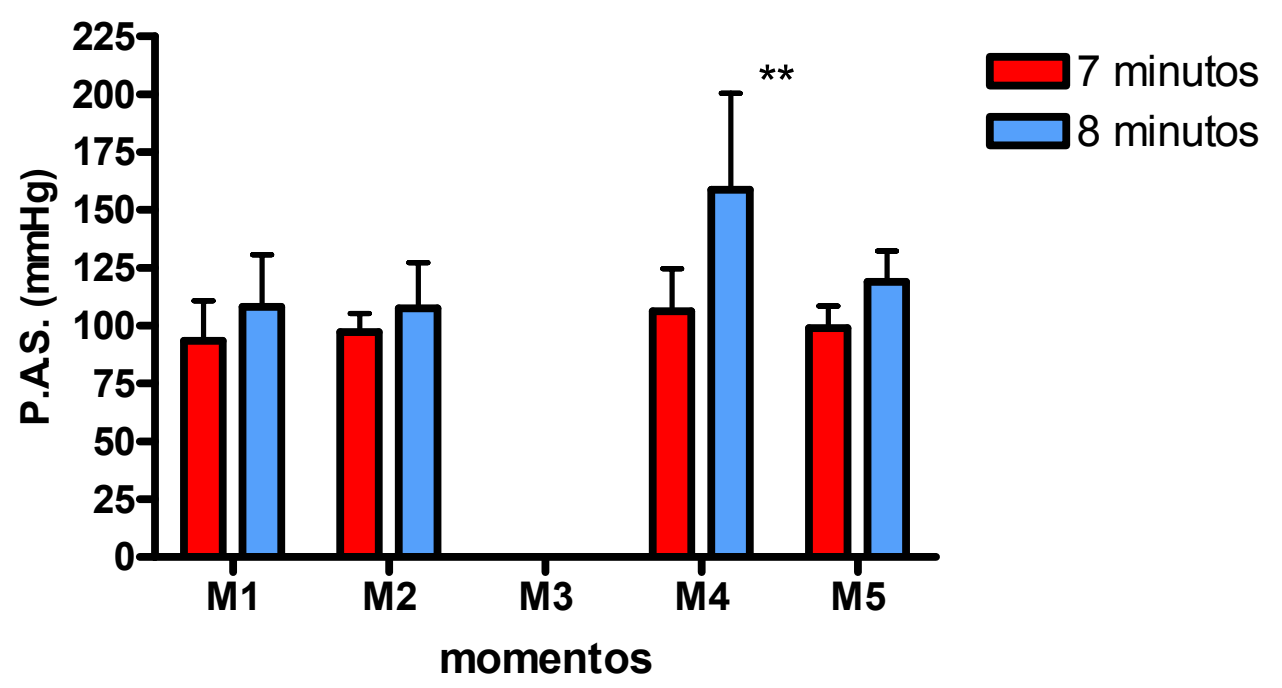

** Segundo a análise estatística, a comparação entre as médias e desvios-padrão dos grupos A e B é considerada muito significativa $(\mathrm{p}<0,01)$.

M1 (30 minutos após estabilização anestésica); M2 (imediatamente antes do "Inflow Occlusion"); M3 (decorridos 5 minutos do "Inflow Occlusion"); M4 (5 minutos após o término do "Inflow Occlusion"); M5 (30 minutos após o término do "Inflow Occlusion")

M3 - momento não considerado para análise deste parâmetro

Gráfico 10 - Comparação entre as médias dos grupos A e B relativas à pressão arterial sistólica (P.A.S.), de cães submetidos a sete e oito minutos de parada circulatória total, respectivamente, durante os momentos correspondentes ao período transoperatório M1 a M5 - São Paulo - 2005 
- $\quad$ Pressão arterial diastólica

Os valores de pressão arterial diastólica (P.A.D.) individuais, médias e desvios-padrão em relação aos momentos analisados, estão discriminados nas tabelas 11 e 12, para os grupos A e B, respectivamente. O momento M3 não foi considerado para análise de resultados para este parâmetro. A comparação entre as médias dos dois grupos foi discriminada nos gráficos 11 e 12.

Em relação aos dados pré e pós-operatórios do grupo A, foi observado que em M6 houve aumento da P.A.D. de três animais (números 6, 7 e 10) em relação a M0; dois cães (números 2 e 4) apresentaram mesmo valor em M6 e M0, sendo que o indivíduo $\mathrm{n}^{\circ} 2$ também manteve o mesmo valor em M7. Somente o animal 8 apresentou valor de P.A.D. menor em M6, comparado ao valor do apresentado momento M0. Já em M7, quatro cães (números 6, 7, 8 e 10), apresentaram valores maiores que M0, com o animal 10 apresentando valor menor que M6. O espécime 4 teve em M7, valor menor que M6 e M0. Em relação ao grupo B, nos mesmos períodos de comparação acima, observou-se dois animais (números 1 e 5) com valores iguais em M0, M6 e M7. Outro cão do grupo B (animal 3) mostrou valores em M6 e M7 menores que o encontrado em M0. Outro indivíduo (animal 9) teve elevação da P.A.D. em M6, mas queda da mesma em M7, com valor menor que M0. Na análise dos períodos transoperatórios, o que se observou tanto no grupo A, como no B, foi estabilidade da P.A.D. nos momento M1 e M2, porém com queda brusca em M3, logo após a parada circulatória, fato que impossibilitou a análise deste momento pela falta de dados, como mencionado anteriormente. Em M4 houve recuperação dos valores, os quais elevaram-se pouco em M5, havendo até queda em alguns animais. Na comparação entre as médias dos dois grupos nos momentos analisados, houve diferença significativa da mesma no momento $\mathrm{M} 0(\mathrm{p}<0,05)$. 
Tabela 11 - Valores individuais de pressão arterial diastólica (P.A.D.) em mmHg, médias e respectivos desviospadrão dos animais do grupo A, submetidos a sete minutos de parada circulatória total - São Paulo 2005

\begin{tabular}{l|c|c|c|c|c|c|c|c}
\hline & M0 & M1 & M2 & M3 & M4 & M5 & M6 & M7 \\
\hline Animal 02 & 90 & 71 & 69 & ---- & 81 & 60 & 90 & 90 \\
Animal 04 & 80 & 63 & 52 & ----- & 42 & 56 & 80 & 70 \\
Animal 06 & 70 & 60 & 59 & ----- & 78 & 54 & 90 & 110 \\
Animal 07 & 80 & 76 & 66 & ----- & 66 & 68 & 90 & 110 \\
Animal 08 & 90 & 57 & 72 & ----- & 59 & 59 & 70 & 100 \\
Animal 10 & 84 & 56 & 68 & ----- & 76 & 78 & 101 & 97 \\
\hline média & 82,33 & 63,83 & 64,33 & ----- & 67,00 & 62,50 & 86,83 & 96,17 \\
\hline DP & 8,41 & 8,04 & 7,45 & ----- & 14,75 & 8,98 & 10,59 & 14,97 \\
\hline
\end{tabular}

M0 (30 minutos antes da medicação pré-anestésica); M1 (30 minutos após estabilização anestésica); M2 (imediatamente antes do "Inflow Occlusion"); M3 (decorridos 5 minutos do "Inflow Occlusion"); M4 (5 minutos após o término do "Inflow Occlusion"); M5 (30 minutos após o término do "Inflow Occlusion"); M6 (24 horas após o término da cirurgia); M7 (48 horas após o término da cirurgia)

DP - desvio padrão

M3 - momento não considerado para análise deste parâmetro

Tabela 12 - Valores individuais de pressão arterial diastólica (P.A.D.) em mmHg, médias e respectivos desviospadrão dos animais do grupo $\mathrm{B}$, submetidos a oito minutos de parada circulatória total - São Paulo 2005

\begin{tabular}{l|c|c|c|c|c|c|c|c}
\hline & M0 & M1 & M2 & M3 & M4 & M5 & M6 & M7 \\
\hline Animal 01 & 80 & 76 & 84 & ----- & 111 & 67 & 80 & 80 \\
Animal 03 & 110 & 85 & 76 & ----- & 98 & 85 & 70 & 90 \\
Animal 05 & 90 & 76 & 58 & ----- & 67 & 66 & 90 & 90 \\
Animal 09 & 100 & 57 & 75 & ----- & 62 & 74 & 121 & 89 \\
Animal 11 & 109 & 75 & 70 & ----- & $\dagger$ & $\dagger$ & $\dagger$ & $\dagger$ \\
Animal 12 & 100 & 42 & 62 & ----- & $\dagger$ & $\dagger$ & $\dagger$ & $\dagger$ \\
\hline média & 98,17 & 70,00 & 73,00 & ---- & 84,50 & 73,00 & 84,25 & 83,00 \\
\hline DP & 7,762 & 13,05 & 8,63 & ---- & 23,78 & 8,76 & 11,79 & 8,72 \\
\hline
\end{tabular}

M0 (30 minutos antes da medicação pré-anestésica); M1 (30 minutos após estabilização anestésica); M2 (imediatamente antes do "Inflow Occlusion"); M3 (decorridos 5 minutos do "Inflow Occlusion"); M4 (5 minutos após o término do "Inflow Occlusion"); M5 (30 minutos após o término do "Inflow Occlusion"); M6 (24 horas após o término da cirurgia); M7 (48 horas após o término da cirurgia)

$\mathrm{DP}$ - desvio padrão

M3 - momento não considerado para análise deste parâmetro $\dagger$ - óbito 


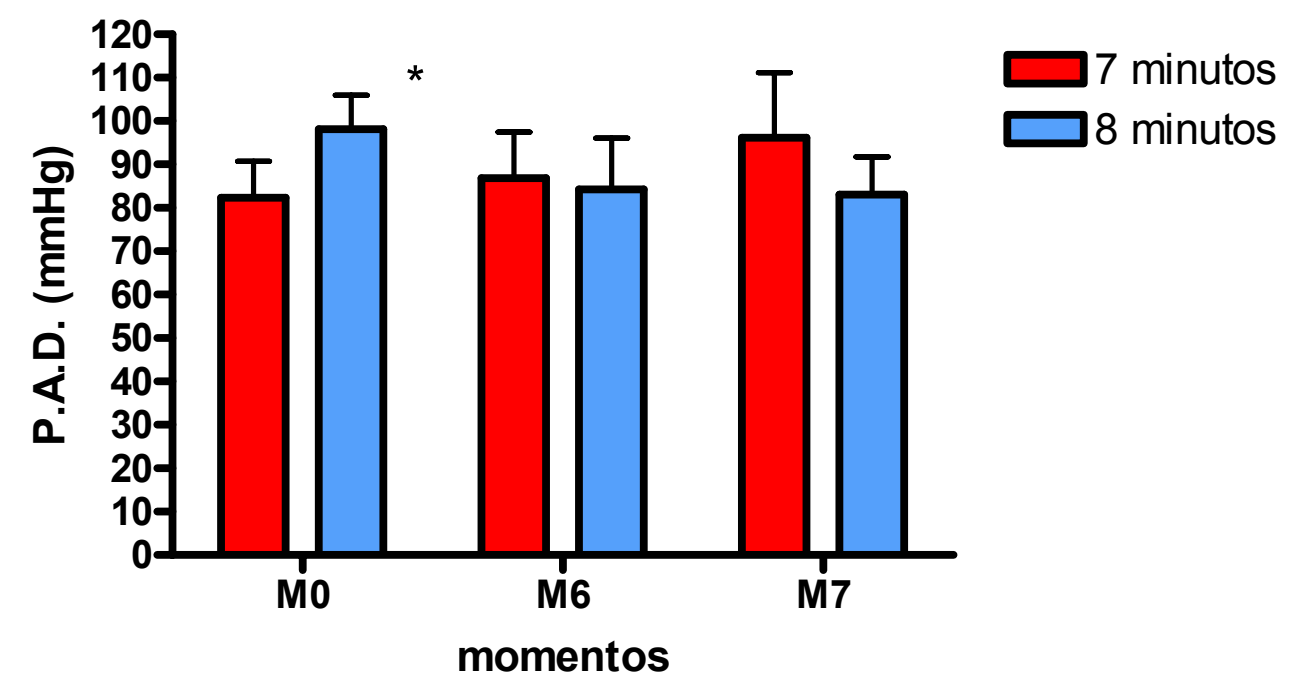

* Segundo a análise estatística, a comparação entre as médias e desvios-padrão dos grupos A e B é considerada significativa $(\mathrm{p}<0,05)$.

M0 (30 minutos antes da medicação pré-anestésica); M6 (24 horas após o término da cirurgia); M7 (48 horas após o término da cirurgia)

Gráfico 11 - Comparação entre as médias dos grupos A e B relativas à pressão arterial diastólica (P.A.D.), de cães submetidos a sete e oito minutos de parada circulatória total, respectivamente, durante os momentos correspondentes aos períodos pré-operatório M0, e pós-operatórios M6 e M7 - São Paulo - 2005

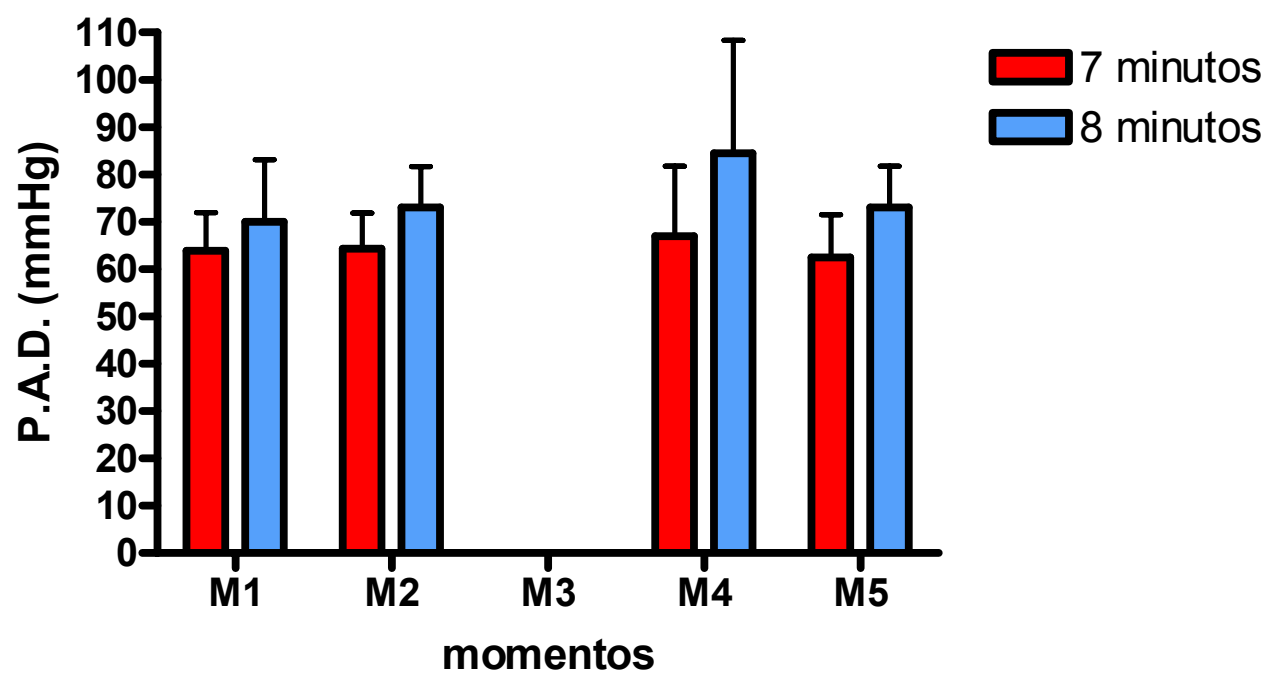

M1 (30 minutos após estabilização anestésica); M2 (imediatamente antes do "Inflow Occlusion"); M3 (decorridos 5 minutos do "Inflow Occlusion"); M4 (5 minutos após o término do "Inflow Occlusion"); M5 (30 minutos após o término do "Inflow Occlusion");

M3 - momento não considerado para análise deste parâmetro

Gráfico 12 - Comparação entre as médias dos grupos A e B relativas à pressão arterial diastólica (P.A.D.), de cães submetidos a sete e oito minutos de parada circulatória total, respectivamente, durante os momentos correspondentes ao período transoperatório M1 a M5 - São Paulo - 2005 


\subsection{AVALIAÇÃO NEUROLÓGICA}

Os seis animais do grupo A, submetidos a sete minutos de parada circulatória total, apresentaram boa evolução neurológica durante todo período de observação pós-operatória, com até vinte dias de seguimento. Os cães 2, 4, 8 e 10 foram doados e os de $n^{\circ} 6$ e 7 foram eutanasiados após este período de observação, como já foi mencionado anteriormente.

Dos quatro sobreviventes do grupo B, um animal ( $\mathrm{n}^{\circ}$ 9) evoluiu satisfatoriamente em todos os parâmetros, apresentando como alteração, convulsão no momento M7, não repetindo idêntico episódio da mesma até 20 dias de observação em seqüência. Nos outros três animais (números 1, 3 e 5) foram observados sintomas como incoordenação motora, não deambulação, dificuldade de desvio de objetos, claudicação, "medo", estado alerta prejudicado, perda ou diminuição de reflexo pupilar, perda de visão, e tremores. Um dos animais $\left(n^{\circ} 1\right)$ permaneceu sem visão até 48 horas após o ato operatório e foi eutanasiado no mesmo período M7. Outros dois animais (números 3 e 5) apresentaram de forma transitória os sintomas descritos (excluindo-se a perda de visão), sendo esses mais brandos, ou mesmo com ausência dos mesmos após as 48 horas preconizadas no experimento, permanecendo bem clinicamente até vinte dias de seguimento pós-cirúrgico. Os animais 3 e 9 foram doados após os vinte dias e o cão $n^{\circ} 5$ foi eutanasiado após o mesmo período.

Além dos parâmetros ora citados, foram realizados exames neurológicos nos animais em M6 e M7, incluindo testes de reação postural, testes de nervos cranianos, reações espinhais e pontuação dos sintomas, os quais foram comparados à Escala de Glasgow, para avaliar-se o prognóstico dos mesmos.

Na avaliação do momento M6, dos seis cães do grupo A, todos apresentaram o teste de reação postural normal, porém os animais 2, 6 e 10 apresentaram reflexos diminuídos referente ao "carrinho de mão" dos membros pélvicos, sendo que o cão 6 também apresentou diminuição da: "propriocepção posterior", "posicionamento tátil posterior" e "reação do pulo posterior", tendo dificuldade de movimentar os membros pélvicos. No relativo aos testes dos nervos cranianos, na avaliação com 24 horas de pós-operatório, os animais 2 e 8 apresentaram todas as reações normais. Já o cão 10 apresentou diminuição na reação dos nervos glossofaríngeo e vago, tendo dificuldade de deglutição, diminuição do reflexo de tosse e fonação. Os de número 4, 6 e 7 apresentaram alteração na avaliação dos nervos facial, vestíbulo-coclear e vago, com diminuição da fonação, audição, expressão facial e movimento auricular. Além disso, o animal 7 apresentou alteração na reação do nervo olfatório, óptico, 
troclear e abducente, pois demonstrou decréscimo na reação para substâncias voláteis, reflexo à ameaça, acompanhamentos de objetos e movimento ocular. O indivíduo 4 apresentou ausência dos estímulos na avaliação dos mesmos pares de nervos cranianos citados acima. $\mathrm{O}$ animal 7 ainda mostrou equilíbrio alterado e reflexo de tosse diminuídos, sugerindo alteração nas funções dos nervos vestíbulo-coclear e vago. Em relação ao teste das reações dos nervos espinhais, ainda no mesmo momento M6, todos os animais apresentaram normalidade em todos os reflexos avaliados. Os animais deste grupo apresentaram pontuação entre 16 e 18 na Escala de Glasgow, o que sugeriu no momento da avaliação, bom prognóstico neurológico.

Já em M7, na avaliação do grupo $\mathrm{A}$, em relação às reações posturais, somente o animal 10 permaneceu com diminuição da reação do "carrinho de mão", estando todos os outros animais com os reflexos normais. Todos os animais deste grupo apresentaram normalidade nas reações espinhais e somente os animais 2, 4, 7 e 8 apresentaram-se totalmente normais na avaliação dos pares de nervos cranianos. $\mathrm{O}$ animal 10 ainda apresentou diminuição dos reflexos de tosse, a substâncias voláteis, alimentação, deglutição e fonação. $\mathrm{O}$ animal 6 também apresentou movimento auricular, expressão facial, fonação e audição diminuídos como anteriormente em M6. A Escala de Glasgow para todos os animais também foi normal em M7 com pontuação situada entre 17 e 18, sugerindo bom prognóstico. Após uma semana do ato operatório, os cães encontravam-se normais para todos os testes neurológicos, sendo que os mesmos apresentaram 18 pontos na Escala de Glasgow, pontuação máxima, permanecendo da mesma maneira até os vinte dias que ficaram no canil em observação.

No tocante à análise neurológica do grupo B no momento M6, apenas os animais 5 e 9 apresentaram todos os testes relacionados às reações posturais normais. $\mathrm{O}$ animal 3 apresentou debilidade nos testes de "carrinho de mão" dos membros posteriores, "hemiestação", e "hemi-locomoção" bilaterais, além do teste de "reação do pulo" anterior e posterior bilaterais. Este animal apresentou ataxia em sua marcha neste momento. Já o animal 1 apresentou ausência de reação a todos os testes posturais, apresentando normalidade apenas na reação "tônica do pescoço". O animal não caminhava, apresentava espasticidade dos membros torácicos e pélvicos, paraparesia dos membros pélvicos e incoordenação de cabeça. A dor profunda estava diminuída neste animal.

Em relação aos testes de nervos cranianos, ainda após 24 horas de evolução, o animal 9 apresentou aumento de estímulo no reflexo de ameaça, apresentando-se com medo de maneira mais acentuada se comparado aos outros animais, indicando possível alteração dos nervos óptico e facial (II e VII pares de nervos cranianos, respectivamente). Este mesmo 
animal apresentou diminuição no reflexo de tosse e fonação, relacionada ao X par de nervos cranianos (vago). O animal 3 apresentou aumento de tamanho pupilar, ausência de acompanhamento de objetos, e reflexo pupilar direto e consensual diminuídos nos dois olhos, estando estas alterações relacionadas aos pares de nervos cranianos números II e III (óptico e oculo-motor). Seu equilíbrio, reflexo de tosse, e fonação, estavam diminuídos, indicando alteração dos pares de nervos VIII e X (vestíbulo-coclear e vago, respectivamente). O animal 5 apresentou diminuição da reação quando testada a ameaça, o acompanhamento de objetos, desvios de obstáculos, equilíbrio e fonação, o que sugere possíveis alterações dos nervos óptico, facial,vestíbulo-coclear e vago. O animal 1 apresentou alteração de todos os nervos cranianos, com diminuição de reação em todos eles, com exceção do tamanho pupilar e fonação que estavam aumentados. O animal gemia e apresentava a boca cerrada, pressionando os dentes superiores contra os inferiores.

Em relação às reações espinhais, também em M6, o animal 1 apresentou ausência de sensibilidade em todos os testes realizados, com exceção do reflexo patelar que estava aumentado, do reflexo perineal que estava normal, e dos reflexos tibial cranial e gastrocnêmio direitos que estavam diminuídos. Os cães 3, 5 e 9 apresentavam praticamente todos os reflexos espinhais normais, porém o de número 3 apresentou diminuição na reação biciptal e triciptal bilateral, o animal 5 apresentou diminuição dos reflexos tibial cranial e gastrocnêmio bilaterais, e o cão 9 apresentou aumento de sensibilidade no reflexo patelar. Apesar das alterações mostradas acima, os animais 3, 5 e 9 apresentaram bom prognóstico segundo a Escala de Glasgow em M6, apresentando escore entre 15 e 18. Apenas o animal 1, o qual apresentou pontuação 5 na mesma escala, obteve prognóstico grave neste momento.

Já no momento M7, com 48 horas de pós-operatório, todos os animais do grupo B, com exceção do animal 1, demonstraram melhora do quadro neurológico. Os animais 3, 5 e 9 apresentaram normalidade em todos os testes de reação postural e de reações espinhais. Entretanto, o animal 9 apresentou episódio de convulsão durante a avaliação, o que influenciou posteriormente na reavaliação imediata ao episódio, demonstrando aumento de alguns itens avaliados, como reação tônica do pescoço ventral, lateral e dorsal, e reflexos tibial cranial, extensor radial do carpo, extensor cruzado, e patelar. O mesmo cão $n^{\circ} 9$ apresentou após a convulsão um período hiperreflexibilidade e espasticidade dos membros, os quais foram diminuindo e normalizando posteriormente. $\mathrm{O}$ mesmo não apresentou qualquer outro episódio convulsivo após as 48 horas de pós-operatório até o final dos 20 dias de seguimento, comportando-se bem do ponto de vista clínico e neurológico. Já o animal 1, teve leve melhora, mas ainda apresentava diminuição em todos os testes de reação postural e em 
alguns de reações espinhais, como reflexo biciptal, triciptal, extensor radial do carpo e extensor cruzado direitos. Em relação à análise dos pares de nervos cranianos, em M7, o mesmo animal 1 apresentou melhora aos testes, porém ainda com diminuição de todos eles. Os animais 3 e 5 melhoraram os reflexos dos nervos óculo-motor e óptico, apresentando diminuição somente dos reflexos de tosse e fonação, e o animal 9 apresentou hiperreflexibilidade à ameaça, tamanho pupilar, tônus muscular e musculatura cervical, em conseqüência à convulsão que teve. Os animais 3,5 e 9 melhoraram a pontuação da Escala de Glasgow em M7, apresentando neste momento, 18 pontos cada, o que indicou bom prognóstico. O animal 1 melhorou pouco, e obteve 10 pontos na escala, indicando um prognóstico reservado a mau.

\subsection{AVALIAÇÃO HEMOGASOMÉTRICA}

A avaliação hemogasométrica consistiu da análise de $\mathrm{pH}$ arterial, $\mathrm{PaCO}_{2}, \mathrm{PaO}_{2}, \mathrm{PvO}_{2}, \mathrm{HCO}_{3}{ }^{-}$, $\mathrm{SaO}_{2}$ e $\mathrm{SvO}_{2}$.

\subsection{1 pH arterial}

Os valores de $\mathrm{pH}$ individuais, médias e desvios-padrão em relação aos momentos analisados, estão discriminados nas tabelas 13 e 14, para os grupos A e B, respectivamente. A comparação entre os grupos A e B pode ser visualizada nos gráficos 13 e 14 .

Dos seis animais do grupo A, todos apresentaram valores de $\mathrm{pH}$ menores em M6, quando comparados ao basal M0. Destes seis, três (cães 2, 6 e 10), mostraram valores em M7 menores que M0, sendo que o de $\mathrm{n}^{\circ} 2$ apresentou $\mathrm{pH}$ em M7 igual ao encontrado em M6, e os indivíduos 6 e 10 o apresentaram menor que em M6. Os outros três animais do mesmo grupo (números 4, 7 e 8) mostraram o pH em M7 maior que M6 e M0. Já no grupo B, foram observados dois óbitos transoperatórios (números 11 e 12), sendo avaliados somente os valores de quatro cães (animais 1, 3, 5 e 9). Os dois animais deste grupo (indivíduos 1 e 5) que apresentaram valores de $\mathrm{pH}$ menores no momento M6 em relação a M0, também os 
apresentaram assim em M7, sendo estes valores menores também em relação a M0. O cão 9 apresentou pH maior em M6 e M7 em comparação com M0, porém em M7 o valor foi inferior ao encontrado em M6, e o animal 3 mostrou em M6, valor inferior a M0, porém sendo M7 igual a M0. Em relação ao período transoperatório, constatou-se que todos animais do grupo A apresentaram valores de $\mathrm{pH}$ inferiores em M2 quando comparados a M1. Em M3 todos com exceção do cão $\mathrm{n}^{\circ} 2$, diminuíram ainda mais o $\mathrm{pH}$. Em M4, logo após o restabelecimento da circulação, o pH sobiu novamente, com exceção dos animais 2 e 6, que apresentaram valores mais baixos ao encontrado em M3. Já em M5, todos os cães apresentaram o pH maior em relação ao momento anterior. Já no grupo B foram avaliados somente quatro indivíduos, devido aos dois óbitos transoperatórios em M3. Em relação àqueles que foram avaliados, todos apresentaram em M2, $\mathrm{pH}$ inferior ao momento M1. Em M3, durante a parada circulatória total, os valores diminuem, exceto para o animal 1. Já em M4 o pH cai mais em relação ao M3, com exceção dos cães 3 e 9, os quais permaneceram com valores superiores aos encontrados no momento M3. Em M5 todos os indivíduos apresentaram o $\mathrm{pH}$ superior ao momento anterior M4. Na análise estatística realizada para comparação das médias entre os grupos A e B nos momentos pré e pós-operatórios, e transoperatórios, não foram encontradas diferenças significativas entre os dois grupos.

Tabela 13 - Valores individuais de $\mathrm{pH}$ arterial, médias e respectivos desvios-padrão dos animais do grupo A, submetidos a sete minutos de parada circulatória total - São Paulo - 2005

\begin{tabular}{l|c|c|c|c|c|c|c|c}
\hline & M0 & M1 & M2 & M3 & M4 & M5 & M6 & M7 \\
\hline Animal 02 & 7,42 & 7,40 & 7,29 & 7,32 & 7,20 & 7,41 & 7,35 & 7,35 \\
Animal 04 & 7,36 & 7,44 & 7,39 & 7,08 & 7,11 & 7,35 & 7,35 & 7,39 \\
Animal 06 & 7,41 & 7,46 & 7,40 & 7,27 & 7,22 & 7,33 & 7,37 & 7,34 \\
Animal 07 & 7,41 & 7,40 & 7,34 & 7,21 & 7,28 & 7,38 & 7,37 & 7,48 \\
Animal 08 & 7,42 & 7,40 & 7,39 & 7,18 & 7,26 & 7,35 & 7,41 & 7,44 \\
Animal 10 & 7,43 & 7,43 & 7,41 & 7,21 & 7,35 & 7,45 & 7,41 & 7,33 \\
\hline Média & 7,41 & 7,42 & 7,37 & 7,21 & 7,24 & 7,38 & 7,38 & 7,39 \\
\hline DP & 0,01 & 0,03 & 0,05 & 0,09 & 0,08 & 0,05 & 0,03 & 0,06 \\
\hline
\end{tabular}

M0 (30 minutos antes da medicação pré-anestésica); M1 (30 minutos após estabilização anestésica); M2 (imediatamente antes do "Inflow Occlusion"); M3 (decorridos 5 minutos do "Inflow Occlusion"); M4 (5 minutos após o término do "Inflow Occlusion"); M5 (30 minutos após o término do "Inflow Occlusion"); M6 (24 horas após o término da cirurgia); M7 (48 horas após o término da cirurgia)

DP - desvio padrão 
Tabela 14 - Valores individuais de $\mathrm{pH}$ arterial, médias e respectivos desvios-padrão dos animais do grupo B, submetidos a oito minutos de parada circulatória total - São Paulo - 2005

\begin{tabular}{l|c|c|c|c|c|c|c|c}
\hline & M0 & M1 & M2 & M3 & M4 & M5 & M6 & M7 \\
\hline Animal 01 & 7,44 & 7,37 & 7,33 & 7,34 & 7,12 & 7,29 & 7,43 & 7,40 \\
Animal 03 & 7,43 & 7,53 & 7,36 & 7,19 & 7,20 & 7,33 & 7,40 & 7,43 \\
Animal 05 & 7,42 & 7,39 & 7,33 & 7,27 & 7,16 & 7,44 & 7,41 & 7,40 \\
Animal 09 & 7,40 & 7,46 & 7,39 & 7,33 & 7,37 & 7,40 & 7,42 & 7,41 \\
Animal 11 & 7,44 & 7,44 & 7,45 & 7,27 & $\dagger$ & $\dagger$ & $\dagger$ & $\dagger$ \\
Animal 12 & 7,41 & 7,47 & 7,35 & 7,22 & $\dagger$ & $\dagger$ & $\dagger$ & $\dagger$ \\
\hline média & 7,42 & 7,44 & 7,37 & 7,27 & 7,21 & 7,36 & 7,41 & 7,41 \\
\hline DP & 0,02 & 0,06 & 0,05 & 0,06 & 0,11 & 0,07 & 0,01 & 0,02 \\
\hline
\end{tabular}

M0 (30 minutos antes da medicação pré-anestésica); M1 (30 minutos após estabilização anestésica); M2 (imediatamente antes do "Inflow Occlusion"); M3 (decorridos 5 minutos do "Inflow Occlusion"); M4 (5 minutos após o término do "Inflow Occlusion"); M5 (30 minutos após o término do "Inflow Occlusion"); M6 (24 horas após o término da cirurgia); M7 (48 horas após o término da cirurgia)

DP - desvio padrão

$\dagger$ - óbito

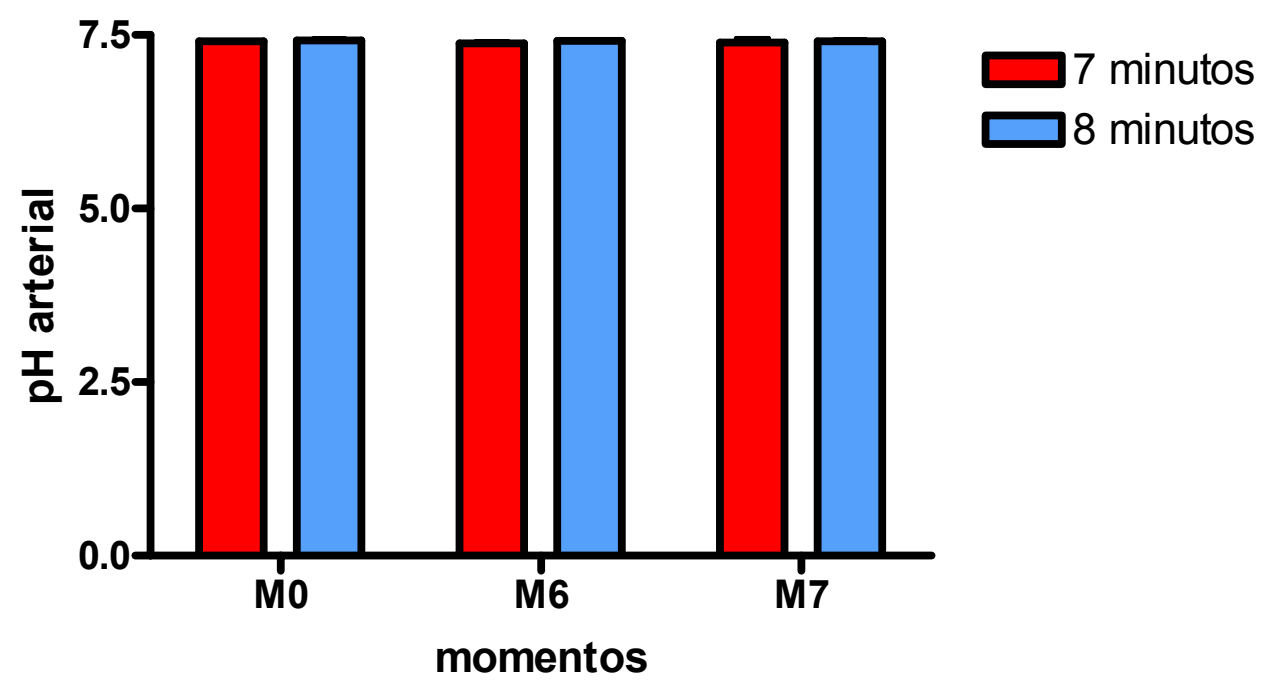

M0 (30 minutos antes da medicação pré-anestésica); M6 (24 horas após o término da cirurgia); M7 (48 horas após o término da cirurgia)

Gráfico 13 - Comparação entre as médias dos grupos A e B relativas ao pH arterial, de cães submetidos a sete e oito minutos de parada circulatória total, respectivamente, durante os momentos correspondentes aos períodos pré-operatório M0, e pós-operatórios M6 e M7 - São Paulo - 2005 


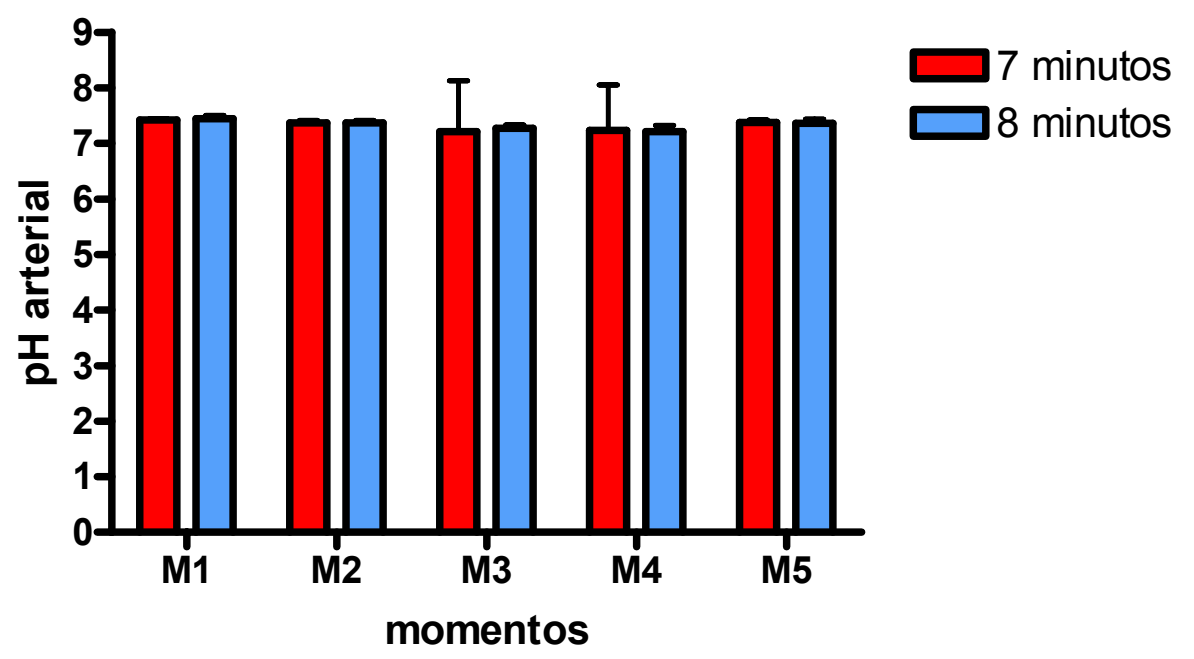

M1 (30 minutos após estabilização anestésica); M2 (imediatamente antes do "Inflow Occlusion"); M3 (decorridos 5 minutos do "Inflow Occlusion"); M4 (5 minutos após o término do "Inflow Occlusion"); M5 (30 minutos após o término do "Inflow Occlusion")

Gráfico 14 - Comparação entre as médias dos grupos A e B relativas ao pH arterial, de cães submetidos a sete e oito minutos de parada circulatória total, respectivamente, durante os momentos correspondentes ao período transoperatório M1 a M5 - São Paulo - 2005

\subsection{2 $\mathrm{PaCO}_{2}$}

Os valores de $\mathrm{PaCO}_{2}$ individuais, médias e desvios-padrão em relação aos momentos analisados, estão discriminados nas tabelas 15 e 16, para os grupos A e B, respectivamente. A comparação entre as médias dos dois grupos pode ser visualizada nos gráficos 15 e 16 .

Dos seis animais do grupo A, dois cães apresentaram valores em M6 iguais a M0 (números 8 e 10), porém em M7 mostraram-se menores que M6 e M0. Outros dois (números 6 e 7), apresentaram valores em M6 maiores que em M0, e em M7 também constatou-se que eram maiores que M0, sendo um deles $\left(n^{\circ} 7\right)$ menor que M6. Outros dois cães do mesmo grupo (animais 2 e 4) apresentaram valores menores em M6 quando comparados a M0, entretando, em um deles $\left(n^{\circ} 4\right)$ foi observado aumento da $\mathrm{PaCO}_{2}$ em M7, o qual era maior que M6 e M0, e o outro ( $\left.n^{\circ} 2\right)$ mostrou valor de M7 igual a M0. Já no grupo B, foram avaliados somente quatro animais (números 1, 3, 5 e 9). Destes, três (números 1, 3 e 9) apresentaram valores em M6 maiores que em M0. Destes três, dois (animais 1 e 9) mostraram valores de M7 maiores que M0 também, porém um deles era menor que M6 (animal 9). O outro (cão 3) apresentou valor em M7 menor que M6 e M0. O animal 5, o qual apresentou valor de $\mathrm{PaCO}_{2}$ 
menor em M6 quando comparado a M0, mostrou em M7 valor maior que M6 e M0. No que diz respeito aos momentos do período transoperatório, seis animais do grupo A (cães 2, 4, 6 e 7) aumentaram os valores de $\mathrm{PaCO}_{2}$ em M2, em relação a $\mathrm{M} 1$, enquanto os indivíduos 8 e 10 mostraram valores inferiores relativos aos mesmos momentos. Durante o período de parada circulatória total em $\mathrm{M} 3$, quatro animais (números 4, 7, 8 e 10) apresentaram $\mathrm{PaCO}_{2}$ maiores que o momento anterior, mas três deles (cães 7, 8 e 10) diminuíram seu valor em M4 e M5, sendo M5 inclusive menor que M3. O animal 4 aumentou a $\mathrm{PaCO}_{2}$ em M4, mas em M5 ainda era menor que M3. Em três animais (números 2, 4 e 6) foram observados valores em M4 maiores que em M3, porém, em M5, estes apresentaram os valores mais baixos em comparação com o momento anterior. Todos animais em M5 mostraram a $\mathrm{PaCO}_{2}$ mais baixa se comparada a M4. Já no grupo B, dos quatro animais avaliados (cães 1, 3, 5 e 9), todos apresentaram valores de $\mathrm{PaCO}_{2}$ maiores em M2 quando comparados a M1. Os indivíduos $1 \mathrm{e}$ 9 apresentaram em M3 valores menores que M2 e M1, e para os cães 3 e 5 constatou-se valores maiores em M3 comparados aos momentos M2 e M1. Logo após a parada circulatória total, o que ocorreu em M4 foi aumento da $\mathrm{PaCO}_{2}$ de três animais (números 1, 5 e 9) em relação a M3, e diminuição da mesma referente ao animal 3 no mesmo momento. Em M5, todos os cães apresentaram valores menores quando comparados a M4 e M2. A análise estatística comparando as médias dos grupos A e B, referente aos momentos transoperatórios, e pré e pós-operatórios não revelou diferença significativa entre os mesmos.

Tabela 15 - Valores individuais de pressão parcial de dióxido de carbono no sangue arterial $\left(\mathrm{PaCO}_{2}\right) \mathrm{em} \mathrm{mmHg}$, médias e respectivos desvios-padrão dos animais do grupo A, submetidos a sete minutos de parada circulatória total - São Paulo - 2005

\begin{tabular}{l|c|c|c|c|c|c|c|c}
\hline & M0 & M1 & M2 & M3 & M4 & M5 & M6 & M7 \\
\hline Animal 02 & 34 & 36 & 51 & 45 & 49 & 30 & 30 & 34 \\
Animal 04 & 31 & 26 & 30 & 40 & 42 & 25 & 30 & 34 \\
Animal 06 & 25 & 24 & 33 & 28 & 41 & 33 & 37 & 42 \\
Animal 07 & 30 & 30 & 33 & 36 & 31 & 27 & 35 & 32 \\
Animal 08 & 30 & 31 & 30 & 47 & 35 & 29 & 30 & 24 \\
Animal 10 & 28 & 29 & 27 & 39 & 27 & 22 & 28 & 23 \\
\hline média & 29,67 & 29,33 & 34,00 & 39,17 & 37,50 & 27,67 & 31,67 & 31,50 \\
\hline DP & 2,36 & 4,18 & 8,63 & 6,79 & 8,04 & 3,88 & 3,50 & 7,09 \\
\hline
\end{tabular}

M0 (30 minutos antes da medicação pré-anestésica); M1 (30 minutos após estabilização anestésica); M2 (imediatamente antes do "Inflow Occlusion"); M3 (decorridos 5 minutos do "Inflow Occlusion"); M4 (5 minutos após o término do "Inflow Occlusion"); M5 (30 minutos após o término do "Inflow Occlusion"); M6 (24 horas após o término da cirurgia); M7 (48 horas após o término da cirurgia) DP - desvio padrão 
Tabela 16 - Valores individuais de pressão parcial de dióxido de carbono no sangue arterial $\left(\mathrm{PaCO}_{2}\right) \mathrm{em} \mathrm{mmHg}$, médias e respectivos desvios-padrão dos animais do grupo $\mathrm{B}$, submetidos a oito minutos de parada circulatória total - São Paulo - 2005

\begin{tabular}{l|c|c|c|c|c|c|c|c}
\hline & M0 & M1 & M2 & M3 & M4 & M5 & M6 & M7 \\
\hline Animal 01 & 30 & 30 & 38 & 28 & 43 & 37 & 32 & 35 \\
Animal 03 & 29 & 23 & 37 & 50 & 39 & 34 & 31 & 28 \\
Animal 05 & 37 & 36 & 40 & 51 & 56 & 22 & 34 & 38 \\
Animal 09 & 31 & 33 & 36 & 27 & 33 & 28 & 37 & 34 \\
Animal 11 & 31 & 31 & 29 & 41 & $\dagger$ & $\dagger$ & $\dagger$ & $\dagger$ \\
Animal 12 & 30 & 27 & 36 & 46 & $\dagger$ & $\dagger$ & $\dagger$ & $\dagger$ \\
\hline média & 31,33 & 30,00 & 36,00 & 40,33 & 42,75 & 30,25 & 33,50 & 33,75 \\
\hline DP & 3,20 & 4,56 & 3,74 & 10,67 & 9,74 & 6,65 & 2,65 & 5,13 \\
\hline
\end{tabular}

M0 (30 minutos antes da medicação pré-anestésica); M1 (30 minutos após estabilização anestésica); M2 (imediatamente antes do "Inflow Occlusion"); M3 (decorridos 5 minutos do "Inflow Occlusion"); M4 (5 minutos após o término do "Inflow Occlusion"); M5 (30 minutos após o término do "Inflow Occlusion"); M6 (24 horas após o término da cirurgia); M7 (48 horas após o término da cirurgia)

DP - desvio padrão

$\dagger$ - óbito

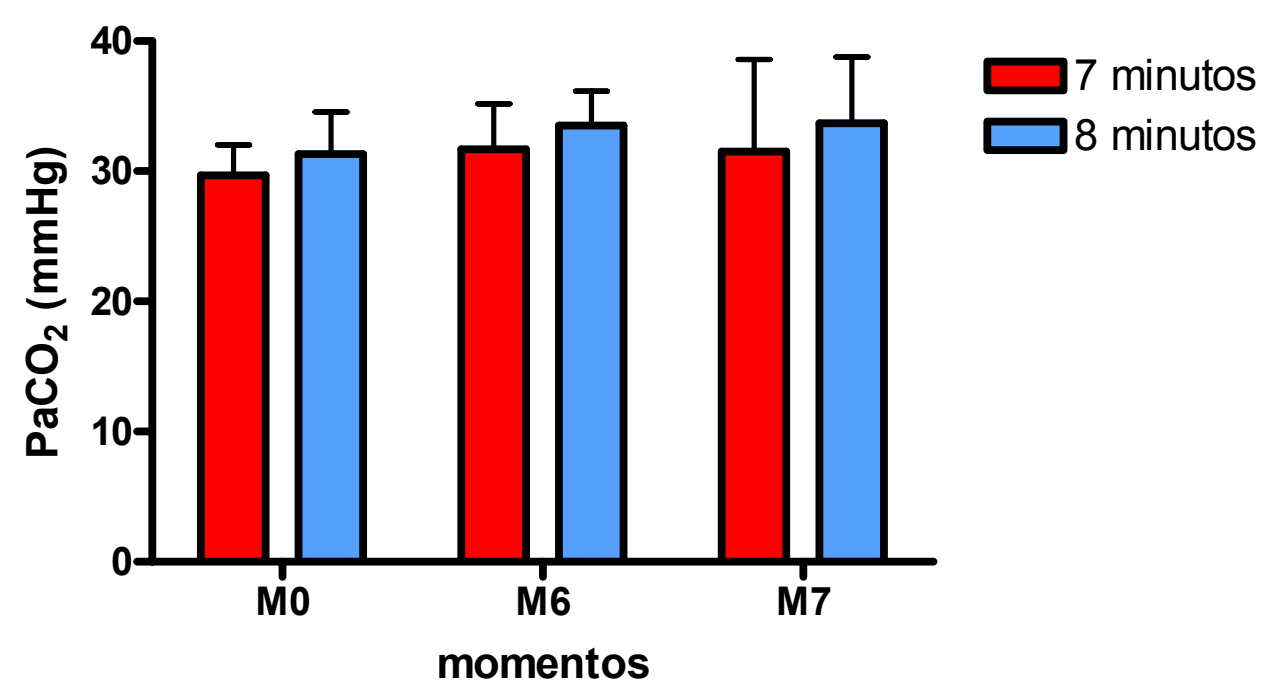

M0 (30 minutos antes da medicação pré-anestésica); M6 (24 horas após o término da cirurgia); M7 (48 horas após o término da cirurgia)

Gráfico 15 - Comparação entre as médias dos grupos $\mathrm{A}$ e $\mathrm{B}$ relativas à pressão parcial de dióxido de carbono no sangue arterial $\left(\mathrm{PaCO}_{2}\right)$, de cães submetidos a sete e oito minutos de parada circulatória total, respectivamente, durante os momentos correspondentes aos períodos pré e pós-operatórios - São Paulo - 2005 


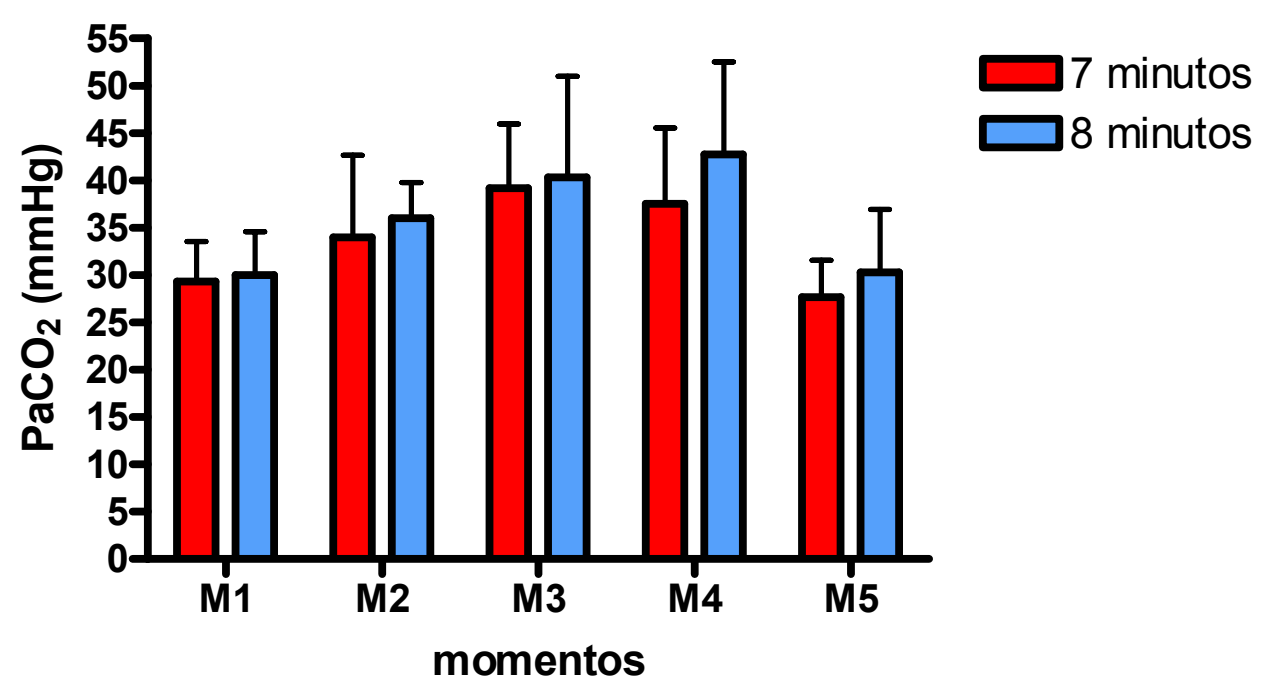

M1 (30 minutos após estabilização anestésica); M2 (imediatamente antes do "Inflow Occlusion"); M3 (decorridos 5 minutos do "Inflow Occlusion"); M4 (5 minutos após o término do "Inflow Occlusion”); M5 (30 minutos após o término do "Inflow Occlusion")

Gráfico 16 - Comparação entre as médias dos grupos $\mathrm{A}$ e $\mathrm{B}$ relativas à pressão parcial de dióxido de carbono no sangue arterial $\left(\mathrm{PaCO}_{2}\right)$, de cães submetidos a sete e oito minutos de parada circulatória total, respectivamente, durante os momentos correspondentes ao período transoperatório - São Paulo 2005

\subsection{3 $\mathrm{PaO}_{2}$}

Os valores de $\mathrm{PaO}_{2}$ individuais, médias e desvios-padrão em relação aos momentos analisados, estão discriminados nas tabelas 17 e 18 para os grupos A e B, respectivamente. A comparação entre as médias dos dois grupos pode ser visualizada nos gráficos 17 e 18 .

Dos seis animais do grupo A, quatro (números 2, 4, 6 e 10) apresentaram valores de $\mathrm{PaO}_{2}$ em M6 menores que M0. Destes quatro, três (cães 2, 6 e 10) mostraram aumento em M7 quando comparados ao M6, porém os valores foram inferiores a M0 somente para os animais 6 e 10. O cão $n^{\circ} 2$ apresentou valor em M7 igual a M0. Foi constatado em dois animais do mesmo grupo (números 7 e 8), valores em M6 maiores que M0, porém um deles (cão $\mathrm{n}^{\circ} 7$ ) diminuiu em M7 comparando-se a M0, enquanto o animal 8 diminuiu a $\mathrm{PaO}_{2}$ em relação a M6, porém apresentou valor maior que M0. Já no grupo B, foram avaliados somente os valores de quatro animais, em decorrência dos dois óbitos. Dois dos animais (números 3 e 5) apresentaram valores em M6 e M7 menores que M0, sendo que o de $n^{\circ} 5$ mostrou em M7, valor menor que M6, e o de $\mathrm{n}^{\circ} 3$ valor maior que M6. Os outros dois animais do grupo (cães 1 e 9) apresentaram valores em M6 maiores que M0. Destes dois, o de $n^{\circ} 9$ apresentou valor 
em M7 maior que M0, porém menor que M6, e o de $\mathrm{n}^{\circ} 1$ mostrou valor em M7 menor que M6 e M7. No período transoperatório, o que se observou no grupo A, foi queda da $\mathrm{PaO}_{2}$ de todos os animais em M2, quando comparado a M1, com exceção do espécime de $n^{\circ} 4$. Esta queda é observada novamente em M3, quando todos os animais apresentaram valores muito baixos em relação a M1 e M2. Em seguida, os valores aumentaram em M4, logo após a parada circulatória, quando foram observados valores maiores que em M3, porém ainda menores que no momento M2, antes da parada circulatória. Em M5, averiguou-se em três animais (números 2, 4 e 7), valores maiores que M4, e em outros três indivíduos (6, 8 e 10), os valores observados foram menores em relação ao mesmo momento. Em M5 todos os animais apresentaram valores de $\mathrm{PaO}_{2}$ menores que $\mathrm{M} 1$. Porém dois dos seis animais (números 2 e 7) mostraram valores mais altos em M5 quando comparados a M2. Já no grupo $\mathrm{B}$, como ocorreu no grupo $\mathrm{A}$, observamos coincidência de comportamento da $\mathrm{PaO}_{2}$. Em M2 há queda dos valores da mesma em relação a M1, com exceção do animal 1, porém em M3 todos apresentaram valores menores que M1 e M2. Como houve duas mortes intraoperatórias, ambas em M3, sobraram apenas quatro animais. Destes, todos apresentaram valores em M4 maiores que M3 e menores que M1, porém dois animais (números 1 e 5) ainda mostraram valores menores que M2. Em M5, três dos quatro animais (cães 1, 3 e 5) mostraram valores maiores que os encontrados em M4, entretanto três deles (animais 1, 5 e 9) apresentaram valores inferiores a M2. Todos os indivíduos em M5 mostraram valores de $\mathrm{PaO}_{2}$ menores que M1. A análise estatística comparando as médias dos grupos A e B, tanto no que se refere aos momentos transoperatórios, pré e pós-operatório não revelou diferença significativa entre os grupos.

Tabela 17 - Valores individuais de pressão parcial de oxigênio no sangue arterial $\left(\mathrm{PaO}_{2}\right)$ em mmHg, médias e respectivos desvios-padrão dos animais do grupo A, submetidos a sete minutos de parada circulatória total - São Paulo - 2005

\begin{tabular}{l|c|c|c|c|c|c|c|c}
\hline & M0 & M1 & M2 & M3 & M4 & M5 & M6 & M7 \\
\hline Animal 02 & 90 & 338 & 308 & 54 & 242 & 222 & 86 & 90 \\
Animal 04 & 134 & 428 & 434 & 43 & 250 & 322 & 113 & 78 \\
Animal 06 & 89 & 267 & 213 & 38 & 161 & 102 & 81 & 86 \\
Animal 07 & 92 & 299 & 130 & 49 & 128 & 175 & 95 & 66 \\
Animal 08 & 82 & 493 & 398 & 32 & 396 & 375 & 98 & 90 \\
Animal 10 & 106 & 463 & 365 & 43 & 275 & 219 & 90 & 95 \\
\hline média & 98,83 & 381,33 & 308,00 & 43,20 & 242,00 & 235,83 & 93,83 & 84,17 \\
\hline DP & 10,08 & 92,78 & 116,56 & 8,70 & 94,26 & 98,87 & 11,19 & 10,55 \\
\hline
\end{tabular}

M0 (30 minutos antes da medicação pré-anestésica); M1 (30 minutos após estabilização anestésica); M2 (imediatamente antes do "Inflow Occlusion"); M3 (decorridos 5 minutos do "Inflow Occlusion"); M4 (5 minutos após o término do "Inflow Occlusion"); M5 (30 minutos após o término do "Inflow Occlusion"); M6 (24 horas após o término da cirurgia); M7 (48 horas após o término da cirurgia)

DP - desvio padrão 
Tabela 18 - Valores individuais de pressão parcial de oxigênio no sangue arterial $\left(\mathrm{PaO}_{2}\right)$ em mmHg, médias e respectivos desvios-padrão dos animais do grupo $\mathrm{B}$, submetidos a oito minutos de parada circulatória total - São Paulo - 2005

\begin{tabular}{l|c|c|c|c|c|c|c|c}
\hline & M0 & M1 & M2 & M3 & M4 & M5 & M6 & M7 \\
\hline Animal 01 & 109 & 209 & 221 & 55 & 169 & 186 & 120 & 86 \\
Animal 03 & 97 & 443 & 165 & 32 & 200 & 371 & 79 & 93 \\
Animal 05 & 148 & 372 & 248 & 17 & 191 & 240 & 82 & 71 \\
Animal 09 & 79 & 458 & 297 & 53 & 336 & 288 & 86 & 83 \\
Animal 11 & 99 & 374 & 247 & 37 & $\dagger$ & $\dagger$ & $\dagger$ & $\dagger$ \\
Animal 12 & 89 & 390 & 289 & 27 & $\dagger$ & $\dagger$ & $\dagger$ & $\dagger$ \\
\hline média & 103,50 & 374,33 & 244,50 & 36,67 & 224,00 & 271,25 & 91,75 & 83,25 \\
\hline DP & 30,61 & 88,66 & 48,22 & 14,87 & 75,79 & 78,47 & 19,05 & 11,24 \\
\hline
\end{tabular}

M0 (30 minutos antes da medicação pré-anestésica); M1 (30 minutos após estabilização anestésica); M2 (imediatamente antes do "Inflow Occlusion"); M3 (decorridos 5 minutos do "Inflow Occlusion"); M4 (5 minutos após o término do "Inflow Occlusion"); M5 (30 minutos após o término do "Inflow Occlusion"); M6 (24 horas após o término da cirurgia); M7 (48 horas após o término da cirurgia)

DP - desvio padrão

$\dagger$ - óbito

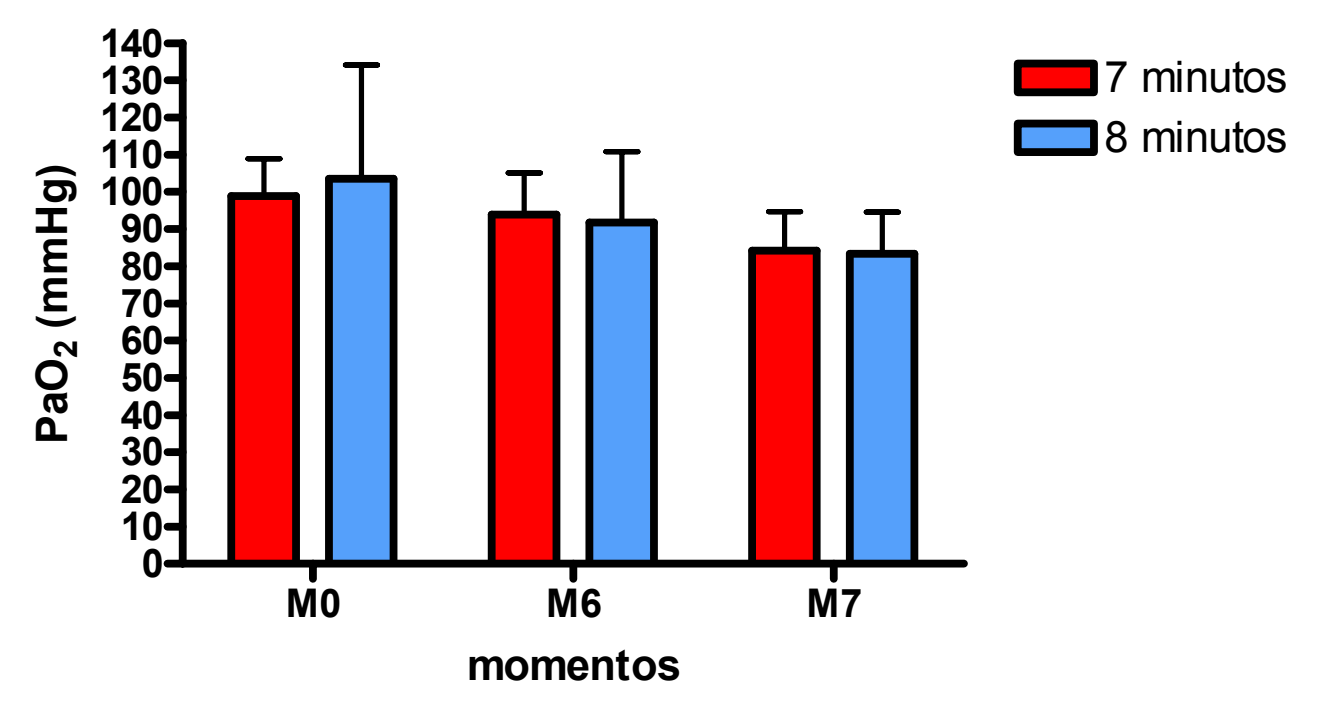

M0 (30 minutos antes da medicação pré-anestésica); M6 (24 horas após o término da cirurgia); M7 (48 horas após o término da cirurgia)

Gráfico 17 - Comparação entre as médias dos grupos A e B relativas à pressão parcial de oxigênio no sangue arterial $\left(\mathrm{PaO}_{2}\right)$, de cães submetidos a sete e oito minutos de parada circulatória total, respectivamente, durante os momentos correspondentes aos períodos pré-operatório M0, e pósoperatórios M6 e M7 - São Paulo - 2005 


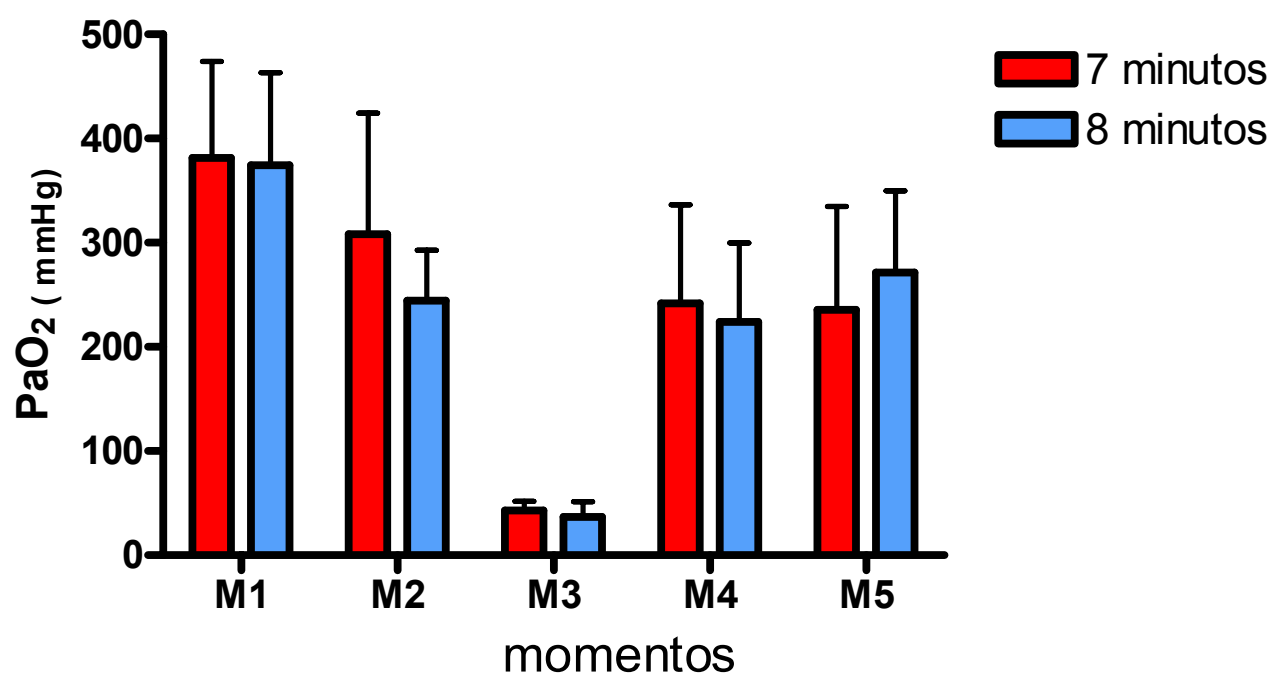

M1 (30 minutos após estabilização anestésica); M2 (imediatamente antes do "Inflow Occlusion"); M3 (decorridos 5 minutos do "Inflow Occlusion"); M4 (5 minutos após o término do "Inflow Occlusion"); M5 (30 minutos após o término do "Inflow Occlusion")

Gráfico 18 - Comparação entre as médias dos grupos A e B relativas à pressão parcial de oxigênio no sangue arterial $\left(\mathrm{PaO}_{2}\right)$, de cães submetidos a sete e oito minutos de parada circulatória total, respectivamente, durante os momentos correspondentes ao período transoperatório M1 a M5 - São Paulo - 2005

\subsection{4 $\mathrm{PvO}_{2}$}

Os valores de $\mathrm{PvO}_{2}$ individuais, médias e desvios-padrão em relação aos momentos analisados, estão discriminados nas tabelas 19 e 20, para os grupos A e B, respectivamente. A comparação entre as médias dos dois grupos pode ser visualizada nos gráficos 19 e 20 .

Dois dos seis animais do grupo $\mathrm{A}$ (números 8 e 10) apresentaram valores de $\mathrm{PvO}_{2}$ aumentados no momento M6 em relação a M0. No cão de $\mathrm{n}^{\circ} 8$, constatou-se valor da $\mathrm{PvO}_{2}$ diminuído em M7, equiparando-se a M0, e no de $\mathrm{n}^{\circ} 10$, o valor aumentou pouco em M7. Os outros quatro animais deste grupo (indivíduos 2, 4, 6 e 7) apresentaram os valores em M6 menores que M0, sendo que apenas um deles $\left(\mathrm{n}^{\circ} 2\right)$ mostrou aumento no momento M7 em relação a M0. No grupo $\mathrm{B}$, os animais 1 e 5 apresentaram valores de $\mathrm{PvO}_{2}$ menores em M6 quando comparados a M0, e valores em M7 menores se comparados a M6. Nos outros dois animais deste grupo (números 3 e 9) houve aumento dos valores de $\mathrm{PvO}_{2}$ em $\mathrm{M} 6$, porém o animal 3 apresentou diminuição em M7 em relação a M0, e o animal 9 mostrou valor semelhante ao encontrado em M0. Em relação ao momento transoperatório M1 a M5, o que se observou foi diminuição dos valores de $\mathrm{PvO}_{2}$ de todos os animais de ambos os grupos em M3, 
com retomada do aumento dos valores logo após restabelecimento da circulação, em M4. Já em M5, todos os valores diminuem em relação a M4. A análise estatística comparando as médias dos grupos A e B, tanto no que se refere aos momentos transoperatórios, pré e pósoperatórios não revelou diferença significativa entre os grupos.

Tabela 19 - Valores individuais de pressão parcial de oxigênio no sangue venoso $\left(\mathrm{PvO}_{2}\right) \mathrm{em} \mathrm{mmHg}$, médias e respectivos desvios-padrão dos animais do grupo A, submetidos a sete minutos de parada circulatória total - São Paulo - 2005

\begin{tabular}{l|c|c|c|c|c|c|c|c}
\hline & M0 & M1 & M2 & M3 & M4 & M5 & M6 & M7 \\
\hline Animal 02 & 42 & 52 & 46 & 29 & 60 & 45 & 31 & 74 \\
Animal 04 & 55 & 52 & 49 & 34 & 73 & 69 & 42 & 42 \\
Animal 06 & 67 & 52 & 53 & 13 & 71 & 52 & 51 & 57 \\
Animal 07 & 63 & 60 & 55 & 37 & 66 & 52 & 61 & 43 \\
Animal 08 & 47 & 54 & 62 & 21 & 66 & 72 & 51 & 47 \\
Animal 10 & 45 & 54 & 49 & 41 & 61 & 49 & 54 & 59 \\
\hline média & 53,17 & 54,00 & 52,33 & 29,20 & 66,17 & 56,50 & 48,33 & 53,67 \\
\hline DP & 11,12 & 3,10 & 5,72 & 11,76 & 5,19 & 11,18 & 10,46 & 12,23 \\
\hline
\end{tabular}

M0 (30 minutos antes da medicação pré-anestésica); M1 (30 minutos após estabilização anestésica); M2 (imediatamente antes do "Inflow Occlusion"); M3 (decorridos 5 minutos do "Inflow Occlusion"); M4 (5 minutos após o término do "Inflow Occlusion"); M5 (30 minutos após o término do "Inflow Occlusion"); M6 (24 horas após o término da cirurgia); M7 (48 horas após o término da cirurgia)

DP - desvio padrão

Tabela 20 - Valores individuais de pressão parcial de oxigênio no sangue venoso $\left(\mathrm{PvO}_{2}\right)$ em mmHg, médias e respectivos desvios-padrão dos animais do grupo $\mathrm{B}$, submetidos a oito minutos de parada circulatória total - São Paulo - 2005

\begin{tabular}{l|c|c|c|c|c|c|c|c}
\hline & M0 & M1 & M2 & M3 & M4 & M5 & M6 & M7 \\
\hline Animal 01 & 81 & 57 & 58 & 28 & 75 & 64 & 79 & 56 \\
Animal 03 & 43 & 52 & 50 & 20 & 75 & 50 & 55 & 35 \\
Animal 05 & 65 & 71 & 66 & 10 & 79 & 58 & 64 & 59 \\
Animal 09 & 50 & 56 & 54 & 23 & 71 & 57 & 54 & 50 \\
Animal 11 & 61 & 61 & 52 & 21 & $\dagger$ & $\dagger$ & $\dagger$ & $\dagger$ \\
Animal 12 & 46 & 47 & 70 & 23 & $\dagger$ & $\dagger$ & $\dagger$ & $\dagger$ \\
\hline média & 57,67 & 57,33 & 58,33 & 20,83 & 75,00 & 57,25 & 63,00 & 50,00 \\
\hline DP & 8,96 & 8,21 & 8,04 & 5,98 & 3,27 & 5,74 & 11,58 & 10,68 \\
\hline
\end{tabular}

M0 (30 minutos antes da medicação pré-anestésica); M1 (30 minutos após estabilização anestésica); M2 (imediatamente antes do "Inflow Occlusion"); M3 (decorridos 5 minutos do "Inflow Occlusion"); M4 (5 minutos após o término do "Inflow Occlusion”); M5 (30 minutos após o término do "Inflow Occlusion"); M6 (24 horas após o término da cirurgia); M7 (48 horas após o término da cirurgia)

DP - desvio padrão

$\uparrow$ - óbito 


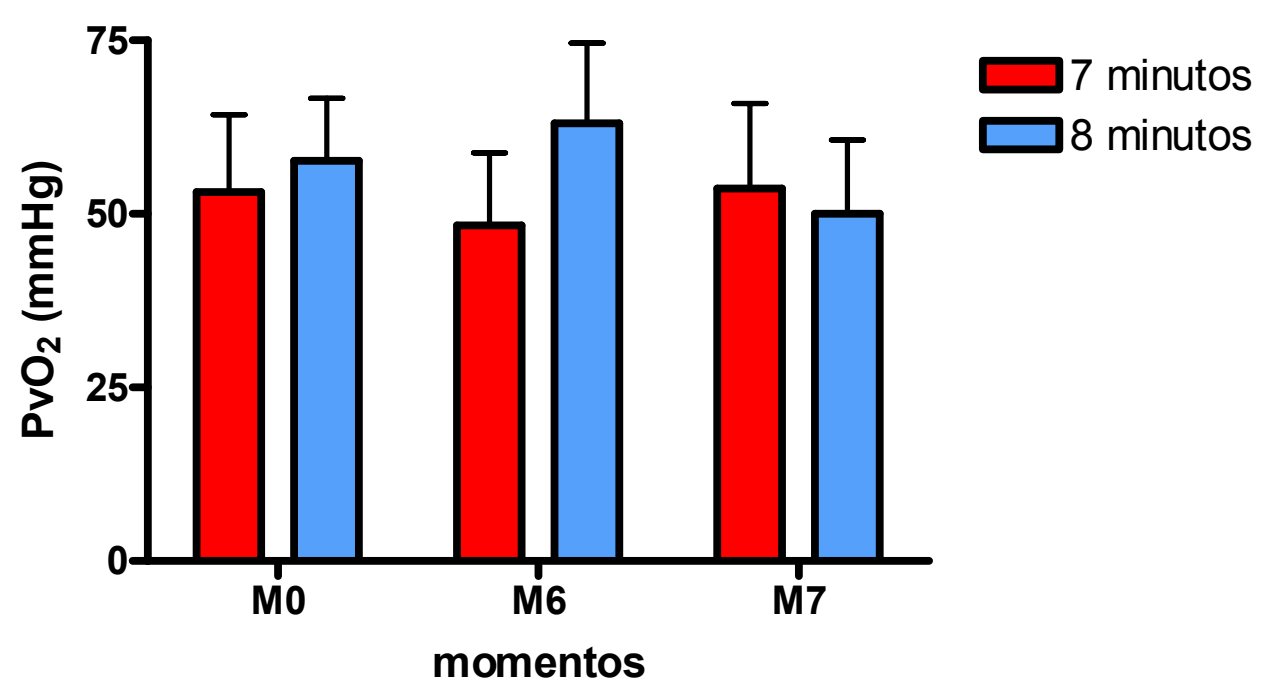

M0 (30 minutos antes da medicação pré-anestésica); M6 (24 horas após o término da cirurgia); M7 (48 horas após o término da cirurgia)

Gráfico 19 - Comparação entre as médias dos grupos A e B relativas à pressão parcial de oxigênio no sangue venoso $\left(\mathrm{PvO}_{2}\right)$, de cães submetidos a sete e oito minutos de parada circulatória total, respectivamente, durante os momentos correspondentes aos períodos pré-operatório M0, e pósoperatórios M6 e M7 - São Paulo - 2005

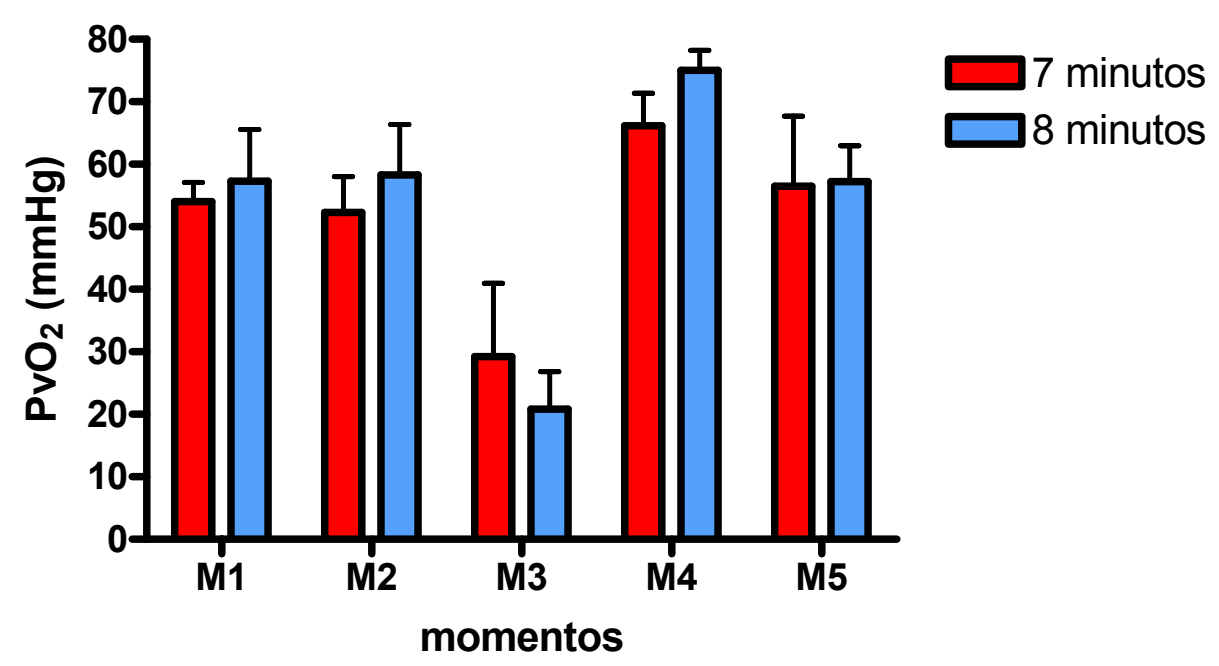

M1 (30 minutos após estabilização anestésica); M2 (imediatamente antes do "Inflow Occlusion"); M3 (decorridos 5 minutos do "Inflow Occlusion"); M4 (5 minutos após o término do "Inflow Occlusion"); M5 (30 minutos após o término do "Inflow Occlusion")

Gráfico 20 - Comparação entre as médias dos grupos A e B relativas à pressão parcial de oxigênio no sangue venoso $\left(\mathrm{PvO}_{2}\right)$, de cães submetidos a sete e oito minutos de parada circulatória total, respectivamente, durante os momentos correspondentes ao período transoperatório M1 a M5 - São Paulo - 2005 


\subsection{5 $\mathrm{HCO}_{3}{ }^{-}$arterial}

Os valores de $\mathrm{HCO}_{3}{ }^{-}$individuais, médias e desvios-padrão em relação aos momentos analisados, estão discriminados nas tabelas 21 e 22, para os grupos A e B, respectivamente. Já a comparação entre as médias dos dois grupos, A e B, são visualizadas nos gráficos 21 e 22 .

Dois animais do grupo A (números 6 e 7), nos quais averiguou-se aumento dos valores de $\mathrm{HCO}_{3}{ }^{-}$em $\mathrm{M} 6$ em relação ao basal $\mathrm{M} 0$, mantiveram os mesmos valores aumentados em M7. Quatro animais do mesmo grupo (cães 2, 4, 8 e 10) apresentaram valores em M6 menores que M0, porém para os indivíduos 8 e 10 os valores em M7 foram menores que em M6. O animal 2 apresentou aumento em relação ao encontrado em M6, porém este sendo menor que M0, e o cão $\mathrm{n}^{\circ} 4$ apresentou valor maior que M6 e M0. Já no grupo B, foram avaliados resultados de quatro animais. Um animal (cão 9) apresentou o $\mathrm{HCO}_{3}{ }^{-}$maior em $\mathrm{M} 6$ e $\mathrm{M} 7$ em relação a M0, e o mostrou em M7 valor menor que M6. O animal 1 obteve o mesmo valor em M0, M6 e M7. O cão de $n^{\circ} 5$ apresentou valor em M6 menor que M0, mas em seguida igualase ao basal em M7; e em outro animal ( $n^{\circ} 3$ ) constatou-se valor igual ao basal em M6, o qual diminuiu em M7. No período transoperatório, o que ocorreu de modo geral, tanto no grupo A quanto no grupo $\mathrm{B}$, é queda do $\mathrm{HCO}_{3}{ }^{-}$ao longo dos períodos analisados, principalmente nos momentos M3 e M4. Apesar dos valores de alguns animais do grupo A (cães 2, 4, 6, 7) e de dois do grupo B (cães 1 e 3) estarem aumentados em M5 quando comparados a M4, todos os cães apresentaram valores de $\mathrm{HCO}_{3}{ }^{-}$menores àqueles obtidos no período anterior à parada circulatória total M2. Dois animais do grupo B (indivíduos 5 e 9) apresentaram valores em M5 menores que M4, porém o animal 5 foi o único dos dois grupos que mostrou aumento do $\mathrm{HCO}_{3}{ }^{-}$em $\mathrm{M} 3$, com queda progressiva até M5. Não houve diferenças significativas na comparação das médias dos grupos A e B nos momentos analisados. 
Tabela 21 - Valores individuais de bicarbonato plasmático $\left(\mathrm{HCO}_{3}{ }^{-}\right) \mathrm{em} \mathrm{mEq} / \mathrm{L}$, médias e respectivos desviospadrão dos animais do grupo A, submetidos a sete minutos de parada circulatória total - São Paulo 2005

\begin{tabular}{l|c|c|c|c|c|c|c|c}
\hline & M0 & M1 & M2 & M3 & M4 & M5 & M6 & M7 \\
\hline Animal 02 & 21 & 22 & 24 & 23 & 19 & 20 & 16 & 18 \\
Animal 04 & 17 & 18 & 18 & 12 & 13 & 14 & 16 & 19 \\
Animal 06 & 15 & 17 & 20 & 12 & 16 & 18 & 20 & 21 \\
Animal 07 & 18 & 18 & 17 & 14 & 14 & 16 & 20 & 23 \\
Animal 08 & 19 & 19 & 18 & 17 & 16 & 16 & 18 & 16 \\
Animal 10 & 18 & 19 & 17 & 16 & 15 & 15 & 17 & 12 \\
\hline média & 18,00 & 18,83 & 19,00 & 15,67 & 15,50 & 16,50 & 17,83 & 18,17 \\
\hline DP & 1,73 & 1,72 & 2,68 & 4,13 & 2,07 & 2,17 & 1,83 & 3,87 \\
\hline
\end{tabular}

M0 (30 minutos antes da medicação pré-anestésica); M1 (30 minutos após estabilização anestésica); M2 (imediatamente antes do "Inflow Occlusion"); M3 (decorridos 5 minutos do "Inflow Occlusion"); M4 (5 minutos após o término do "Inflow Occlusion”); M5 (30 minutos após o término do "Inflow Occlusion"); M6 (24 horas após o término da cirurgia); M7 (48 horas após o término da cirurgia)

DP - desvio padrão

Tabela 22 - Valores individuais de bicarbonato plasmático $\left(\mathrm{HCO}_{3}^{-}\right)$em $\mathrm{mEq} / \mathrm{L}$, médias e respectivos desviospadrão dos animais do grupo $\mathrm{B}$, submetidos a oito minutos de parada circulatória total - São Paulo 2005

\begin{tabular}{l|c|c|c|c|c|c|c|c}
\hline & M0 & M1 & M2 & M3 & M4 & M5 & M6 & M7 \\
\hline Animal 01 & 22 & 19 & 20 & 17 & 13 & 18 & 22 & 22 \\
Animal 03 & 19 & 19 & 20 & 18 & 15 & 17 & 19 & 18 \\
Animal 05 & 23 & 22 & 21 & 23 & 19 & 15 & 21 & 23 \\
Animal 09 & 19 & 23 & 22 & 14 & 19 & 18 & 23 & 20 \\
Animal 11 & 20 & 20 & 20 & 18 & $\dagger$ & $\dagger$ & $\dagger$ & $\dagger$ \\
Animal 12 & 19 & 20 & 20 & 19 & $\dagger$ & $\dagger$ & $\dagger$ & $\dagger$ \\
\hline média & 20,33 & 20,50 & 20,50 & 18,17 & 16,50 & 17,00 & 21,25 & 20,75 \\
\hline DP & 1,89 & 1,64 & 8,84 & 2,93 & 3,00 & 1,41 & 1,71 & 2,22 \\
\hline
\end{tabular}

M0 (30 minutos antes da medicação pré-anestésica); M1 (30 minutos após estabilização anestésica); M2 (imediatamente antes do "Inflow Occlusion"); M3 (decorridos 5 minutos do "Inflow Occlusion"); M4 (5 minutos após o término do "Inflow Occlusion"); M5 (30 minutos após o término do "Inflow Occlusion"); M6 (24 horas após o término da cirurgia); M7 (48 horas após o término da cirurgia)

DP - desvio padrão

$\uparrow$ - óbito 


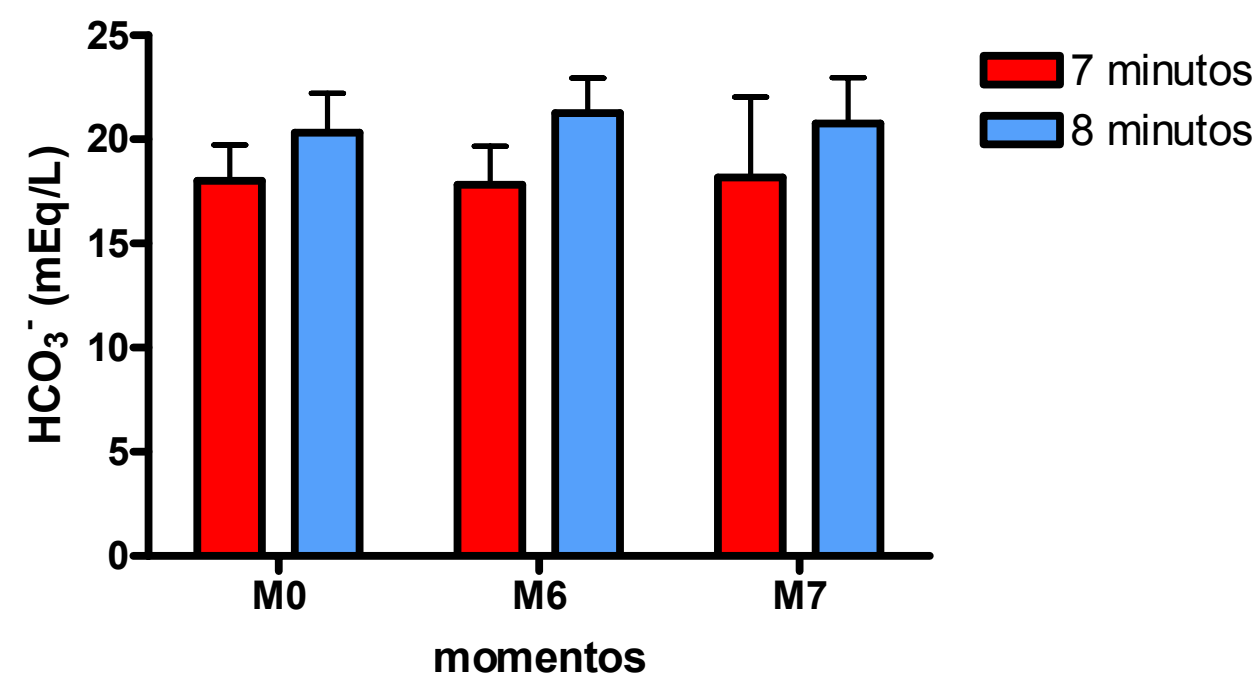

M0 (30 minutos antes da medicação pré-anestésica); M6 (24 horas após o término da cirurgia); M7 (48 horas após o término da cirurgia)

Gráfico 21 - Comparação entre as médias dos grupos A e B relativas ao bicarbonato plasmático $\left(\mathrm{HCO}_{3}{ }^{-}\right)$, de cães submetidos a sete e oito minutos de parada circulatória total, respectivamente, durante os momentos correspondentes aos períodos pré-operatório M0, e pós-operatórios M6 e M7 - São Paulo - 2005

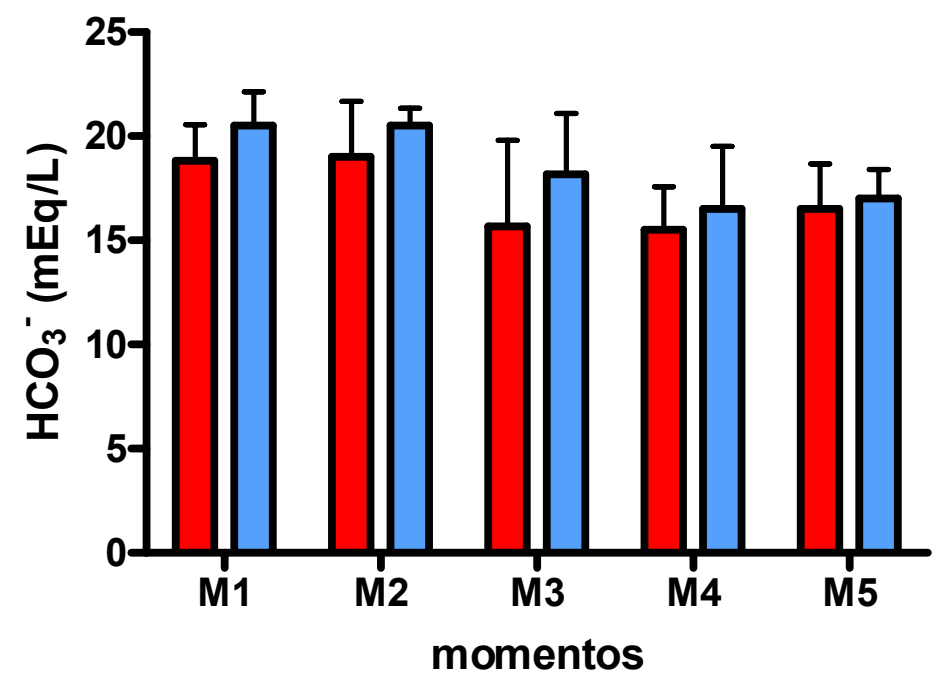

$\square 7$ minutos $\square 8$ minutos

(30 minutos após estabilização anestésica); M2 (imediatamente antes do "Inflow Occlusion"); M3 (decorridos 5 minutos do "Inflow Occlusion"); M4 (5 minutos após o término do "Inflow Occlusion"); M5 (30 minutos após o término do "Inflow Occlusion")

Gráfico 22 - Comparação entre as médias dos grupos A e B relativas ao bicarbonato plasmático $\left(\mathrm{HCO}_{3}{ }^{-}\right)$, de cães submetidos a sete e oito minutos de parada circulatória total, respectivamente, durante os momentos correspondentes ao período transoperatório M1 a M5 - São Paulo - 2005 


\subsection{6 $\mathrm{SaO}_{2}$}

Os valores de $\mathrm{SaO}_{2}$ individuais, médias e desvios-padrão em relação aos momentos analisados, estão discriminados nas tabelas 23 e 24, para os grupos A e B, respectivamente. Os valores que servem de comparação entre os dois grupos A e B, podem ser visualizados nos gráficos 23 e 24 .

Em quatro dos seis animais do grupo A (números 2, 4, 6 e 10) houve queda dos valores de $\mathrm{SaO}_{2}$ em M6, em relação a M0. Dois destes quatro (cães 2 e 10), apresentaram valores em M7 menores que M0, porém iguais a M6; outro animal ( $\left.\mathrm{n}^{\circ} 4\right)$ mostrou valor em M7 menor que M6 e outro (animal 6), maior que M6. Outro cão do mesmo grupo ( ${ }^{\circ} 7$ ) apresentou valor igual em M6 e M0, sendo que o valor em M7 foi menor nos dois momentos citados; e outro animal (indivíduo 8) apresentou valores iguais em M6 e M7, porém estes eram maiores aos encontrados em M0. Já no grupo B, foram avaliados somente os resultados de quatro animais $(1,3,5$ e 9). Dois dos quatro animais (números 3 e 5) apresentaram valores em M6 menores que M0, porém o animal 3 mostrou aumento em M7, e no animal 5 constatou-se diminuição da $\mathrm{SaO}_{2}$ em relação a M6. Outro animal do mesmo grupo $\mathrm{B}$ (cão $\mathrm{n}^{\circ}$ 1) apresentou aumento de $\mathrm{SaO}_{2}$ em $\mathrm{M} 6$, porém em $\mathrm{M} 7$ o valor foi menor que M0. Outro animal, sendo este o de $n^{\circ} 9$, apresentou valor em M6 igual a M0, porém o mesmo diminuiu em M7. Já no período transoperatório todos os animais dos dois grupos, com exceção de um animal do grupo B (espécime 11) tinham valor de 100\% em M1. Estes valores diminuíram drasticamente em M3, durante a parada circulatória, e após a mesma em M4, retornaram a subir. Em M5, sete animais, incluindo animais dos dois grupos (cães n 2, 4, 8 e 10 do grupo $\mathrm{A}$, e cães $\mathrm{n}^{\circ} 3,5$ e 9 do grupo B) já retomaram valores iguais a $\mathrm{M} 1$ de $100 \%$ de $\mathrm{SaO}_{2}$. A análise estatística comparando as médias dos grupos $\mathrm{A}$ e $\mathrm{B}$, tanto no que se refere aos momentos transoperatórios, pré e pós-operatórios não revelou diferença significativa entre os grupos. 
Tabela 23 - Valores individuais de saturação de oxigênio no sangue arterial $\left(\mathrm{SaO}_{2}\right)$ em \%, médias e respectivos desvios-padrão dos animais do grupo A, submetidos a sete minutos de parada circulatória total São Paulo - 2005

\begin{tabular}{l|c|c|c|c|c|c|c|c}
\hline & M0 & M1 & M2 & M3 & M4 & M5 & M6 & M7 \\
\hline Animal 02 & 96 & 100 & 96 & 89 & 97 & 100 & 95 & 95 \\
Animal 04 & 99 & 100 & 100 & 64 & 100 & 100 & 98 & 94 \\
Animal 06 & 96 & 100 & 100 & 69 & 99 & 98 & 94 & 95 \\
Animal 07 & 96 & 100 & 99 & 76 & 98 & 99 & 96 & 93 \\
Animal 08 & 96 & 100 & 100 & 54 & 100 & 100 & 97 & 97 \\
Animal 10 & 98 & 100 & 100 & 71 & 100 & 100 & 96 & 96 \\
\hline média & 96,83 & 100,00 & 99,17 & 70,50 & 99,00 & 99,50 & 96,00 & 95,00 \\
\hline DP & 1,00 & 0 & 1,60 & 13,13 & 1,26 & 0,84 & 1,41 & 1,41 \\
\hline
\end{tabular}

M0 (30 minutos antes da medicação pré-anestésica); M1 (30 minutos após estabilização anestésica); M2 (imediatamente antes do "Inflow Occlusion"); M3 (decorridos 5 minutos do "Inflow Occlusion"); M4 (5 minutos após o término do "Inflow Occlusion"); M5 (30 minutos após o término do "Inflow Occlusion"); M6 (24 horas após o término da cirurgia); M7 (48 horas após o término da cirurgia)

DP - desvio padrão

Tabela 24 - Valores individuais de saturação de oxigênio no sangue arterial $\left(\mathrm{SaO}_{2}\right)$ em \%, médias e respectivos desvios-padrão dos animais do grupo $\mathrm{B}$, submetidos a oito minutos de parada circulatória total São Paulo - 2005

\begin{tabular}{l|c|c|c|c|c|c|c|c}
\hline & M0 & M1 & M2 & M3 & M4 & M5 & M6 & M7 \\
\hline Animal 01 & 98 & 100 & 100 & 84 & 99 & 99 & 99 & 95 \\
Animal 03 & 97 & 100 & 99 & 47 & 99 & 100 & 95 & 96 \\
Animal 05 & 99 & 100 & 100 & 19 & 99 & 100 & 95 & 92 \\
Animal 09 & 96 & 100 & 100 & 89 & 100 & 100 & 96 & 94 \\
Animal 11 & 97 & 97 & 100 & 57 & $\dagger$ & $\dagger$ & $\dagger$ & $\dagger$ \\
Animal 12 & 96 & 100 & 100 & 45 & $\dagger$ & $\dagger$ & $\dagger$ & $\dagger$ \\
\hline média & 97,17 & 99,50 & 99,83 & 56,83 & 99,25 & 99,75 & 96,25 & 94,25 \\
\hline DP & 1,41 & 1,22 & 0,41 & 29,33 & 0,50 & 0,50 & 1,89 & 1,71 \\
\hline
\end{tabular}

M0 (30 minutos antes da medicação pré-anestésica); M1 (30 minutos após estabilização anestésica); M2 (imediatamente antes do "Inflow Occlusion"); M3 (decorridos 5 minutos do "Inflow Occlusion"); M4 (5 minutos após o término do "Inflow Occlusion"); M5 (30 minutos após o término do "Inflow Occlusion"); M6 (24 horas após o término da cirurgia); M7 (48 horas após o término da cirurgia)

DP - desvio padrão

$\dagger$ - óbito 


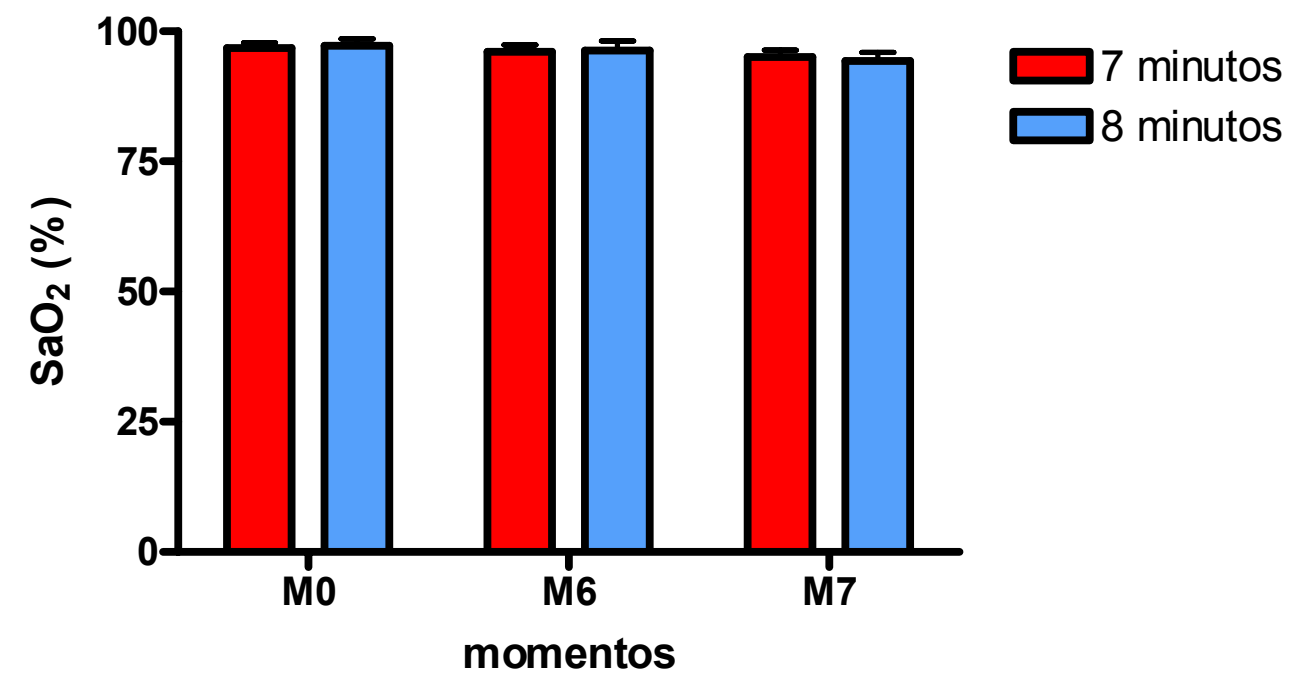

M0 (30 minutos antes da medicação pré-anestésica); M6 (24 horas após o término da cirurgia); M7 (48 horas após o término da cirurgia)

Gráfico 23 - Comparação entre as médias dos grupos A e B relativas à saturação de oxigênio no sangue arterial $\left(\mathrm{SaO}_{2}\right)$, de cães submetidos a sete e oito minutos de parada circulatória total, respectivamente, durante os momentos correspondentes ao período transoperatório - São Paulo - 2005

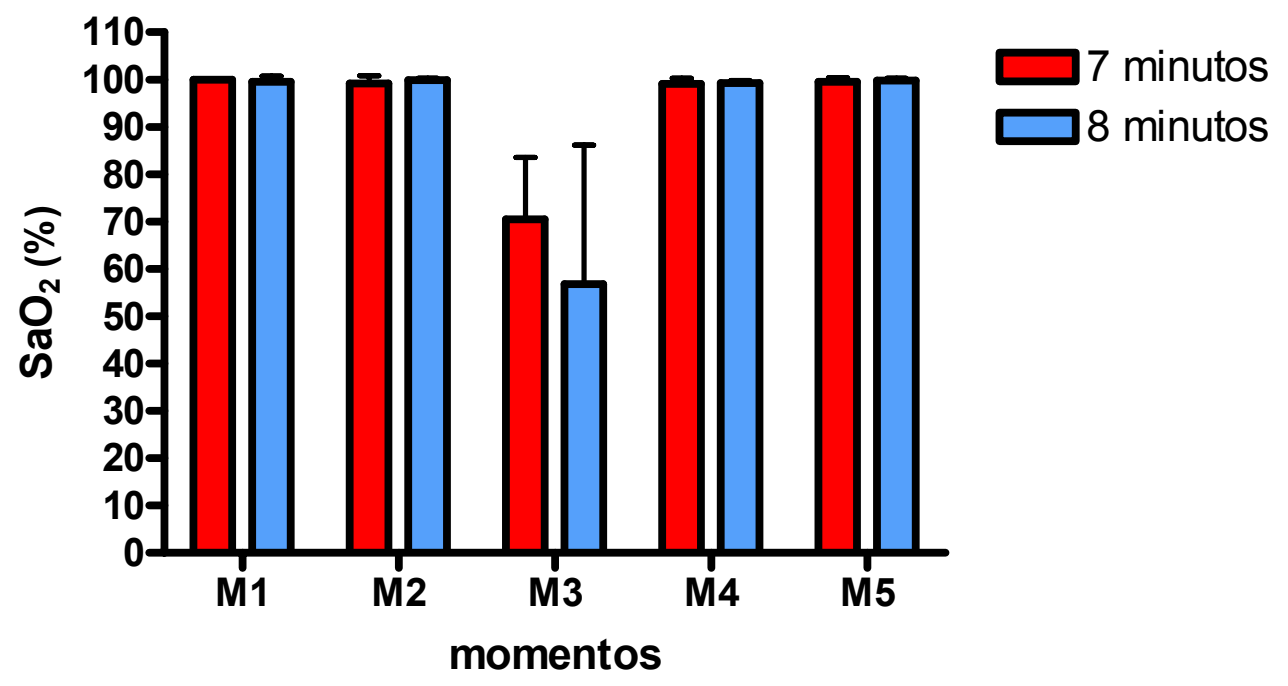

M1 (30 minutos após estabilização anestésica); M2 (imediatamente antes do "Inflow Occlusion"); M3 (decorridos 5 minutos do "Inflow Occlusion"); M4 (5 minutos após o término do "Inflow Occlusion"); M5 (30 minutos após o término do "Inflow Occlusion")

Gráfico 24 - Comparação entre as médias dos grupos A e B relativas à saturação de oxigênio no sangue arterial $\left(\mathrm{SaO}_{2}\right)$, de cães submetidos a sete e oito minutos de parada circulatória total, respectivamente, durante os momentos correspondentes ao período transoperatório M1 a M5 - São Paulo - 2005 


\subsection{7 $\mathrm{SvO}_{2}$}

Os valores de $\mathrm{SvO}_{2}$ individuais, médias e desvios-padrão em relação aos momentos analisados, estão discriminados nas tabelas 25 e 26, para os grupos A e B, respectivamente. Os valores que servem de comparação entre os dois grupos A e B, podem ser visualizados nos gráficos 25 e 26.

Dois dos seis animais do grupo A (cães 8 e 10) apresentaram valores em M7 maiores que o basal M0, sendo que o valor constatado para o de $\mathrm{n}^{\circ} 10$ também foi maior que M6. Os outros quatro animais (números 2, 4, 6 e 7) mostraram valores em M6 menores que M0, porém um deles (animal 2) apresentou valor de $\mathrm{SvO}_{2}$ maior em $\mathrm{M} 7$ em relação a $\mathrm{M} 0$, e outros dois (animais 4 e 6) tinham valores em M7 maiores que M6. Já no grupo B, foi observado que os quatro cães sobreviventes (números 1, 3, 5 e 9) apresentaram valores de $\mathrm{SvO}_{2}$ em M7 menores que M0 e M6. Dois deles, sendo os animais de $\mathrm{n}^{\circ} 3$ e 5, apresentaram valores em M6 superiores a M0, e os de $\mathrm{n}^{\circ} 1$ e 9 mostraram valores inferiores a M0. Durante o período transoperatório, todos os animais dos grupos A e B apresentaram queda brusca dos valores de $\mathrm{SvO}_{2}$ em M3, mas os valores aumentaram posteriormente em M4, e diminuíram novamente no momento M5, quando comparado a M4 (com exceção do animal 3 do grupo A). A análise estatística não mostrou diferença significativa entre os grupos nos momentos pré e pósoperatórios, e tampouco nos momentos transoperatórios.

Tabela 25 - Valores individuais de saturação de oxigênio no sangue venoso $\left(\mathrm{SvO}_{2}\right)$ em \%, médias e respectivos desvios-padrão dos animais do grupo A, submetidos a sete minutos de parada circulatória total São Paulo - 2005

\begin{tabular}{l|c|c|c|c|c|c|c|c}
\hline & M0 & M1 & M2 & M3 & M4 & M5 & M6 & M7 \\
\hline Animal 02 & 70 & 90 & 82 & 51 & 89 & 85 & 42 & 83 \\
Animal 04 & 83 & 92 & 83 & 62 & 90 & 92 & 65 & 67 \\
Animal 06 & 91 & 89 & 88 & 19 & 91 & 85 & 79 & 83 \\
Animal 07 & 89 & 90 & 86 & 64 & 90 & 85 & 80 & 72 \\
Animal 08 & 78 & 86 & 87 & 32 & 92 & 90 & 86 & 83 \\
Animal 10 & 77 & 89 & 86 & 79 & 92 & 85 & 85 & 86 \\
\hline média & 81,33 & 89,33 & 85,33 & 51,17 & 90,67 & 87,00 & 74,17 & 79,00 \\
\hline DP & 7,92 & 1,97 & 2,34 & 22,18 & 1,21 & 3,16 & 17,83 & 7,62 \\
\hline
\end{tabular}

M0 (30 minutos antes da medicação pré-anestésica); M1 (30 minutos após estabilização anestésica); M2 (imediatamente antes do "Inflow Occlusion"); M3 (decorridos 5 minutos do "Inflow Occlusion"); M4 (5 minutos após o término do "Inflow Occlusion"); M5 (30 minutos após o término do "Inflow Occlusion"); M6 (24 horas após o término da cirurgia); M7 (48 horas após o término da cirurgia)

DP - desvio padrão 
Tabela 26 - Valores individuais de saturação de oxigênio no sangue venoso $\left(\mathrm{SvO}_{2}\right) \mathrm{em} \%$, médias e respectivos desvios-padrão dos animais do grupo $\mathrm{B}$, submetidos a oito minutos de parada circulatória total São Paulo - 2005

\begin{tabular}{l|c|c|c|c|c|c|c|c}
\hline & M0 & M1 & M2 & M3 & M4 & M5 & M6 & M7 \\
\hline Animal 01 & 89 & 92 & 89 & 42 & 89 & 87 & 88 & 84 \\
Animal 03 & 73 & 88 & 82 & 32 & 91 & 79 & 86 & 52 \\
Animal 05 & 88 & 92 & 92 & 7 & 92 & 91 & 81 & 86 \\
Animal 09 & 82 & 91 & 91 & 38 & 90 & 89 & 84 & 74 \\
Animal 11 & 87 & 87 & 89 & 31 & $\dagger$ & $\dagger$ & $\dagger$ & $\dagger$ \\
Animal 12 & 83 & 87 & 90 & 37 & $\dagger$ & $\dagger$ & $\dagger$ & $\dagger$ \\
\hline média & 83,67 & 89,50 & 88,33 & 31,17 & 90,50 & 86,50 & 84,75 & 74,00 \\
\hline DP & 5,92 & 2,43 & 3,54 & 12,51 & 1,29 & 5,26 & 2,99 & 15,58 \\
\hline
\end{tabular}

M0 (30 minutos antes da medicação pré-anestésica); M1 (30 minutos após estabilização anestésica); M2 (imediatamente antes do "Inflow Occlusion"); M3 (decorridos 5 minutos do "Inflow Occlusion"); M4 (5 minutos após o término do "Inflow Occlusion"); M5 (30 minutos após o término do "Inflow Occlusion"); M6 (24 horas após o término da cirurgia); M7 (48 horas após o término da cirurgia)

DP - desvio padrão

$\uparrow$ - óbito

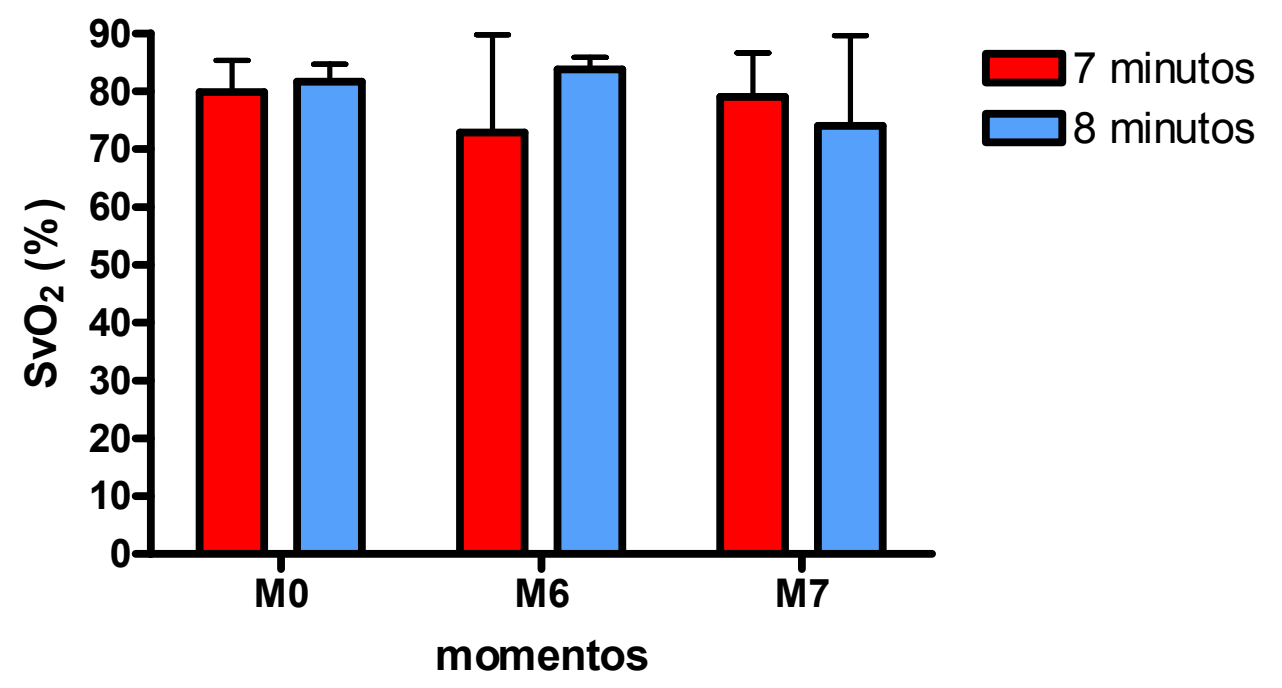

M0 (30 minutos antes da medicação pré-anestésica); M6 (24 horas após o término da cirurgia); M7 (48 horas após o término da cirurgia)

Gráfico 25 - Comparação entre as médias dos grupos A e B relativas à saturação de oxigênio no sangue venoso $\left(\mathrm{SvO}_{2}\right)$, de cães submetidos a sete e oito minutos de parada circulatória total, respectivamente, durante os momentos correspondentes aos períodos pré-operatório M0 e pós-operatórios M6 e M7 São Paulo - 2005 


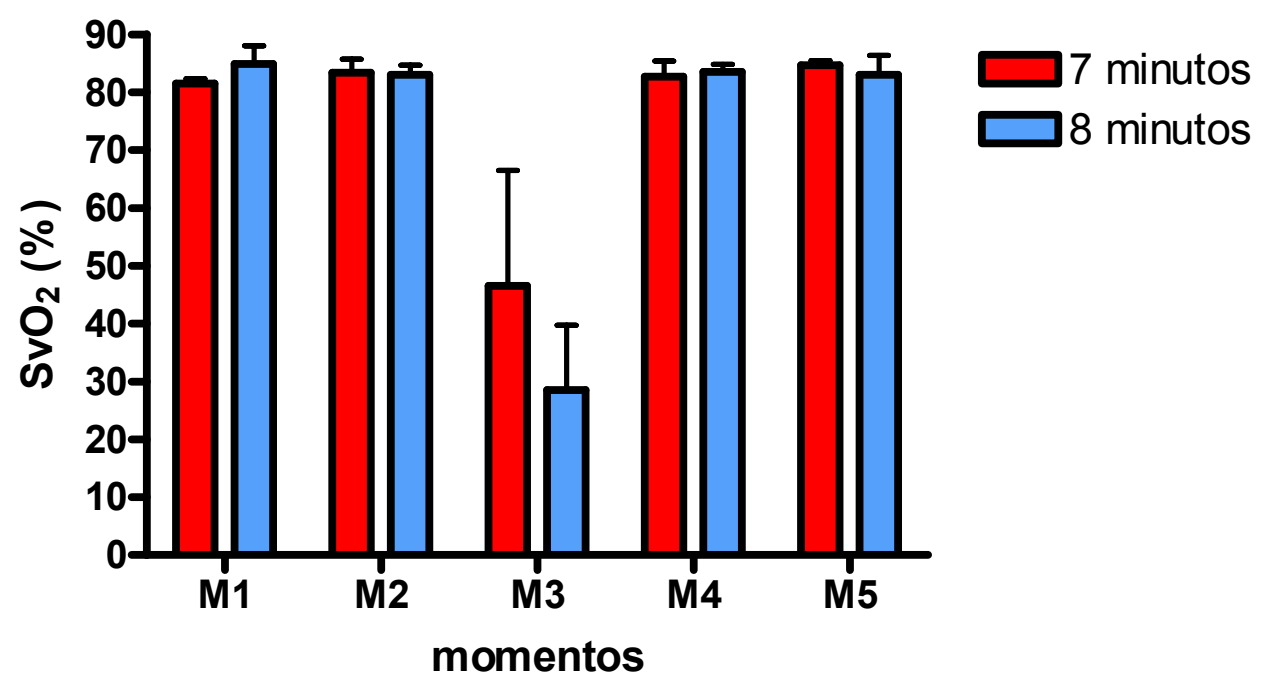

M0 (30 minutos antes da medicação pré-anestésica); M1 (30 minutos após estabilização anestésica); M2 (imediatamente antes do "Inflow Occlusion"); M3 (decorridos 5 minutos do "Inflow Occlusion"); M4 (5 minutos após o término do "Inflow Occlusion”); M5 (30 minutos após o término do "Inflow Occlusion”); M6 (24 horas após o término da cirurgia); M7 (48 horas após o término da cirurgia)

Gráfico 26 - Comparação entre as médias dos grupos A e B relativas à saturação de oxigênio no sangue venoso $\left(\mathrm{SvO}_{2}\right)$, de cães submetidos a sete e oito minutos de parada circulatória total, respectivamente, durante os momentos correspondentes ao período transoperatório M1 a M5 - São Paulo - 2005 


\section{DISCUSSÃO}

Com embasamento nos resultados obtidos neste presente estudo e na literatura atinente ao assunto em questão, desenvolveu-se a discussão, a seguir:

Ficou evidente pela literatura consultada que a relação entre o nível da temperatura do paciente no período transoperatório e o tempo da parada circulatória estão intimamente relacionadas quando da aplicação da técnica do "Inflow Occlusion" (BIGELOW; LINDSAY; GREENWOOD, 1990; ORTON, 1995; ORTON; BRUECKER; McCRACKEN, 1990).

Apesar de um dos objetivos deste trabalho ter sido a observação de animais submetidos à técnica de parada circulatória total em normotermia, estabelecendo-se como limite mínimo de temperatura corpórea $36^{\circ} \mathrm{C}$, e temperatura empregada no colchão térmico de $40{ }^{\circ} \mathrm{C}$ durante o intra-operatório para todos os animais do grupo A e B, pôde-se constatar que em alguns casos as mesmas atingiram até mais que dois graus abaixo do estabelecido para o indivíduo. Tal fato pôde ser atribuído ao ineficiente sistema de manutenção térmica realizado à base de colchão d'água aquecido. O mesmo pôde ser observado nos trabalhos de Kwasnicka et al. (2000) e Stopiglia et al. (2001), nos quais o colchão térmico utilizado também foi ineficiente para manutenção da normotermia nos cães. Contudo, tais temperaturas ainda mostraram-se bem superiores aos $28^{\circ} \mathrm{C}$ relatados por Kameya (1960), nível este que levaria à modificação e diminuição do metabolismo, diminuindo em $50 \%$ a demanda de oxigênio. $\mathrm{Ou}$ mesmo, como indicou Holmberg e Olsen (1987), valendo-se de temperaturas entre $23^{\circ} \mathrm{C}$ e $25^{\circ} \mathrm{C}$, que associadas a infusões coronarianas de soluções cardioplégicas abaixariam a temperatura a $5^{\circ} \mathrm{C}$, permitindo paradas circulatórias totais por longos períodos, como trinta minutos.

Desta maneira, levando-se em conta a ineficiência do sistema de aquecimento em manter a normotermia dos animais, poderia-se inferir que a queda da temperatura observada constituiu-se em mecanismo de defesa orgânica metabólica contra a parada circulatória. No entanto, a temperatura dos cães caiu a partir de M1, e manteve-se desse modo até M5, o que indica que a hipotermia observada poderia ter ocorrido simplesmente em decorrência do processo anestésico/cirúrgico, e não exclusivamente devido à parada circulatória total. Comparando-se as temperaturas dos animais em M1, com aquelas dos momentos seguintes M2, M3, M4 e M5, notou-se que houve pouca variação das mesmas entre estes momentos, principalmente referente ao M3, momento que poderia se esperar que a temperatura caísse mais, devido à interrupção da circulação, e principalmente no grupo $\mathrm{B}$, no qual a parada 
circulatória foi mais longa. No entanto, isso não ocorreu, e inclusive as médias de temperatura do grupo $\mathrm{B}$ nos períodos transoperatórios, foram superiores às do grupo $\mathrm{A}$, não havendo, no entanto, diferenças significativas entre elas. O mesmo ocorreu no trabalho realizado por Stopiglia et al. (2001), onde as temperaturas apresentaram valores abaixo daquela proposta pelos autores, sendo coincidentemente estipuladas também em $36^{\circ} \mathrm{C}$, como neste presente estudo; havendo também muito pouca variação das mesmas entre os momentos transoperatórios avaliados desde M1 até M5. Corroborando com a presente pesquisa, o grupo B avaliado por Stopiglia et al. (2001), o qual sofreu parada circulatória total por período de dez minutos, também apresentou no momento da parada da circulação (M3), temperatura maior que a do momento anterior (M2), além da mesma ser inclusive, maior que a do grupo A no mesmo momento M3. Da mesma forma, não houve diferenças significativas entre as médias dos dois grupos nos momentos avaliados.

Porém, se avaliarmos os animais sobreviventes neste experimento, apenas um deles (cão $\mathrm{n}^{\circ} 1$ do grupo B) apresentou lesões neurológicas permanentes, sendo que todos os outros (cães 2, 4, 6, 7, 8 e 10 do grupo A e cães 3, 5 e 9 do grupo B) já com 48 horas de evolução, demonstraram funções fisiológicas normalizadas. Isto poderia indicar que a hipotermia ocorrida neste período transoperatório, especialmente aquela ocorrida durante a parada circulatória, tenha sido benéfica para os indivíduos, havendo de certa maneira proteção neurológica perioperatória, já que os sintomas observados, com exceção de um caso, foram transitórios. Isto vai ao encontro dos de relatos de Manohar e Tyagi (1972) e Sleigh et al. (1986), nos quais recomenda-se a hipotermia para proteção cerebral para períodos de parada circulatória acima de oito minutos.

Em comparação com outros trabalhos sobre o assunto, os resultados obtidos neste experimento, em relação ao tempo de parada circulatória, mostraram-se superiores ao preconizado por Orton, Bruecker e McCracken (1990) - cinco minutos e trinta segundos - e inferiores aos mostrados por Hunt et al. (1992). Nesta presente pesquisa há resultados que contradizem aqueles encontrados pelo último autor, os quais mostram que os três animais estudados utilizando-se oito minutos de parada circulatória total em normotermia, sobreviveram e não apresentaram quaisquer lesões neurológicas no período pós-operatório.

Tendo em vista que este trabalho visou estabelecer tempo limite para realização de paradas circulatórias totais sem que houvesse comprometimento clínico dos animais no período pós-cirúrgico, e avaliar alterações hemogasométricas trans e pós-operatórias, para assim, obter métodos seguros e práticos para realização de cirurgias cardíacas rápidas em cães, na rotina hospitalar, pode-se afirmar pelos resultados obtidos neste estudo, que paradas 
circulatórias totais por sete minutos valendo-se da técnica de "Inflow Occlusion" em cães sadios, foram levadas a bom termo. Desta maneira, Freitas et al. (1998) citaram o emprego desta técnica, com sucesso, no reparo de comunicação inter-atrial em cão da raça Lhasa Apso, porém utilizando-se de duas paradas circulatórias, uma de três e outra de cinco minutos, respectivamente.

Devido aos óbitos transoperatórios e às observações clínicas nas avaliações após 24 e 48 horas seguintes ao procedimento cirúrgico e até 20 dias de acompanhamento pósoperatório, pode-se inferir que paradas circulatórias por períodos de oito minutos são contraindicadas, segundo resultados deste trabalho. Sobre os demais quadros clínicos observados, somente há referências no estudo realizado por Stopiglia et al. (2001) com paradas circulatórias de cinco e dez minutos, no qual corroboram-se sintomas neurológicos ocorridos provavelmente pela hipóxia/anóxia cerebral, e óbitos.

São encontrados poucos trabalhos na literatura veterinária sobre cirurgias cardíacas, principalmente no Brasil, sendo que a maioria delas é de caráter experimental. Pouco se sabe sobre as principais complicações relacionadas a este tipo de procedimento, principalmente ao que se refere ao aspecto neurológico e comportamental no pós-operatório. Complicações neurológicas estão intimamente relacionadas à cirurgia cardíaca e são muito estudadas na Medicina Humana, na tentativa de minimizar suas ocorrências durante os procedimentos (FORTUNA, 2002).

Kwasnicka et al. (2000) e Stopiglia et al. (2001) tiveram sucesso apenas com cinco minutos de parada circulatória, e encontraram problemas neurológicos e óbitos com dez minutos (STOPIGLIA et al., 2001) de interrupção da circulação. Um dos óbitos observados pelo autor foi ocasionado por fibrilação ventricular, mesma causa mortis de dois cães do grupo B deste presente trabalho. Estes quadros de arritmias, e principalmente fibrilação ventricular, com dificuldade de ressuscitação cardíaca, também foi relatado por Awariefe, Clarke e Pappas (1983). Hunt et al. (1992), relataram arritmias, principalmente do nodo átrioventricular, em quatro animais após o "Inflow Occlusion", as mesmas ocorrendo de dois a quatro minutos após oclusão das veias. Porém as mesmas reverteram-se espontaneamente antes do restabelecimento da circulação. No presente estudo, as arritmias ventriculares iniciaram-se após o sétimo minuto de oclusão, não se revertendo espontaneamente, e tampouco foram passíveis de reversão por medidas de ressuscitação. Odegard (2004) apresentou em seu trabalho 4 casos de arritmias em 11 pacientes estudados, sendo que em dois deles, o quadro foi também de fibrilação ventricular. Este mesmo autor ainda relata que deve-se ter cautela ao administrar agentes inotrópicos ou vasoativos na hora da retirada dos 
torniquetes para restabelecimento da circulação, e ao utilizar bicarbonato se houver déficit de bases, pois há riscos de hipertensão por rebote e arritmias. No presente trabalho, o objetivo não era reverter possíveis alterações metabólicas, e sim avaliar os efeitos das mesmas, decorrentes da parada circulatória pelos diferentes períodos observados - sete e oito minutos mas instituiu-se agentes vasoativos e choque na tentativa de reanimação dos animais após a ocorrência das fibrilações. Em nenhum momento as drogas citadas foram utilizadas no momento da retirada dos torniquetes (no restabelecimento da circulação), para melhorar a condição dos animais, principalmente referente à acidose metabólica e baixa pressão.

Neste presente estudo tampouco houve óbitos pós-operatórios, porém um dos cães evoluiu com lesões neurológicas sérias, como perda de visão e incoordenação motora, o que mostrou que após sete minutos já se pode encontrar danos severos ao organismo utilizando-se a técnica em questão. Os problemas ocorridos durante o experimento e relatados nos resultados reforçam o fato de que o cérebro necessita de proteção durante o período de parada circulatória. Como o mesmo possui alto consumo de oxigênio e extração aumentada em condições basais, facilmente sofre eventos isquêmicos quando há queda do fluxo sangüíneo. Este fato corrobora com aquele relatado por Neto (2000), no qual afirmou-se que o cérebro recebe $15 \%$ a $20 \%$ do débito cardíaco, e que seu fluxo é sete vezes maior que a circulação sistêmica e seu consumo de oxigênio é onze vezes maior que a mesma. Talvez, utilizando-se protetores neurológicos nos períodos perioparatórios ou valendo-se de hipotermia mais acentuada durante a cirurgia e principalmente, no momento do "Inflow Occlusion", o tempo de parada circulatória possa ser excedido com menores comprometimentos comportamentais e neurológicos no período pós-operatório.

Do ponto de vista clínico, os aspectos observados nos animais dos dois grupos, principalmente no $\mathrm{B}$, cuja parada foi de oito minutos, levam a pensar, principalmente em distúrbios circulatórios - hipóxia e anóxia - do sistema nervoso central segmentar e suprasegmentar, alguns transitórios, entre 24 e 48 horas de pós-operatório e outros irreversíveis até 20 dias de seguimento, como a cegueira do animal número 1 do grupo $\mathrm{B}$ e sua incoordenação motora. Estas condições foram verificadas anteriormente por DeLahunta (1983), Chrisman (1985) e Stopiglia et al. (2001).

Desta forma, o quadro clínico nas primeiras 24 horas, referente ao estado alterado de consciência, como o quadro depressivo apresentado pelos animais 1, 4, 6, 7 e 10 sugerem quadro de hipóxia/anóxia, o qual mostrou-se reversível nestes mesmos cães com 48 horas, havendo um estado de alerta mais acentuado, com exceção do animal 1 que apesar de não estar mais em estado comatoso, ainda tinha reflexo pupilar ausente neste momento M7 e 
estava um pouco depressivo. Em contrapartida, no trabalho realizado por Hunt et al. (1992), mesmo não havendo seqüelas neurológicas nos três animais estudados segundo o autor, todos eles apresentaram-se em estado mais depressivo e de prostração no período pós-operatório. $\mathrm{O}$ autor não sabe ao certo se este fato está relacionado à anestesia e uso de analgésicos, ou a uma isquemia transitória cerebral causada pela parada circulatória. Em seu trabalho, após 24 horas da cirurgia, dois animais já estavam bem alertas e conscientes, e outro ainda apresentava déficit de propriocepção. Após 36 horas, os três animais apresentavam-se normais.

No presente estudo, o animal $\mathrm{n}^{\circ} 1$, pelo exame clínico efetuado e de acordo com os momentos observados, provavelmente apresentou lesão por isquemia ou anóxia determinado cegueira total, possivelmente acometendo o nível caudal do trato óptico, quer no corpo geniculado lateral, ramificações ópticas ou córtex cerebral (CHRISMAN, 1985; DELAHUNTA, 1983; STOPIGLIA et al., 2001). Segundo a literatura, as áreas do cérebro mais gravemente acometidas em quadros de isquemia cerebral, são aquelas cujo suprimento sangüíneo é realizado pelas terminações das artérias cerebrais médias e anterior, em que há necrose cortical na região occipital, resultando em cegueira (CHRISMAN, 1985).

Segundo Chrisman (1985) e Stopiglia et al. (2001), os distúrbios comportamentais indicam que os cães 5, 7, 9 e 10 possam ter sofrido lesão no lobo frontal ou cápsula interna, o que justificaria a presença de "medo", e que cão n 1 apresentou sintomas que poderiam estar relacionados a lesão no sistema olfatório, estas relacionadas a alteração em diencéfalo, nas primeiras 24 horas de observação pós-cirúrgica, observando-se melhora do quadro clínico após 48 horas de seguimento pós-operatório. O estado comatoso do indivíduo 1 nas primeiras 24 horas, assim como os tremores observados nos animais $n^{\circ} 1$ e $n^{\circ} 7$, poderiam indicar distúrbio em diencéfalo (tálamo e hipotálamo) ou telencéfalo (cérebro), podendo implicar especialmente parte do sistema límbico. A convulsão ocorrida em M7 do cão $\mathrm{n}^{\circ}$, pode indicar que possa ter ocorrido de forma transitória, porém se manifestando mais tardiamente, após 48 horas de pós-cirúrgico, lesão em cérebro, especificamente em região de diencéfalo. A incoordenação motora ou ataxia observada em alguns dos animais (cães 1, 3, 5, 6, 7 e 10) logo no período M6, é sugestivo de lesão cerebelar, porém as mesmas foram transitórias, e apenas o animal 1 do grupo B permaneceu incoordenado após as 48 horas após o ato operatório (CHRISMAN, 1985; STOPIGLIA et al., 2001).

Em relação à freqüência respiratória, podemos inferir que a mesma teve bom comportamento, e que mesmo havendo parada da ventilação no momento M3, não qualquer indício de lesão pulmonar pós-operatória, já que manteve-se praticamente o mesmo padrão respiratório em comparação com basal em M0. Alguns animais apresentaram taquipnéia no 
momento da coleta dos dados, tanto em M0, como em M6 e M7, mas isto ocorreu em conseqüência à manipulação dos animais, e não em decorrência da técnica em questão.

Em relação à F.C., ficou impossibilitada a análise dos dados em M3, devido à alternância de períodos de taquicardia e bradicardia acarretadas pela parada circulatória. A comparação de dados, neste momento, poderia revelar inverdades, e por isso optou-se por não incluí-los na análise dos resultados. No entanto, podemos relatar o comportamento da F.C. após o "Inflow occlusion". Após oclusão das veias, houve esvaziamento das câmaras cardíacas e instalação de taquicardia reflexa à parada circulatória, a qual persistiu pelos primeiros dois minutos, havendo após algum tempo, em torno de cinco minutos, diminuição da F.C. e o coração passou a bater mais lentamente e "murcho". Este comportamento também é descrito por Hunt et al. (1992) de maneira semelhante. Da mesma forma, o comportamento da F.C. nesta pesquisa corrobora com aquele apresentado pelo autor ora citado, quando iniciase taquicardia novamente após liberação da circulação. No entanto, cinco minutos após liberação das veias e retorno circulatório, os valores já encontraram-se normais.

Relativo à P.A.S, esta apresentou diferença significativa no momento M4, quando comparado os dois grupos, principalmente pelo fato dos animais números 1 e 3 apresentarem neste momento, valores muito discrepantes em relação aos valores dos outros animais, de ambos os grupos. A P.A.S. foi imensurável em M3 devido à oclusão das veias e interrupção da circulação. No momento seguinte, em M4, o esperado seria elevação da P.A.S. após a parada circulatória, pois haveria aumento da freqüência cardíaca e maior contração miocárdica para restabelecimento de fluxo sangüíneo aos órgãos. Porém nos dois cães anteriormente citados, os valores foram muito mais elevados, o que interferiu de maneira significante na média do grupo no momento avaliado (M4).

Já na avaliação da P.A.M., certamente as diferenças significativas observadas em M0 e M4, foram em decorrência de maiores pressões sistólicas e diastólicas de animais do grupo B, já que a P.A.M. é dependente da P.A.S. e P.A.D.. A pressão sistólica apresentou significante aumento no grupo B em relação ao grupo A em M4, e a diastólica apresentou valor significante em M0. Dois animais do grupo B apresentaram picos bem maiores de P.A.M. em M4 em relação aos outros cães do mesmo grupo e em relação ao grupo A, e o animal do grupo B que teve a maior P.A.M. neste momento foi o de $n^{\circ} 1$, o mesmo que apresentou lesões neurológicas em M6 e M7. Este fator também acabou influenciando na média do grupo $\mathrm{B}$, mostrando diferença significativa da pressão arterial média entre os grupos. Porém o ocorrido poderia ser imputado simplesmente a uma variação individual, pois no mesmo momento os outros animais dos dois grupos não apresentaram tal variação de 
modo tão acentuado, e ao contrário, apresentaram valores muito próximos de P.A.M. (com exceção de dois animais do grupo A, os quais retomaram a P.A.M. mais lentamente após M4). O comportamento da P.A.M. é descrito de maneira semelhante por Hunt et al. (1992), Kwasnicka et al. (2000) e Stopiglia et al. (2001). A pressão cai acentuada e rapidamente no momento M3, período de oclusão das veias, e permanece desta maneira até restabelecimento da circulação. Após liberação dos torniquetes, a pressão eleva-se a valores acima daqueles considerados normais, e em seguida retorna a valores próximos àqueles encontrados em M2, período anterior à parada circulatória total. Inclusive Hunt et al. (1992) relataram que seus valores pós-oclusão retornaram ao basal, momento anterior ao clampeamento, em torno de 30 a 40 minutos após o "Inflow oclusion". Tal fato pôde ser constatado também neste presente experimento.

No tocante á analise hemogasométrica, pode-se tecer alguns comentários. Neste presente estudo analisou-se o comportamento do $\mathrm{pH}$, bicarbonato plasmático e dos gases sangüíneos de cães submetidos a períodos de sete e oito minutos de parada circulatória total. Segundo Raia e Zerbini (1998), as cirurgias cardíacas cursam com importantes alterações no equilíbrio ácido-básico, como pôde ser verificado.

O diagnóstico das desordens ácido-básicas está baseado na interpretação das alterações do $\mathrm{pH}, \mathrm{PCO}_{2}$ e concentração de $\mathrm{HCO}_{3}{ }^{-}$no sangue. Assim, mudanças no $\mathrm{pH}$ são sinais tanto de aumento nos íons $\mathrm{H}^{+}$(acidose), quanto de uma diminuição na concentração destes (alcalose). A análise em conjunto das alterações de dióxido de carbono e concentração de bicarbonato ajuda a determinar a causa precisa da diferença de $\mathrm{pH}$.

Durante a análise dos valores dos gases sanguíneos é importante lembrar que alterações da temperatura corpórea produzem alterações significativas do $\mathrm{pH}$ sanguíneo.

Bailey (1998) relatou que a cada grau centígrado o $\mathrm{pH}$ sofre alteração de 0,15 unidades. No entanto tal proporção não foi encontrada nesta pesquisa. Os valores de temperatura referentes a M0 e M1 do grupo A variaram aproximadamente $3,3^{\circ} \mathrm{C}$, enquanto que o $\mathrm{pH}$ variou 0,01 . Em relação ao grupo $\mathrm{B}$, nos mesmos momentos, a variação foi de $2,4^{\circ} \mathrm{C}$ na temperatura corpórea, para variação de 0,02 no $\mathrm{pH}$. No período transoperatório houve momento em que o $\mathrm{pH}$ teve alteração de 0,15 , porém a temperatura não variou $1{ }^{\circ} \mathrm{C}$. Com certeza existe variação no $\mathrm{pH}$ quando há alteração da temperatura, mas talvez haja necessidade de realização outros trabalhos, utilizando maior número de animais para padronização desta variação.

Kwasnicka et al. (2000) utilizando três grupos de cães, realizou paradas circulatórias por cinco, dez e quinze minutos, respectivamente em cada grupo, e encontrou diferenças 
significativas nos dois primeiros grupos em relação aos valores hemogasométricos de $\mathrm{pH}$, pressão parcial de $\mathrm{CO}_{2}$ e $\mathrm{O}_{2}$, saturação de $\mathrm{O}_{2}$ e concentração de bicarbonato plasmático, todos obtidos de sangue arterial. Do mesmo modo Hunt et al. (1992) também encontrou diferenças significantes no $\mathrm{pH}$ antes e após a instituição do "Inflow Occlusion" nos animais que avaliou tanto por oito minutos, quanto por quatro minutos de parada circulatória total. No entanto nesta presente comparação entre sete e oito minutos de parada circulatória total, não foram encontradas diferenças significativas no tocante ao $\mathrm{pH}$, ou a qualquer outro parâmetro hemogasométrico.

A diminuição do $\mathrm{pH}$ verificada nos dois grupos A e B deste experimento, no momento da parada circulatória e logo após a mesma, ocorreu devido ao desvio da atividade metabólica para a via do ácido lático, uma vez que as condições eram de anaerobiose, decorrentes da parada da circulação. No entanto, nesta pesquisa não foi dosado o lactato para comparação com outros trabalhos. Hunt et al. (1992) relataram significante aumento do lactato após a parada da circulação e instituição do metabolismo anaeróbico, no entanto, mesmo que tenha sido maior no grupo de oito minutos de parada circulatória, não houve diferenças significativas em relação ao grupo com paradas circulatórias de quatro minutos.

Segundo Ettinger e Feldman (1992), o afluxo de um ácido fixo consome bicarbonato e outros tampões, provocando acidemia $(\mathrm{pH}<7,35)$. A acidose metabólica primária (queda do $\mathrm{HCO}_{3}{ }^{-}$) leva a uma alcalose respiratória compensatória (queda na $\mathrm{PaCO}_{2}$ ), logo, o pH cai no início (acidose), mas a resposta compensatória praticamente corrige-o até a normalidade (acidemia leve). Assim, em conjunto com um $\mathrm{HCO}_{3}{ }^{-}$reduzido e uma $\mathrm{PaCO}_{2}$ elevada, o $\mathrm{pH}$ do fluido extra-celular (FEC) cai, levando à ativação dos quimiorreceptores que estimulam a respiração. A hiperventilação com uma redução $\mathrm{PaCO}_{2}$ é resposta compensatória que tende a retornar o pH do F.E.C. ao normal. Esta compensação fica clara ao analisar-se os valores obtidos de $\mathrm{PaCO}_{2}$ nos momentos subseqüentes (M5, M6 e M7). Pode-se verificar redução nos valores de pressão parcial de dióxido de carbono em relação a M4, devido provavelmente, à hiperventilação compensatória. A correção do $\mathrm{pH}$ não foi necessária, apesar disto não fazer parte dos objetivos do estudo, uma vez que houve normalização do mesmo em seguida à parada circulatória. Esta característica corroborou com o trabalho de Kwasnicka et al. (2000), no qual os valores de $\mathrm{pH}$ também normalizaram-se nos períodos seguintes ao "Inflow Occlusion", sem qualquer interferência por parte dos pesquisadores.

No estudo realizado por Kwasnicka et al. (2000) utilizando a técnica de "Inflow occlusion”, foram observados valores de $\mathrm{pH}$ abaixo do normal após cinco, dez e quinze minutos de parada circulatória total, sendo os mesmos 7,16 $\pm 0,08,7,18 \pm 0,08$ e 7,17 $\pm 0,13$, 
respectivamente. A recuperação dos valores ocorreu apenas com 24 horas de pós-operatório. Já no estudo realizado por Hunt et al. (1992), valendo-se da mesma técnica, verificou-se valores também reduzidos de $\mathrm{pH}$ durante quatro e oito minutos de parada circulatória, sendo $7,22 \pm 0,1$ e 7,16 $\pm 0,1$, respectivamente. Porém no referido trabalho os valores normais foram restaurados trinta minutos após a parada circulatória, fato igualmente observado neste presente estudo com sete e oito minutos de parada circulatória, quando a média do $\mathrm{pH}$ em M3 foi de 7,21 $\pm 0,09$ e 7,27 $\pm 0,06$ para os grupos $\mathrm{A}$ e $\mathrm{B}$, respectivamente, durante o "Inflow Occlusion", e em seguida retornaram ao normal após trinta minutos (momento M5) para 7, 38 $\pm 0,05$ e 7,36 $\pm 0,07$, respectivamente para cada grupo.

Auler Jr. e Andrade (2004) e Fantoni (2002) relataram que com a queda do pH abaixo de 7,4 há queda na contratilidade miocárdica, e que a acidose metabólica predispõe a arritmias ventriculares, principalmente fibrilação ventricular. Observamos que durante a parada circulatória em M3 o pH dos animais estão abaixo do valor citado anteriormente, e que poderia inferir-se então, que os óbitos ocorreram devido ao processo de acidose metabólica, a qual estimulou as arritmias nos cães. Porém todos os cães dos dois grupo apresentaram o pH inferior a 7,4, inclusive em M4, após cinco minutos da parada circulatória, não apresentando quaisquer quadros de arritmias. Podemos supor que tais animais que foram a óbito poderiam estar mais suscetíveis e mais sensibilizados no momento da cirurgia, e que a partir de características individuais, apresentaram mais facilmente o episódio de fibrilação ventricular, culminando com os óbitos.

Muir e Hubbel (1989) sugerem que uma redução em $10 \mathrm{mmHg}$ na $\mathrm{PaCO}_{2}$ resulta em aumento de 0,1 unidades no pH. Concordando com os autores, como exemplo, pode-se analisar os valores deste presente estudo relativos aos momentos M4 e M5 do grupo A, onde os valores de $\mathrm{pH}$ variaram de 7,24 para 7,38, enquanto os valores de $\mathrm{PaCO}_{2}$ sofreram queda de 37,50 mmHg para 27,67 mmHg, nos mesmos momentos.

Em discordância com os estudos realizados por Hunt et al. (1992) e Kwasnicka et al. (2000), nos quais os autores verificaram acréscimo de aproximadamente $20 \mathrm{mmHg}$ da $\mathrm{PaCO}_{2}$ após a parada circulatória (depois da liberação das veias cavas e restituição do fluxo sangüíneo normal), quando comparada àquelas observadas logo antes do "inflow occlusion" em M2, o presente estudo mostrou que houve pouca variação da pressão arterial de dióxido de carbono entre os momento M2 e M4, sendo a variação máxima de 6,75 mmHg (grupo B) entre as médias destes momentos.

Em relação à $\mathrm{PaCO}_{2}$, sua elevação durante a parada circulatória e posterior queda em M4 já era esperada, uma vez que a oferta de oxigênio estava diminuída tanto pela interrupção 
da circulação quanto pela ausência da ventilação. Hunt et al. (1992) verificaram valores de $\mathrm{PaCO}_{2}$ da ordem de $48 \pm 73 \mathrm{mmHg}$ e $56 \pm 6 \mathrm{mmHg}$ durante o "Inflow Occlusion" nos grupos com quatro e oito minutos de parada circulatória, respectivamente, sendo que estes valores voltaram ao normal (não descritos) logo após a liberação da circulação. Neste presente estudo foi encontrado valores inferiores $(\mathrm{M} 3=39,20 \pm 7,60$ e $\mathrm{M} 4=37,50 \pm 8,04$ para o grupo A, e M3 $=40,33 \pm 10,67$ e M4 $=42,75 \pm 9,74$ para o grupo B), assim como foi relatado no trabalho de Kwasnicka et al. (2000), provavelmente pelo fato de a $\mathrm{FiO}_{2}$ utilizada no experimento de Hunt et al. (1992) ser de 50\%, enquanto que nos outros dois trabalhos, a mesma foi de $100 \%$.

Em relação à $\mathrm{PaO}_{2}$, o comportamento foi semelhante ao ocorrido no relato de Hunt et al. (1992), ou seja, queda brusca no momento M3 pela interrupção da circulação, restabelecendo-se logo após a parada circulatória. Logo em seguida à liberação dos torniquetes das veias, e restabelecimento da circulação, realizava-se a hiperventilação dos animais, o que permitia a normalização das pressões dos gases sangüíneos, além de retirar o pulmão da condição atelectásica. Tanto este procedimento, como a hiperventilação antes de instituir a parada circulatória total, também foram descritas por Hunt et al. (1992). O mesmo ainda inflava os pulmões dos animais cada um minuto, o que também permitiu a normalização das pressões dos gases do sangue.

No que alude aos valores de $\mathrm{PaCO}_{2}$ pós-operatórios, verificou-se restabelecimento dos valores a padrões considerados normais para a espécie canina, demonstrando que a realização da parada circulatória não compromenteu a capacidade de oxigenação dos animais. Não obstante o tempo prolongado de ausência de circulação, pôde-se inferir que o centro respiratório e os pulmões não foram afetados.

Uma desordem respiratória ou não-respiratória aguda pode ser diferenciada pela observação dos valores de $\mathrm{PaCO}_{2}$ e $\mathrm{HCO}_{3}{ }^{-}$. Valores de bicarbonato abaixo de $15 \mathrm{mEq} / \mathrm{L}$ implicam em componente metabólico (não-respiratório). Para cada diminuição de $10 \mathrm{mmHg}$ na $\mathrm{PaCO}_{2}$ abaixo de $40 \mathrm{mmHg}$, ocorre uma alteração de 1 a $2 \mathrm{mEq} / \mathrm{L}$ na concentração de bicarbonato, como pôde ser verificado neste presente estudo, nos momentos M4 e M5 do grupo A, e corroborando com os trabalhos de Kwasnicka et al. (2000) e Muir e Hubbel (1989). Isto é, o valor da $\mathrm{PaCO}_{2}$ em M4 era 37,50 e caiu para 27,67 em M5, e ao mesmo tempo o valor do $\mathrm{HCO}_{3}{ }^{-}$variou de 15,50 em M4 para 16,50 em M5.

Ainda no que diz respeito ao bicarbonato plasmático, no presente estudo os animais submetidos a sete minutos de parada circulatória total demonstraram valores menores que aqueles que a sofreram por oito minutos, sendo que a média do grupo A em M3, mostrou-se 
2,50 $\mathrm{mEq} / \mathrm{L}$ menor que a do grupo $\mathrm{B}$, mantendo-se sempre mais baixa até 48 horas de pósoperatório em relação ao mesmo grupo. Este comportamento difere daquele observado por Kwasnicka et al. (2000), que relataram valores menores de $\mathrm{HCO}_{3}{ }^{-}$nos animais submetidos a maior tempo de parada circulatória total, no caso, aqueles submetidos à interrupção por dez e quinze minutos da circulação, fato que indicaria comprometimento metabólico resultante do quadro de isquemia imposto aos animais submetidos a um tempo maior de oclusão das veias. Apesar dos valores de $\mathrm{HCO}_{3}{ }^{-}$estarem baixos no momento da parada circulatória, e também em alguns dos cães após os momentos M3 a M5, não foi realizada a correção dos mesmos com a administração intravenosa de bicarbonato de sódio, pois não era este o objetivo do experimento.

Ao analisar as alterações de saturação de oxigênio arterial, percebeu-se que há elevação da mesma nos momentos de M1 a M5 (exceto em M3), nos dois grupos experimentais, atingindo valores de média próximos a 100\%, fato ocasionado pela ventilação controlada nos animais, os quais recebiam nestes momentos transoperatórios, uma fração inspirada de oxigênio de 100\%. Já nos momentos pré e pós-operatórios M0, M6 e M7, o animal recebia ar atmosférico, no qual a $\mathrm{FiO}_{2}$ era de $21 \%$. No momento da parada circulatória, fica evidente uma ampla redução da $\mathrm{SatO}_{2}$, a qual já era esperada, pois nesta hora há parada da ventilação, diminuindo a oferta de $\mathrm{O}_{2}$.

Em relação à saturação venosa de oxigênio, pode-se dizer que a mesma é um indicador direto da função ventricular e também um indicador da disponibilidade de oxigênio aos tecidos, bem como de seu metabolismo oxidativo, sendo considerado um indicador mais fiel que os cálculos convencionais do consumo de oxigênio. Quando a saturação está baixa, pode ser indicativo de queda de débito cardíaco, queda na saturação arterial de oxigênio, queda da hemoglobina ou aumento do consumo de oxigênio (MARTINS, 2004).

Os valores de $\mathrm{SvO}_{2}$ de ambos os grupos nos momentos transoperatórios foram ligeiramente superiores aos encontrados nos momentos pré e pós-operatórios, devido ao fato da coleta sangüínea nestes momentos ter sido realizada a partir do cateter de artéria pulmonar, enquanto que nos outros momentos utilizou-se a veia cefálica. Analisando-se a saturação venosa de oxigênio obtida destes resultados, observou-se grande variação entre as médias dos dois grupos em M3, porém a mesma sem significância estatística, e isso se deu provavelmente, pelo fato do animal $\mathrm{n}^{\circ} 5$ do grupo $\mathrm{B}$ apresentar baixo valor da $\mathrm{SvO}_{2}$ neste momento, associado a valores mais altos dos animais 4, 7 e 10 do grupo A. Se observarmos a $\mathrm{SaO}_{2}$ do mesmo cão $\mathrm{n}^{\circ} 5$, vemos que a mesma também está baixa em comparação a todos os outros animais, fato que corrobora com o relato de Martins (2004). Estas observações diferem 
daquelas verificadas por Kwasnicka et al. (2000), que mesmo após dez minutos de parada circulatória, não encontrou valores baixos como os indicados neste trabalho. Sequer, as médias relatadas pela autora são tão discrepantes quanto as apresentadas nesta pesquisa. Enquanto os valores das médias mostrados por ela são em M3, de 65\% e 68,8\%, para o grupo A (cinco minutos de parada circulatória) e B (dez minutos de parada circulatória), respectivamente, os valores das médias encontrados nestes mesmos momentos para este experimento foram de $51,2 \%$ e $31,2 \%$ para os grupos A e B, respectivamente. Estes fatores provavelmente ocorreram por características individuais, e não devido à técnica aplicada somente, já que tampouco houve diferença significativa entre os grupos no relato de Kwasnicka et al. (2000). Além disso, alguns animais do grupo A, em M3, mantiveram a saturação venosa de oxigênio acima dos $62 \%$.

Tendo em vista os resultados obtidos, alguns corroborando com resultados de pesquisas anteriores, e outros em desacordo, principalmente em relação ao tempo de oclusão das veias para estabelecimento da parada circulatória, assim como manutenção de normotermia ou hipotermia no transoperatório, e possíveis comprometimentos neurológicos decorrentes da técnica utilizada, novos estudos devem ser levados a efeito, a fim de minimizar os efeitos deletérios do "Inflow Occlusion", e preservar-se principalmente, o sistema nervoso dos animais sob hipóxia/anóxia cerebral, visto que neste e em outros trabalhos realizados, os valores hemogasométricos, apesar de estarem abaixo do normal no período transoperatório, e tal fato estar relacionado à instalação do quadro de acidose metabólica nos animais, não houve quaisquer diferenças significativas entre os grupos relativas aos parâmetros avaliados, e tampouco tais alterações exigiram correções nos momentos pós-parada circulatória e no período pós-operatório, as mesmas normalizando sem interferência dos pesquisadores. Com isto, pretende-se instituir a técnica descrita com maior segurança nas rotinas hospitalares, sendo empregada em animais com patologias que possam ser beneficiados com este tipo de cirurgia, correndo menores riscos nos períodos trans e pós-operatórios. 


\section{CONCLUSÕES}

Após análise dos resultados deste experimento, segundo metodologia empregada, é lícito afirmar:

- Clínica e neurologicamente, e frente aos valores hemogasométricos, pode-se inferir a aplicação da técnica de "Inflow Oclusion" por até 7 minutos em cães sadios.

- Há alterações neurológicas claras no período pós-operatório quando utilizada a técnica cirúrgica em questão, porém as mesmas foram transitórias para o grupo com parada circulatória total por período de 7 minutos. No grupo com parada circulatória por período de 8 minutos, as alterações foram bem mais intensas, havendo caso com lesão permanente.

- Face aos óbitos ocorridos no grupo B no período transoperatório, bem como alterações clínicas e neurológicas importantes observadas no período pós-operatório, é contraindicada a realização da técnica de "Inflow Occlusion" por 8 minutos.

- Verificou-se acidose metabólica nos dois grupos estudados durante o período transoperatório, entretanto nos momentos pós-operatórios avaliados, os valores se normalizaram.

- Em relação à hemogasometria, não foram observadas quaisquer diferenças significativas nos parâmetros avaliados, quando realizada comparação entre 7 e 8 minutos de parada circulatória total utilizando a técnica de "Inflow Occlusion".

- Visto a magnitude da variância entre valores individuais verificada no presente trabalho, novas pesquisas devem ser realizadas para ampliar a margem de segurança sobre os valores obtidos e melhor avaliá-los. 


\section{REFERÊNCIAS}

AGHAJI, M. A.; GALLEN, W. F.; LITWIN, S. B. Bilateral semilunar valvotomies using inflow occlusion in a neonate. Journal of Cardiovascular Surgery, v. 29, n. 5, p. 617-619, 1988.

ATIK, F. A. Complicações neurológicas. In: AULER JR., J. O. C.; OLIVEIRA, S. A. Pósoperatório de cirurgia torácica e cardiovascular. Porto Alegre: Editora Artmed S. A., 2004. p. 313-320.

AULER JR., J. O. C.; ANDRADE, A. C. M. Equilíbrio eletrolítico e distúrbio ácido-básico. In: AULER JR., J. O. C.; OLIVEIRA, S. A. Pós-operatório de cirurgia torácica e cardiovascular. Porto Alegre: Editora Artmed S. A., 2004. p. 58-72.

AWARIEFE, S. O.; CLARKE, D. R.; PAPPAS, G. Surgical approach to critical pulmonary valve stenosis in infants less than six months of age. Journal of Thoracic and

Cardiovascular Surgery, v. 85, n. 3, p. 375-387, 1983.

BAHNSON, H. T.; BAKER, C. B. Study of prosthetic materials used inside the heart. Surgery, v. 23, p. 78-83, 1953.

BAILEY, J. E.; PABLO, L. S. Practical approach to acid-base disorders. Veterinary Clinics of North America: Small Animal Practice, v. 28, n. 3, p. 645-661, 1998.

BERNHARD, W. F.; KEANE, J. F.; FELLOWS, K. E.; LITWIN, S. B.; GROSS, R. E. Progress and problems in the surgical management of congenital aortic stenosis. Journal of Thoracic and Cardiovascular Surgery, v. 66, n. 3, p. 404-419, 1973.

BIGELOW, W. G.; LINDSAY, W. K.; GREENWOOD, W. F. Hypothermia. It's possible role in cardiac surgery: an investigation of factors governing survival in dogs at low body temperatures. Annals of Surgery, v.132, p.849-866, 1950.

BRODMAN, R. F.; ESTNER, S.; PASSIK, C.; GOLDMAN, M. Prosthetic aortic arch replacement. A new experimental technique. Journal of Cardiovascular Surgery, v. 31, n. 2, p. 142-146, 1990.

BROOKS, D. K.; FELDMAN, S. A. Metabolic acidosis (A new approach to "neostigmine resistant curarization"). Anaesthesia, v. 17, p. 161-164, 1962. 
COOKSON, B. A.; NEPTUNE, W.; BAILEY, C. P. Intracardiac surgery with hypothermia. Journal of International College of Surgeons, v. 18, p. 685-694, 1952.

CHRISMAN, C. L. Neurologia dos pequenos animais. São Paulo: Roca, 1985. p. 72-86.

DIBARTOLA, S. P. Metabolic acid-base disorders. In: DIBARTOLA, S. P. Fluid therapy in small animal practice. Philadelphia: W. B. Saunders Company, 2000. p. 211-240.

DELAHUNTA, A.Veterinary neuroanatomy and clinical neurology. Philadelphia: W. B. Saunders, 1983. p. 296, 356-364, 368, 375-376.

DRAGOSAVAC, D. Pós-operatório de cirurgia cardíaca. In: TERZI, R.; ARAÚJO, S. Monitorização hemodinâmica e suporte cardiocirculatório do paciente crítico. São Paulo: Editora Atheneu, 1995, p. 311-328.

FANTONI, D. T. Anestesia no cardiopata. In: FANTONI, D. T.; CORTOPASSI, S. R. G. Anestesia em cães e gatos. São Paulo: Editora Roca, 2002. p. 294-320.

FORTUNA, P. Ordens pós-operatórias (monitorização hemodinâmica e respiratória) e Setor neurológico. In: Fortuna, P. Pós-operatório imediato em cirurgia cardíaca. São Paulo: Editora Atheneu, 2002. p. 12, 219.

FREITAS, R. R.; STOPIGLIA, A. J.; FANTONI, D. T.; FUTEMA, F.; KWASNICKA, K. L.; JATENE, F. B.; LARSSON, M. M.; DOMINGOS, L. O.; ABDUCH, M. C. Surgical Correction of Atrial Septal Defect Using the Inflow Occlusion Technique. Brazilian Journal of veterinary Animal Science, v. 42, n. 3, p. 193-195, 2005.

FYLER, D. C. Report of the New England Regional Infant Cardiac Program. Pediatrics, 65:suppl., p. 447-449, 1980.

GIRALDEZ, R. R. C. V.; RAMIRES, J. A. F. Fisiopatologia da isquemia miocárdica: da isquemia às novas síndromes isquêmicas e lesão de reperfusão. In: ROCHA E SILVA, M. Fisiopatologia cardiovascular. São Paulo: Editora Atheneu, 2000. p. 91-100.

HALL, L. W.; CLARKE, K. W. Anestesia veterinária. London: W. B. Saunders Company, 1987. p. 438.

HAMM, L.; JACOBSON, H. R. Mixed acid-base disorders. In: KOKKO, J. P.; TANNEN, R. L. Fluids and electrolytes. Philadelphia: W. B. Saunders Company, 1986. p. 382. 
HASKINS, S. C. Fluid, Eletrolyte and Acid-Base Maintenace in Perioperative Period. In: PADDLEFORD, R. R. Manual of small animal anesthesia. 1ed. New York: Churchill Livingstone, 1988. p. 242.

HOLMEMBERG, D. L.; OLSEN, D. B. Anesthesia and cardiopulmonary bypass technique in calves and sheep. Veterinary Surgery, v. 16, p. 463, 1987.

HUNT, G. B.; MALIK, R.; BELLENGER, C. R.; PEARSON, M. R. B. Total Venous Inflow Occlusion in the normothermic dog: a study of haemodynamic, metabolic and neurological consequences. Research in Veterinary Science, v. 52, n. 3, p. 371-377, 1992.

JONAS, R. A.; CASTANEDA, A. R.; FREED, M. D. Normothermic caval inflow occlusion. Application to operations for congenital heart disease. Journal of Thoracic and Cardiovascular Surgery, v. 89, n. 5, p. 780-786, 1985.

JONAS, R. A.; CASTANEDA, A. R.; NORWOOD, W. I.; FREED, M. D. Pulmonary valvotomy under normothermic caval inflow occlusion. Australian and New Zealand Journal of Surgery, v. 55, n. 1, p. 39-44, 1985.

KAMEYA, S. A study of consumption during profound hypothermia induced by perfusion on the entire body. Surgical Forum, v. 11, p. 190, 1960.

KEANE, J. F.; BERNHARD, W. F. NADAS, A. S. Aortic stenosis surgery in infancy. Circulation, v. 52, p. 1138-1143, 1975.

KITAGAWA, H.; YASUDA, K.; SASAKI, Y. Blood gas analysis in dogs with heartworm caval syndrome. Journal of Veterinary Medical Science, v. 56, n. 5, p. 861-867, 1994.

KIZILTEPE, U.; EYILETEN, Z. B.; UYSALEL, A.; AKALIN, H. Acute pulmonary hypertensive crisis after TAPVC repair treated with atrial septectomy with inflow occlusion. International Journal of Cardiology, v. 87, p. 107-109, 2003.

KWASNICKA, K. L.; STOPIGLIA, A. J.; FREITAS, R. R.; FANTONI, D. T. Avaliação hemogasométrica durante a parada circulatória total - Inflow Occlusion - aplicada por diferentes períodos de tempo em cães sadios. Brazilian Journal of Veterinary Research, v. 37, n. 3, p. 234-242, 2000.

LUNA, S. P. L. Equilíbrio ácido-básico. In: FANTONI, D. T.; CORTOPASSI, S. R. G. Anestesia em cães e gatos. São Paulo: Editora Roca, 2002. p. 120-129. 
MANOHAR, M.; TYAGI, R. P. S. Surface-induced deep hypothermia and prolonged circulatory stasis in dog. Journal of the American Veterinary medical Association, v. 161, p. $371,1972$.

MARTINS, F. Monitorização no pós-operatório de cirurgia cardíaca. In: AULER JR, J. O. C.; OLIVEIRA, S. A. Pós-operatório de cirurgia torácica e cardiovascular, Porto Alegre: Editora Artmed S. A., 2004. p. 28.

MASSONE, F. Anestesia veterinária: farmacologia e técnica. Rio de Janeiro: Editora Guanabara, 1994. p. 17.

MISTROT, J.; NEAL, W.; LYONS, G.; MOLLER, J.; LUCAS, R.; CASTANEDA, A.; VARCO, R.; NICOLOFF, D. Pulmonary valvotomy under inflow stasis for isolated pulmonary stenosis. Annals of Thoracic Surgery, v. 21, n. 1, p. 30-37, 1976.

MITTEN, R. W.; EDWARDS, G. A.; RISHNIW, M. Diagnosis and management of cor triatriatum dexter in a Pyrenean Montain Dog and an Akita Inu. Australian Veterinary Journal, v. 79, n. 3, p. 177-180, 2001.

MUIR, W. W.; HUBBEL, J. A. E. Acid-base balance and blood gases. In: MUIR, W. W.; MUIR, J. A. E. Handbook of veterinary anesthesia. Washington D.C.: C. V. Mosby Company, 1989. p. 191-201.

NETO, A. C. Fisiopatologia da circulação cerebral. In: ROCHA E SILVA, M. Fisiopatologia cardiovascular. São Paulo: Editora Atheneu, 2000. p. 127-136.

NUGENT, E. W.; FREEDOM, R. M.; NORA, J. J. et al. Natural History Study: Clinical course in pulmonary stenosis. Circulation suppl., v. 1, n. 56, p. 138-147, 1977.

ODEGARD, K. C.; SCHURE, A.; SAIKI, Y.; HANSEN, D. D.; JONAS, R. A.; LAUSSEN, P. C. Anesthetic considerations during caval Inflow Occlusion in children with congenital heart disease. Journal of Cardiothoracic and Vascular Anesthesia, v. 18, n. 2, p. 144-147, 2004.

OLIVA, V. N. L. S. Reanimação cardiorrespiratória. In: FANTONI, D. T.; CORTOPASSI, S. R. G. Anestesia em cães e gatos. São Paulo: Editora Roca, 2002. p. 362-368.

ORTON, E.C. Inflow occlusion and cardiopulmonary bypass. In: ORTON, E. C. Small Animal Thoracic Surgery. Philadelphia: lea \& Febiger, 1995. p. 185-202. 
ORTON, E. C.; BRUECKER, K. A.; McCRACKEN, T. O. An open patch-graft technique for correction of pulmonic stenosis in the dog. Veterinary Surgery, v. 19, n. 2, p. 148-154, 1990.

PINTO, V. A. C. Contribuição para o estudo da hemodinâmica e da eletrocardiografia em normotermia e sob hibernação artificial. 1955. Tese (Livre Docência) - Faculdade de Medicina, Universidade de São Paulo, São Paulo, 1955.

RAIA, A. A.; ZERBINI, E. J. Clínica Cirúrgica Alípio Correa Netto. São Paulo: Sarvier, 1988. p. 502-515.

SADE, R. M.; CRAWFORD, F. A.; HOHN, A. R. Inflow Occlusion for semilunar valve stenosis. Annals of Thoracic Surgery, v. 33, n. 6, p. 570-5, 1982.

SINK, J. D.; SMALLHORN, J. F.; MACARTNEY, F. J.; TAYLOR, J. F. N.; STARK, J.; DE LEVAL, M. R. Management of critical aortic stenosis in infancy. Journal of Thoracic Cardiovascular Surgery, v. 87, p. 82-86, 1984.

SENIOR, D. F. Fluidoterapia, eletrólitos e controle ácido-básico. In: ETTINGER, S. J.; FELDMAN, E. C. Tratado de medicina interna veterinária: moléstia do cão e gato. 1 ed. São Paulo: Editora Manole, 1997. p. 436-445.

SLEIGH, J. W.; MAHALU, W.; RENNER, A. A.; CHINYANGA, H. M. A case report of the use of inflow occlusion and moderate hypothermia for a pulmonary valvotomy: anaesthetic and surgical management. Central African Journal of Medicine, v. 32, n. 9, p. 221-223, 1986.

STOPIGLIA, A. J.; FANTONI, D. T.; FREITAS, R. R.; FUTEMA, F.; MIGLIATI, E. R.; AMBROSIO, A. M.; BECHARA, J. N.; KWASNICKA, K. L. Hemodynamic evaluation of Inflow Stasis in dogs. In: CONGRESS OF THE WORLD SMALL ANIMAL VETERINAY ASSOCIATION, 23., 1998, Buenos Aires. Anais... Buenos Aires, 1998. p. 760.

STOPIGLIA, A. J.; FREITAS, R. R.; IRINO, E. T.; POGLIANI, F. C.; SIMÕES, E. A.; KWASNICKA, K. L.; FANTONI, D. T.; JATENE, F. B. Avaliação clínica da parada circulatória total em cães (Canis familiaris). Acta Cirúrgica Brasileira, v. 16, n. 4, p. 211 217, 2001.

TERZI, R. G. G. Acidose lática no paciente hemodinamicamente instável. In: TERZI, R.; ARAÚJO, S. Monitorização hemodinâmica e suporte cardiocirculatório do paciente crítico. São Paulo: Editora Atheneu, 1995. p. 219-232. 
TIMERMAN, A. Monitorização hemodinâmica e hemogasométrica na parada cardiorrespiratória. In: TERZI, R. G. G.; ARAÚJO, S. Monitorização hemodinâmica e suporte cardiocirculatório do paciente crítico. São Paulo: Editora Atheneu, 1995. p. 269278.

TOKMAKOGLU, H.; KANDEMIR, O.; GUNAYDIN, S.; YORGANCIOCLU, C.;

ZORLUTUNA, Y. Extraction of right atrial thrombus with inflow-occlusion technique in a patient with gastric cancer. Journal of Cardiovascular Surgery, v. 43, p. 899, 2002.

VARCO, R. L. In: MULLER, W. H. LONGMIRE, W. P. The surgical treatment of cardiac valvular stenosis. Surgery, v.30, p.41, 1951.

WARE, W. A.; MERKLEY, D. F.; RIEDESEL, D. H. Intracardiac thyroid tumor in a dog: diagnosis and surgical removal. Journal of the American Animal Hospital Association, v. 30, n. 1, p. 20-23, 1994. 